

\section{DISCLAIMER}

This report was prepared as an account of work sponsored by an agency of the United States Government. Neither the United States Government nor any agency Thereof, nor any of their employees, makes any warranty, express or implied, or assumes any legal liability or responsibility for the accuracy, completeness, or usefulness of any information, apparatus, product, or process disclosed, or represents that its use would not infringe privately owned rights. Reference herein to any specific commercial product, process, or service by trade name, trademark, manufacturer, or otherwise does not necessarily constitute or imply its endorsement, recommendation, or favoring by the United States Government or any agency thereof. The views and opinions of authors expressed herein do not necessarily state or reflect those of the United States Government or any agency thereof. 


\section{DISCLAIMER}

Portions of this document may be illegible in electronic image products. Images are produced from the best available original document. 
Reference to a company or product name does not imply approval or recommendation of the product by Union Carbide Corporation or the U.S. Energy Research and Development Administration to the exclusion of others that may meet specifications.

\author{
Printed in the United States of America. Available from \\ National Technical Information Service \\ U.S. Department of Commerce \\ 5285 Port Royal Road, Springfield, Virginia 22161 \\ Price: Printed Copy $\$ 5.45$; Microfiche $\$ 2.25$
}

This report was prepared as an account of work sponsored by the United States Government. Neither the United States nor the Energy Research and Development Administration, nor any of their employees, nor any of their contractors, subcontractors, or their employees, makes any warranty, express or implied, or assumes any legal liability or responsibility for the accuracy, completeness or usefulness of any information, apparatus, product or process disclosed, or represents that its use would not infringe privately owned rights. 
Date of Issue: April 30, 1975

Distribution Category: UC-79h

Report Number: Y-1967

\title{
THERMOPHYSICAL PROPERTIES OF A TYPE 308 \\ STAINLESS STEEL WELD
}

\author{
J. D. Lore \\ H. L. Richards \\ L. M. Greerie \\ D. M. Darby \\ Laboratory Development Department \\ Y.12 Development Division \\ R. T. King \\ Metals and Ceramics Division \\ Holifield National Laboratory
}
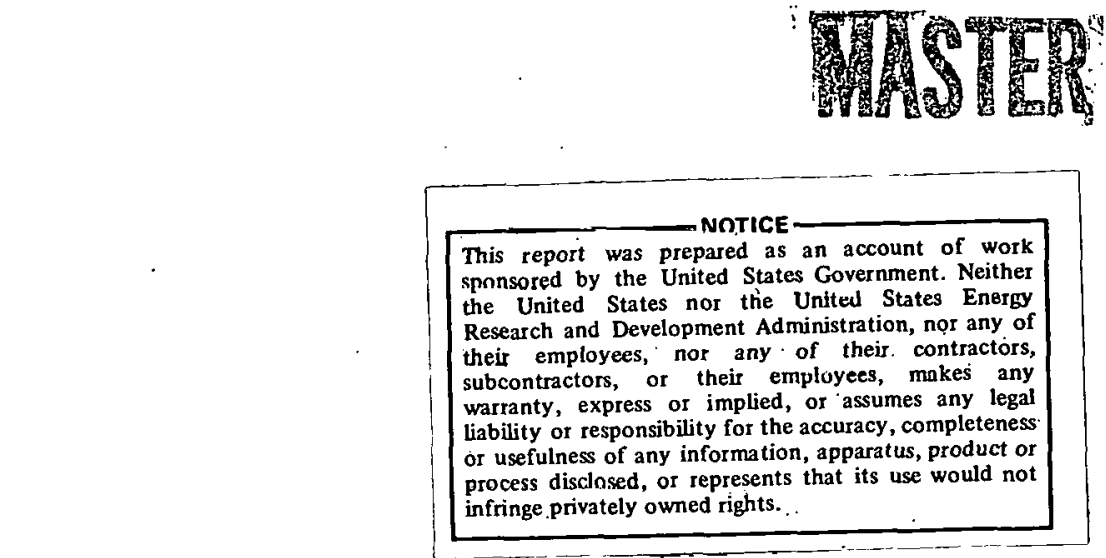

Oak Ridge Y-12 Plant

P. O. Box Y, Oak Ridge, Tennessee 37830

Prepared for the US Energy Research

and Development Administration

Under US Government Contract W-7105-eng-26 


\section{ABSTRACT}

Thermophysical characterization of a stainless steel weldment for Liquid Metal Fast Breeder Reactor application was conducted over the expected operating temperature interval $\left(25-1000^{\circ} \mathrm{C}\right)$. Observed behavior was characteristic, and expected thermal anisotropy was not evidenced. 


\section{CONTENTS}

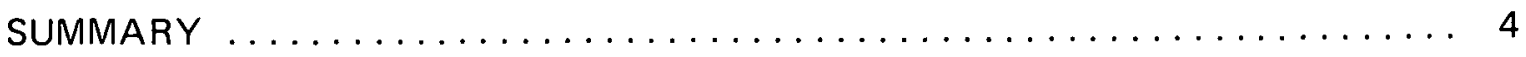

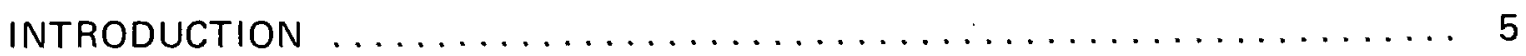

THERMOPHYSICAL STUDY OF TYPE 304 AND 308 STAINLESS STEELS ...... 6

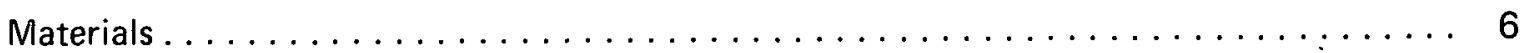

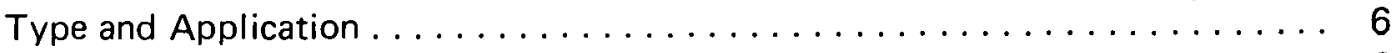

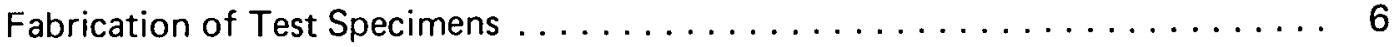

Measurement Techniques ............................... 7

Linear Thermal Expansion .......................... 7

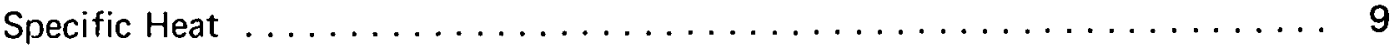



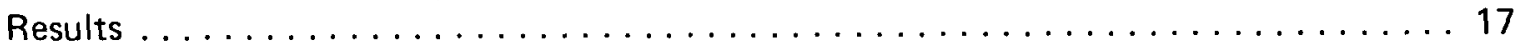

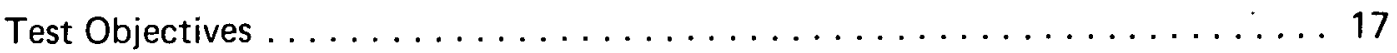

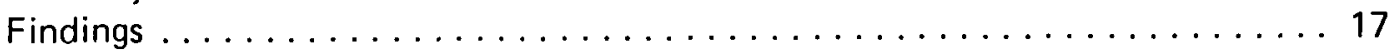

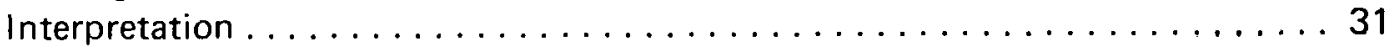

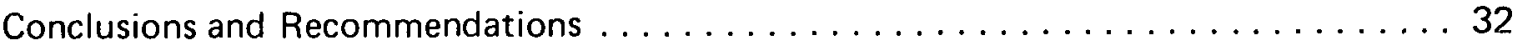

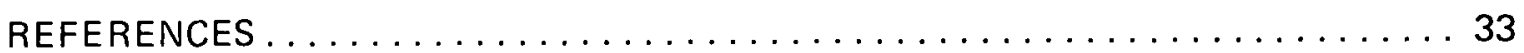

ACKNOWLEDGEMENTS ................................... 34

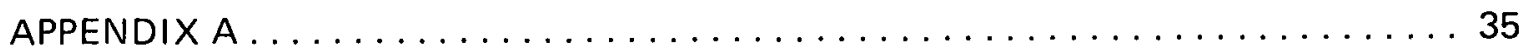

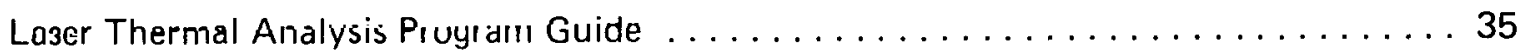

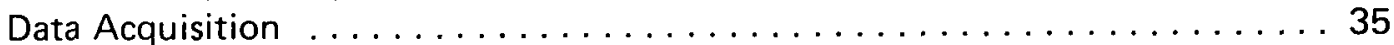

Data Reduction .................................. 37

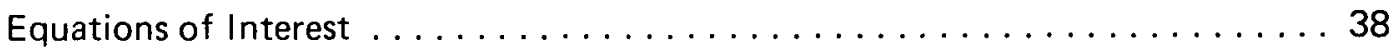

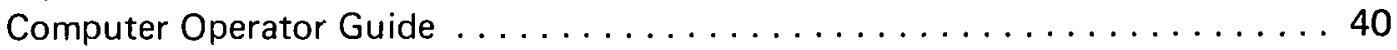

Plot Program .............................. 40

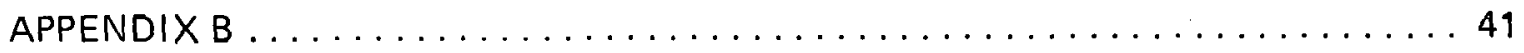

Typical Report Form Summary for Laser Thermal Analysis $\ldots \ldots \ldots \ldots \ldots \ldots \ldots 4$



Data Reduction $\ldots \ldots \ldots \ldots \ldots \ldots \ldots \ldots \ldots \ldots \ldots \ldots \ldots \ldots$ 


\section{SUMMARY}

Thermal expansion, thermal diffusivity, specific heat, and thermal conductivity measurements were obtained in vacuo for a Type 304-308 stainless steel weldment for use in the Liquid Metal Fast Breeder Reactor. Property measurements were somewhat variant, depending upon the direction of measurement, but the observed differences were small. 


\section{INTRODUCTION}

Structural design criteria for Liquid Metal Fast Breeder Reactors (LMFBR) present some problems not encountered in light water reactors or in many other high-temperature nuclear systems. Components that are fabricated of Type 304 or 316 stainless steel in current LMFBR designs operate at high temperatures where design rules require consideration of inelastic and time-dependent deformation. Because of the good heat-transfer characteristics of the sodium coolant and its relatively poor thermal conductivity, high thermal expansion coefficient, and load-sustaining characteristics of austenitic stainless steels, changes on the order of those anticipated in the LMFBR can cause rapid temperature transients and severe thermal stresses in structures that are in contact with the coolant. Under these conditions, structural materials tend to creep and deform plastically under load; large strains may concentrate in critical regions such as structural discontinuities; and the repeated cyling of temperature at high temperatures, as will occur during the normal 30-year lifetime of an LMFBR, can lead to progressive deformation through inelastic behavior mechanisms such as ratchetting and creep fatigue.

A program is in progress at the Oak Ridge Y-12 Plant(a) to evaluate the mechanical properties of test welds that are prototypic longitudinal seam and girth welds for the Fast Flux Test Facility (FFTF) in Hanford, Washington. Understanding the responses of these weldments to thermal stresses is desirable to ascertain the degree of conservativeness of ASME code design rules for elevated temperature structures. For this purpose, thermal properties of the base and weld metal should be known as reliably as the mechanical properties.

(a) Operated by the Union Carbide Corporation's Nuclear Division for the US Energy Research and Development Administration. 


\section{THERMOPHYSICAL STUDY OF TYPE 304 AND 308 STAINLESS STEELS}

\section{MATERIALS}

\section{Type and Application}

Test welds have been made in 60.33-mm-thick Type 304 stainless steel plates using a joint design, welding procedures, and materials that have been described previously. (1) The weld was made by the shielded metal-arc process using electrodes that contained controlled amounts of the residual elements-boron, phosphorus, and titanium. These test welds are prototypic of certain welds in the FFTF vessel, and they are not atypical of modern multipass shielded metal-arc Type 308 welds.

\section{Fabrication of Test Specimens}

The macrostructure of a polished and etched section taken normal to the welding direction is illustrated in Figure 1. The weld metal consists of elongated austenitic grains whose local orientation nearly parallels the solidification direction, with approximately 5 to $7 \%$ ferrite distributed in a cellular dendritic pattern. The details of this microstructure are reported by King, et al. (1)

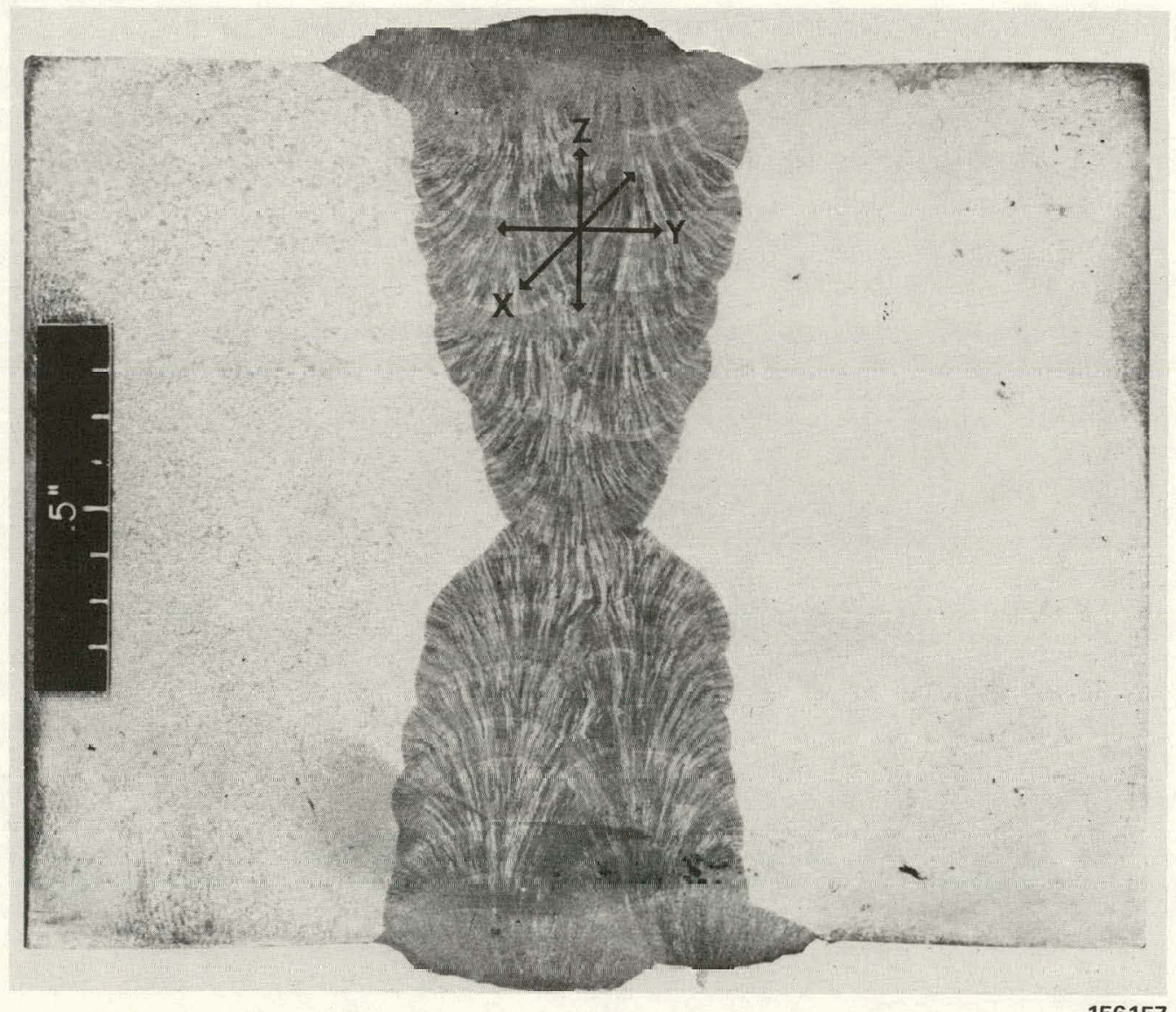

Figure 1. TYPICAL TYPE 304 STAINLESS STEEL WELDMENT. (Test Weld Section FF9-S3) 
Because of the directional nature of the structure that might lead to anisotropic thermophysical behavior, the orthogonal directions for property measurements were defined, as shown in Figure 1 . The $X$ orientation represents the weld pass direction; $Y$, the weld width; and $Z$, the weld depth, which is perpendicular to the plate surface and extends through the plate thickness. The $X$ orientation is the direction perpendicular to the plane of the figure and is only indicated approximately in Figure 1.

Solid cylindrical specimens were fabricated to measure for: (1) the coefficients of thermal expansion of the base metal in one direction and of the weld metal in the $X, Y$, and $Z$ direction; (2) the specific heats of the weld metal and base metal, and (3) the thermal diffusivity of the base metal in one direction and of the weld metal in the $X, Y$, and $Z$ directions. Test Weld Section FF9-S3 was used for the thermal expansion and specific heat measurements; Test Weld FF-76 was used for the thermal diffusivity measurements. These welds were nearly identical. In all cases, the specimens were cut from the central most section of the weld.

Dimensions of the specimens, all of a solid cylindrical geometry, in length and diameter (in $\mathrm{mm})$ were as follows: thermal expansion $(22 \times 5.1)$, specific heat $(2.5 \times 6.4)$, and thermal diffusivity $(2.5 \times 12.7)$. The specimens were prepared by light-finish-pass grinding to minimize cold working during fabrication.

\section{MEASUREMENT TECHNIQUES}

\section{Linear Thermal Expansion}

Linear thermal expansion, $\Delta \ell / \ell_{0}$, was measured using a high-temperature, quartz-push-rod automatic dilatometer (Dynatech-Netzsch Model 402E). The instrument consists of three separate units: (1) the measuring module including the furnace, sample support, and displacement transducer; (2) the temperature programmer and controller, and (3) the display module which includes a carrier-frequency amplifier and a strip-chart recorder. The sample is supported in a half-open horizontal tube made of quartz. The rod which transmits the change in length to the transducer is made of the same quartz material as the holder. The transducer is shielded from the furnace and the sample holder by a water-cooled block which also acts as a convenient base for electrical and vacuum connections. Tests can be performed in air, inert gas, or in high vacuum. These tests were performed in vacuo $\left(1 \times 10^{-4} \mathrm{~Pa}\right)$. The experimental procedure consists of mounting the specimen, moving the furnace into position, and balancing the preamplifier for the recorder chart. Data may be acquired in two ways: (1) a two-channel chart recorder that is supplied with the instrument, and (2) an added digital data acquisition system, as outlined in Figure 2. The furnace temperature is increased at a programmed rate of $2^{\circ} \mathrm{C} / \mathrm{min}$. The two-channel recorder gives five successive printings of the dimensional change followed by one printing of the temperature at two-second intervals. Magnification of the sample expansion can be increased in seven steps from 125:1 to 12,500:1. In calculating the linear thermal expansion of a specimen, a correction for the expansion of the quartz sample holder and the push-rod system must be applied. This correction factor was obtained by previous calibration of the system using NBS-SRM copper and is the difference between the experimental and literature values. The correction factor is also adjusted slightly for the furnace heating rate. 


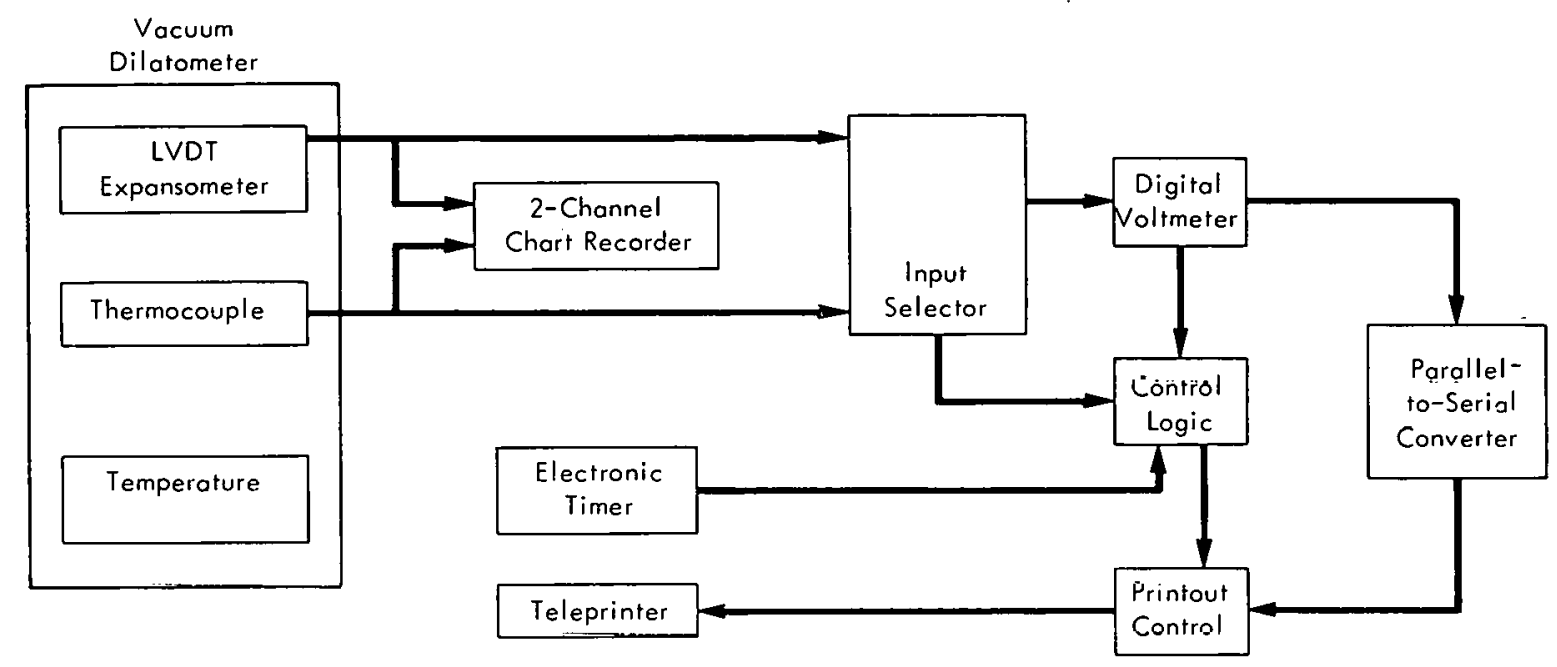

Figure 2. AUTOMATIC DATA ACQUISITION SYSTEM AND VACUUM DILATOMETER.

Quantitatively, the instantaneous coefficient of linear expansion of a material is the rate of expansion obtained from the slope of the length as a function of temperature, ie:

$$
\epsilon=\lim _{T_{1} \rightarrow T_{2}} \frac{\ell_{2}-\ell_{1}}{\ell_{U}\left(I_{2}-I_{1}\right)} .
$$

where:
$\ell_{1} \quad$ Represents the original length,
$\ell_{2}$ the final length,
$\ell_{0} \quad$ the length at a particular temperature,
$T_{1}$ the original temperature, and
$T_{2}$ the final temperature.

Figure 2 is a block diagram of the automatic data system used with the vacuum dilatometer. The instrument system provides a record of the specimen expansion and temperature signals with a selected time interval between data points. A digital voltmeter (DVM) records these signals and provides a digital output to a parallel-to-serial converter that drives a teleprinter. The teleprinter records the data for immediate evaluation and provides a punched paper tape for subsequent computer analysis. The automatic digital data acquisition system serializes and decodes data, controls the input selector, provides time-interval control, and operates the teleprinter. The parallel-to-serial converter, printout control, and scaler-timer unit are commercially available plug-in modules. The control logic was developed to coordinate the functions of these units with the input selector and the DVM.

The timer determines the time interval between data points and can be preset from $1-10,000$ seconds. The timing pulse initiates the start of the print cycle. The control logic 
waits until the DVM is in the display mode, then outputs a print command to the printer control unit, which outputs a print command to the printout control unit, which then outputs the temperature measurement to the teleprinter. The logic then transfers the input selector so that the DVM is monitoring the linear variable differential transformer (LVDT) signal. The DVM goes through four display cycles to eliminate the possibility of considering an extraneous data point; and, on the fifth cycle, the LVDT measurement is recorded by the teleprinter. The timer is then reset, and the unit is ready to recycle. The linear thermal expansion coefficient, Equation 1, may be more commonly restated as:

$$
\bar{\epsilon}=\frac{\Delta l}{l_{0} \Delta T} .
$$

Over a moderate temperature range, the length may be expressed by an empirical equation of the form:

$$
\ell_{T}=\ell_{0}\left(1+A T \pm B T^{2}+\ldots\right)
$$

where $A$ and $B$ are constants for the power series expansion.

\section{Specific Heat}

Specific-heat data were obtained using a differential scanning calorimeter (Perkin-Elmer Model DSC-2). This method involves determining the energy, expressed as a peak height amplitude, required to heat a material at a given rate over a small temperature interval, usually $15^{\circ} \mathrm{C}$. By correlating this value with one obtained from a calorimetric standard, such as $a-\mathrm{Al}_{2} \mathrm{O}_{3}$ under identical test conditions, the specific heat, $\mathrm{Cp}\left(\mathrm{cal}-\mathrm{g}^{-1}-\mathrm{o}^{\circ} \mathrm{C}^{-1}\right)$, of an unknown material $(x)$ is as follows:

$$
C p(x)=\frac{A_{x} \cdot W_{\text {std }}}{A_{\text {std }} \cdot W_{x}} \times C p_{\text {std }}
$$

where:

A represents a dimensionless relative amplitude representative of a voltage differential, and

W the weight $(g)$ of the sample.

\section{Thermal Diffusivity}

Thermal-diffusivity measurements of the stainless steel weldments were made by the "laser flash" or "positive pulse" technique, whereby one surface of a thin sample disc is heated with a short-duration laser pulse. (2 -5) For a perfectly insulated specimen of uniform thickness, uniformly irradiated across its front surface by a high-intensity light pulse of short duration compared to the time required for the heat pulse to travel through the specimen, the back surface temperature is given ideally by: 


$$
\frac{T(d, t)}{T_{m}}=1+2 \sum_{n-1}^{\infty} \cdot \frac{-n^{2} \pi^{2} \alpha t}{d^{2}}
$$

where:

$T(d, t)$ represents the instantaneous back surface temperature rise at time, $t$,

d the thickness of the specimen, in $\mathrm{cm}$,

$T_{m}$ the maximum back surface temperature rise, in ${ }^{\circ} \mathrm{C}$, and

$\alpha \quad$ the thermal diffusivity, in $\mathrm{cm}^{2}-\mathrm{sec}^{-1}$.

The halt-rise time, $t_{1 / 2}$, is the time rèquirèd for the băck surface to reach half of the maximum temperature, $T(d, t) / T_{m}=1 / 2$. Substituting in Equation 5 and solving for thermal diffusivity:

$$
\begin{gathered}
\alpha=\frac{1.37 d^{2}}{\pi^{2} t_{1 / 2}}, \text { or } \\
\alpha=\frac{0.139 d^{2}}{t_{1 / 2}} .
\end{gathered}
$$

The validity of Equation 7 is dependent upon the degree of conformity to the following conditions:

1. The energy pulse is uniformly absorbed over the front surface of the sample and only at the surface.

2. The pulse time of the heat source is small compared to the time for the heat pulse to pass thrnigh the sample.

3. Heat flow is normal to the heated surface of the sample.

4. No heat is lost from the sample during the measuring period.

Ideally, heat losses from the sample should be negligible; however, radiation losses from the sample surfaces increase with temperature. Radial conduction losses from the edge of the sample into the sample holder are usually small and, in most measurements, need not be considered. Radiative heat losses from both the front and back surfaces of the sample are more significant and, if indicated, must be evaluated since the boundary conditions for Equation 5 are not valid.

The effect of radiation heat losses from the sample surfaces has been considered by Parker, (4) Cowan, (5), and Cape. (6) The subject has been applied in a very straightforward 
fashion by Bates $(7)$ after whom this analysis was developed. The generally accepted approach considers losses at elevated temperatures from both front and back surfaces. If heat losses occur, the shape of the temperature-response curve changes as the sample surfaces are cooled (Figure 3). The correction can be made by comparing the back-surface temperature at some multiple of the half time with the maximum temperature rise. This ratio is:

$$
R=\frac{\Delta T_{\left(n \times t_{1 / 2}\right)}}{\Delta T_{\left(t_{1 / 2}\right)}} .
$$

The term $\Delta T$ represents the incremental temperature rise above the ambient temperature measured at an $n^{\text {th }}$ multiple time interval of $t_{1 / 2}$ (Figure 3 ). When there are no heat losses, the ratio of Equation 8 is 2.0, and the constant, 0.139 , of Equation 7 is valid according to Cowan's analysis. (5) As heat losses increase, $R$ in Equation 8 decreases, as does the constant (Equation 7). Thus, employment of Equation 7 under nonideal experimental conditions wherein heat losses occur will result in apparent thermal-diffusivity values which are biased. If other boundary conditions are obeyed, the bias will be nonsystematic and positive.

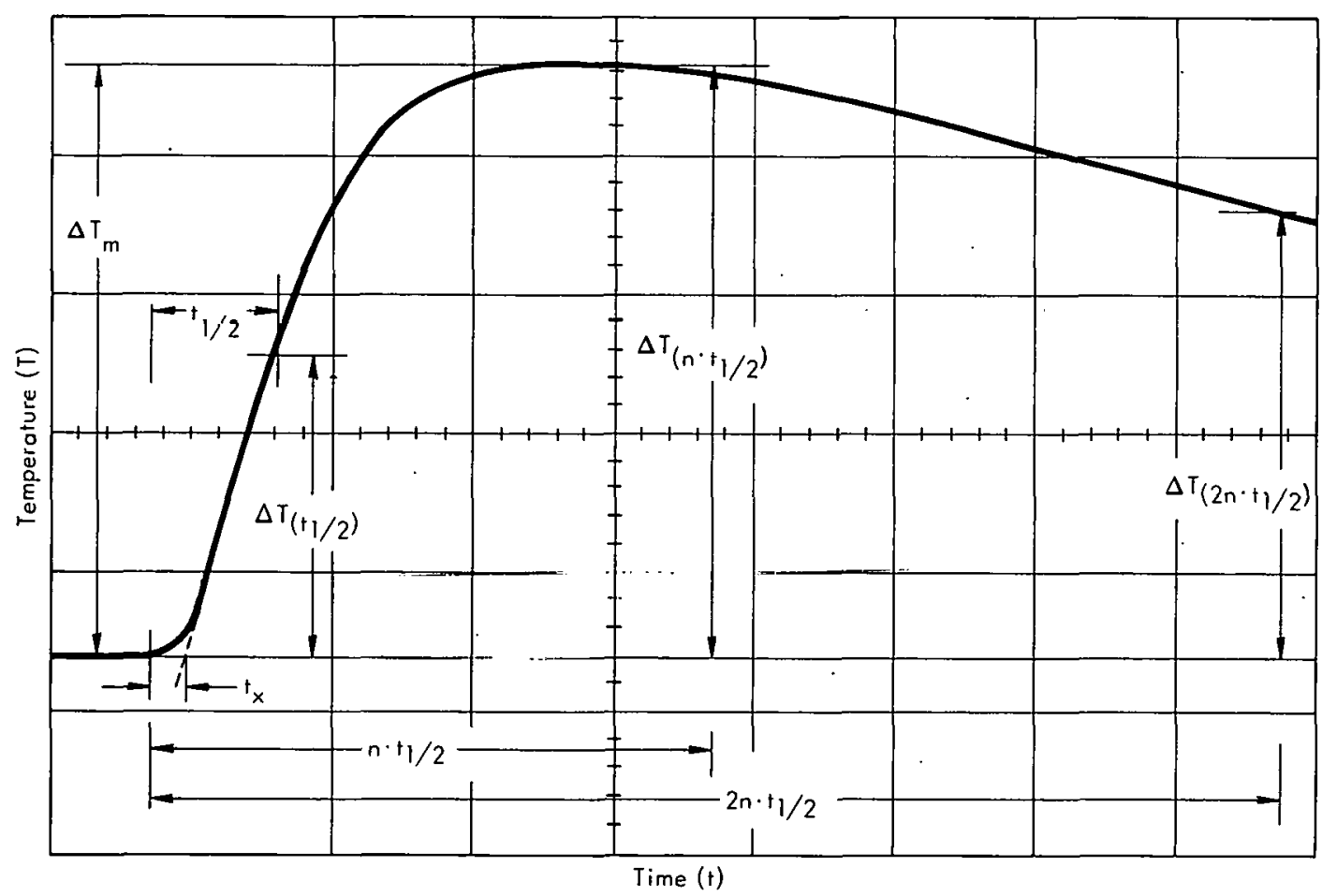

Figure 3. THERMAL TRANSIENT WAVEFORM THAT DEFINES THE IMPORTANT HEAT-LOSS PARAMETERS.

When the heating pulse, $\tau$, of the laser is comparable to the time for the heat pulse to pass through the sample, the rate of the temperature rise is delayed. $(6,7)$ This condition results in an apparent decrease in thermal diffusivity. While radiation losses are reduced by decreasing the sample thickness, finite pulsctime effects are increased. Thus, there is an 
optiumum sample thickness which will minimize the error in calculating the thermal diffusivity.

The characteristic time, $t_{c}$, or the approximate time for a heat pulse to pass through the sample, is defined by the relationship:

$$
t_{c}=\frac{d^{2}}{\alpha \pi^{2}}
$$

For a square-waveform-type heating pulse, $(8)$ such as that from the pulsed ruby laser used in these experiments, $t_{c}$ may be expressed in terms of $t_{1 / 2}$ and $\tau$ as:

$$
t_{c}=\frac{t_{1 / 2} c .55 \tau}{1.37}
$$

When $t_{c}>50 \tau$, Equation 7 can be used to calculate thermal diffusivity within $\pm 1 \%$. Corrections for finite pulse-time effects were inconsequential for stainless steels with the employed specimen geometry. The sample thickness, d, may be corrected for thermal expansion according to the relation:

$$
d=d_{o}\left(1+\frac{\Delta l}{\ell_{0}}\right)
$$

where:
$\Delta \ell / \ell_{0}$ represents the fractional thermal expansion at temperature $T\left({ }^{\circ} \mathrm{C}\right)$,
$\ell_{0} \quad$ the sample length at $25^{\circ} \mathrm{C}$, and
$\mathrm{d}_{\mathrm{O}} \quad$ the sample thickness at $25^{\circ} \mathrm{C}$.

Thermal-expansion corrections would increase the thermal-diffusivity values by, at most, less than $1.5 \%$, which is small compared to the other errors and were therefore disregarded.

The thermal conductıvity, $\mathrm{K}\left(\mathrm{w}-\mathrm{m} \mathrm{C}^{1} \mathrm{O} \mathrm{C}^{1}\right)$, was calculated frum llie relationship:

$$
K=4.19 \times 10^{2} \times \rho(T) \times C p(T) \alpha(T),
$$

where:

$\mathrm{Cp}\left(\mathrm{cal}-\mathrm{g}^{-1}-\mathrm{o}^{-1}\right)$ represents the heat capacity, and $\rho\left(\mathrm{g}-\mathrm{cm}^{-3}\right)$ the sample density.

Although $\rho$ is somewhat dependent on temperature, its slight variation was again negligible compared to the overall method imprecision. 
An overview of the experimental setup for thermal-diffusivity testing is given in Figure 4. The pulsed-laser system (Hadron Model 8512) provides a 3-10 J-cm-2 pulse from a $15.9-\mathrm{mm}$-diameter by $279-\mathrm{mm}$-long ruby rod $(\lambda=694.3 \mathrm{~nm})$. The pulse time was $1.0 \mathrm{~ms}$ and approximated a square wave. The 19.1-mm-diameter radiant flux is focussed to 11.1 $\mathrm{mm}$ at the sample front surface by a high-power silica converging lens that has been "hard coated" for antireflection at the ruby wavelength. The tubular furnace (Marshall Model 1011), capable of temperatures approaching $1000^{\circ} \mathrm{C}$, is equipped with a radial chromel-alumel Type $\mathrm{K}$ thermocouple for steady-state temperature determination and an axial platinum/platinum-10\% rhodium Type $S$ thermocouple for furnace temperature control. A 51.0-mm vacuum system with air-cooled diffusion and mechanical pumping is capable of maintaining pressures of $1 \times 10^{-4} \mathrm{~Pa}$ at operating temperatures in the quartz envelope which houses the sample and holder assembly.

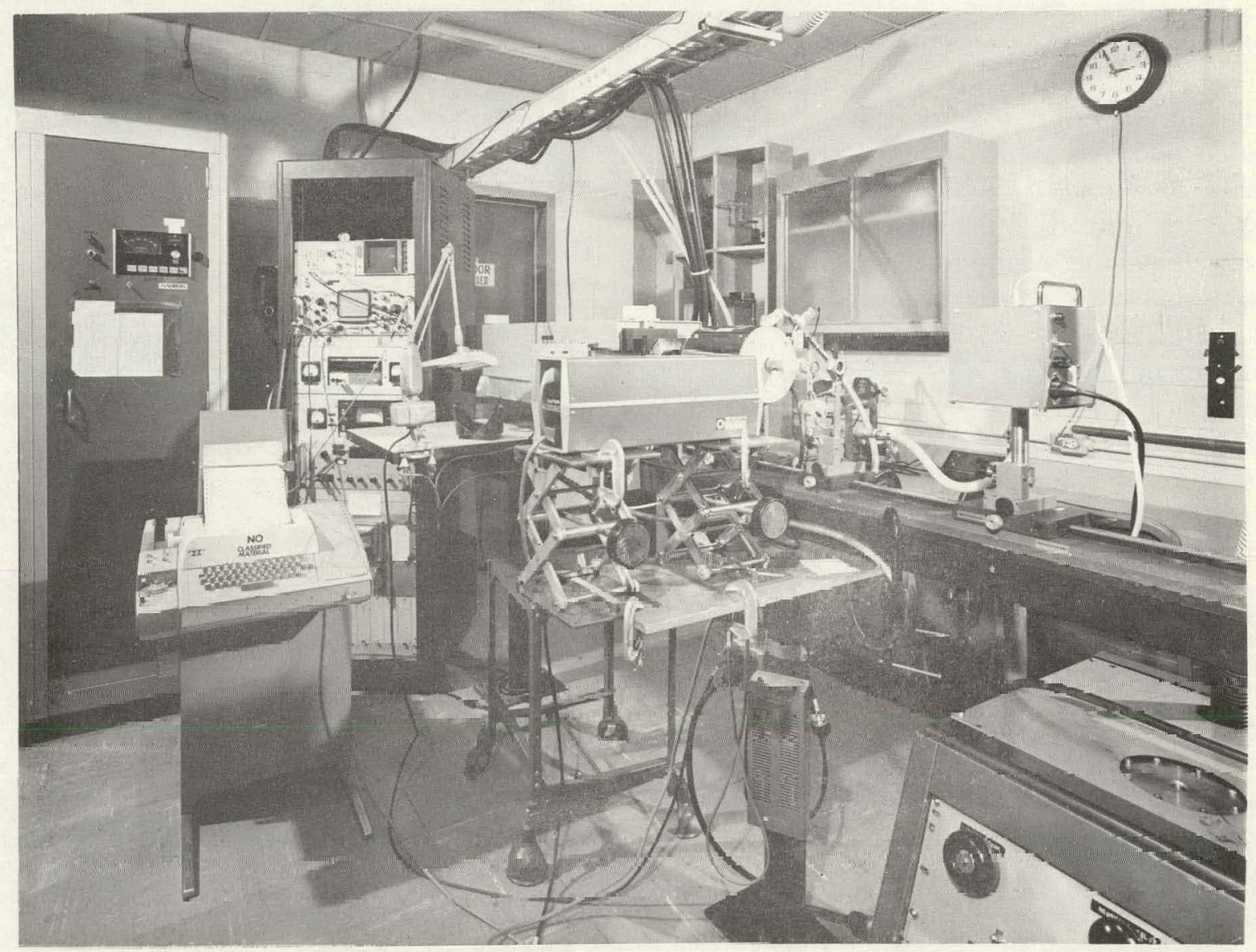

Figure 4. NVFRVIEW OF THE THERMAL-DIFFUSIVITY APTARATUS.

157568

Two methods are under development for measuring specimen steady-state temperatures and transient-temperature excursions. An intrinsic thermocouple (IT) assembly, seen in Figure 5, consists of a 30-mm-OD quartz envelope having an intrinsic chromel-alumel thermocouple employing size $28 \mathrm{~B}+\mathrm{S}$ (0.32-mm-diameter) matched pairs of bare wire housed in Inconel tubing. Ceramic insulation and a custom spring-loading mechanism are contained inside the 
tubing with a two-conductor thermocouple gland and assorted pipe fittings necessary for maintaining a vacuum integrity. The threaded Lavite holder (American Lava Grade A) contains the sample and attaches to the 9.5- $\mathrm{mm}$ FPT connector to complete the chromel-sample/sample-alumel thermojunction. This couple measures both steady-state and transient sample temperature, with a response time of approximately $1 \mathrm{~ms}$. An end view of the IT transducer is presented in Figure 6. The couple is placed in intimate contact with the central-most $32-\mathrm{mm}^{2}$ area of the $127-\mathrm{mm}^{2}$ specimen.

The noncontact-detection system is capable of measuring only the transient temperature excursion. When this technique is employed, a chromel-alumel Type $\mathrm{K}$ thermocouple, inserted radially into the furnace muffle, is used to determine the steady-state specimen temperature, based on a prior calibration. The sample holder assembly for the noncontact-detection technique can be seen in Figure 7. The standard 30-mm-OD quartz envelope houses the Lavite sample holder and sight tube which is employed to shield the infrared detector from extraneous furnace radiation. The male quartz joint contains a silicon window which is approximately $40 \%$ transmissive in the 1 to $5.5-\mu \mathrm{m}$ wavelength region of detector responsivity.

The noncontact-detection operational setup is shown in Figure 8. A 25-mm-diameter planoconvex silicon lens ( $F L$ : $150 \mathrm{~mm}$ ) focuses a back-surface specimen image (3-mm-diameter spot) on the 3-mm-diameter detector aperture with a $1: 1$ magnification.

The detector is an indium antimonide (InSb), cryogen-cooled, III-V semiconductor (Judson Research Model J-10A) which was custom designed for this application. $\wedge$ low-noise preamplifier automatically provides the bias current that is necessary to optimize the detector performance and sensitivity, ie, the signal-to-noise ratio, which is critical for successful operation at ambient specimen

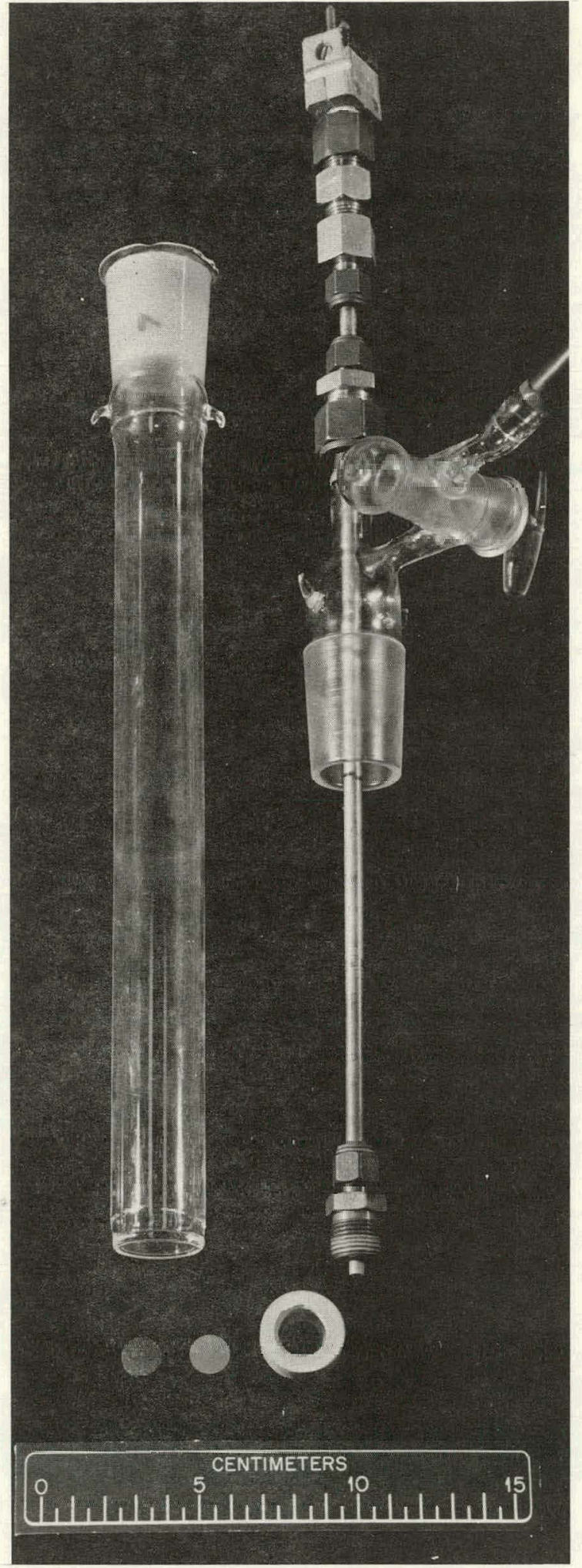

157572

Figure 5. INTRINSIC CHROMEL-ALUMEL THERMOCOUPLE ASSEMBLY. 




Figure 6. END VIEW OF THE INTRINSIC THERMOCOUPLE APPENDAGE.

157569

temperatures. A differential amplifier is employed to further enhance the detector sensitivity under these conditions. The detector gives a steady-state DC output that ranges from 100 to $300 \mathrm{mV}$, with a zero-bias current between RT and $1000^{\circ} \mathrm{C}$. The response time of the detector is approximately $1 \mu \mathrm{s}$. Its output increases exponentially with increasing temperatures; thus, at $400^{\circ} \mathrm{C}$, a neutral density filter (A: 1.0 ) is placed between the lens and detector to maintain the voltage null and prevent saturation. A DVM is employed to monitor the bias preamplifier output and to verify the condition of thermal equilibrium between laser pulses. A schematic of the thermal analysis instrumentation is given in Figure 9. Disregarding the laser and furnace controls, which are standard, the instrumentation may be separated into two integrated systems: One system monitors the back-surface specimen temperature; the other relevantly correlates this temperature with respect to elapsed time. When the laser pulsing switch is actuated, a finite, predetermined time elapses, depending on the capacitor bank charging voltage which is employed. Therefore, a variable delay circuit is required to allow triggering sweeps of the transient recorder (Biomation Model 802) and the display oscilloscope (Tektronix Model 602) in the interval between the pulse command and the actual laser burst. In order to analyze back surface transient heat-pulse waveforms by computer, there must be synchronization between the waveform and the actual laser burst. This synchronization is accomplished by employing a photosensitive solar cell to detect the xenon flash lamp discharge. This signal is converted into a single pulse and added to the 

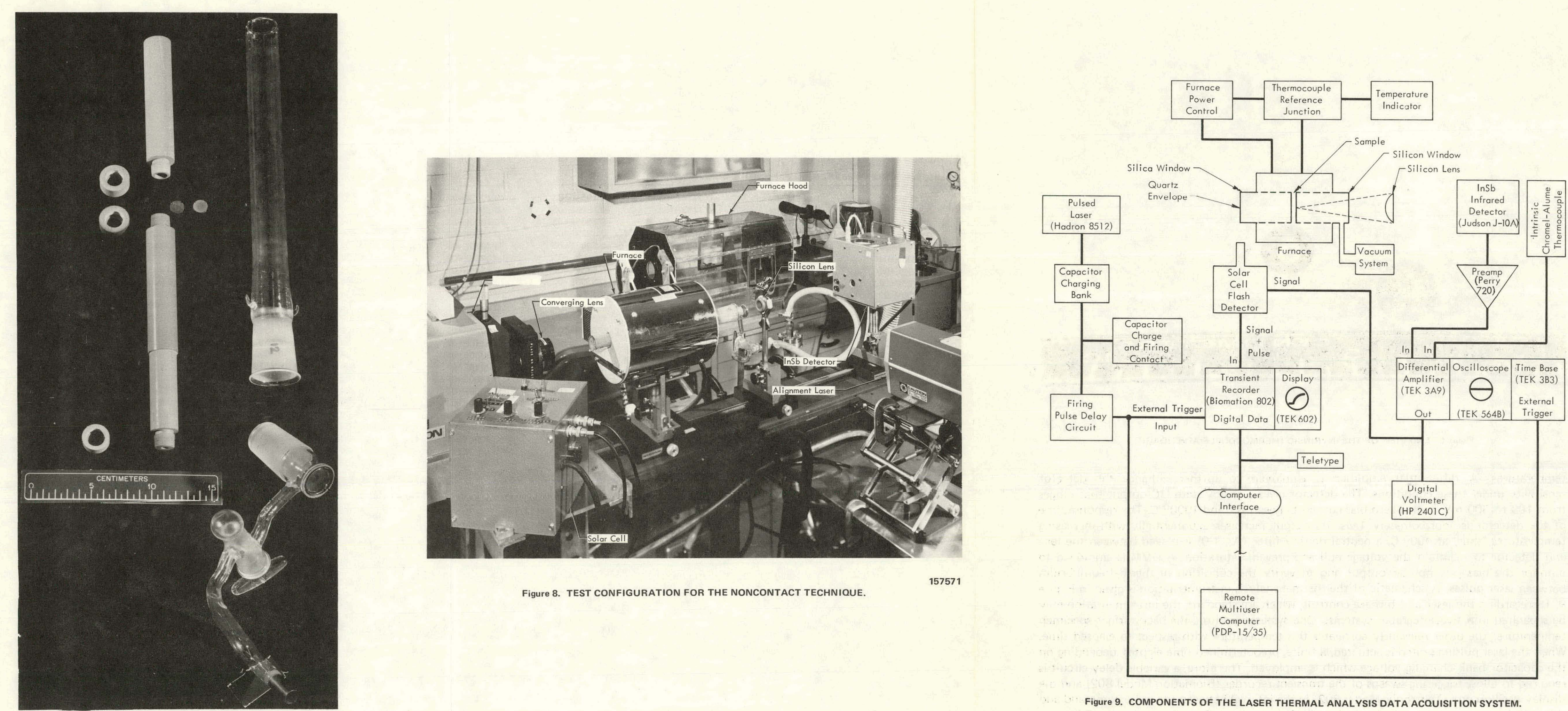

157574
Figure 7. COMPONENTS OF THE NONCONTACT DEFECTOR
SAMPLE HOLDER ASSEMBLY. 
signal received from the back surface of the specimen. The transient recorder is triggered prior to the laser burst and, thus, records, digitizes, and displays the integrated sum. The computer (PDP 15/35), remote from the test station but in the same area, uses the superimposed pulse as a reference point to initiate the data analysis and reduction. The computer provides real-time analysis of the thermal-diffusivity data. Hardware and software development has been described elsewhere;(9) only a brief functional description of its operation will be given here.

A typical heat-pulse transient is illustrated in Figure 10. Upon command of the operator, this transient oscillographic display, residing in digital format in the transient recorder, and other pertinent operational parameters are scanned. The data are then analyzed with FORTRAN routines and the results are printed out at the test station on a teletypewriter. The analysis includes finding an average value and computing statistical measurement parameters and other test conditions. A report-form summary is printed out out at the end of a determination.

The schematic diagram, illustrated in Figure 11, shows the basic computer

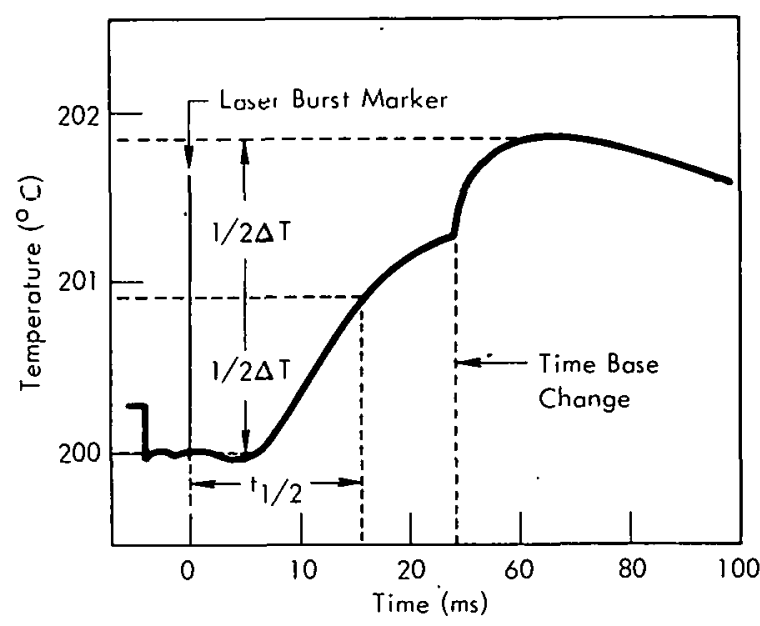

Figure 10. TYPICAL HEAT-PULSE WAVEFORM AS DISPLAYED ON THE TRANSIENT RECORDER. analysis system and its interactions. An auxiliary program for regression analysis and graphic display of $\alpha(T)$ and $K(T)$ functions is also employed. Typical data acquisition and reduction routines are given in the Appendixes.

\section{RESULTS}

\section{Test Objectives}

Because of their excellent compatibility; ie, currusion resistance, strength, and fabricability, various types of stainless steel are used in nuclear reactors as fuel cladding, structures, welds, and as general piping. Types 304 and 308 have been the subject of a number of separate mechanical and thermophysical studies. However, their character in service together as a weldment has not been well defined. Concern about the possible mechanical and thermal anisotropy of $304 / 308$ SS weldments at elevated temperatures led to this evaluation of the isotropic base material and the three orthogonal directions of the weld material.

\section{Findings}

Chemical compositions of the Type 304 base metal and Type 308 weld metal are given in Table 1. Thermal-expansion results are compiled in Tables 2 through 6 and are illustrated in Figures 12 through 16 wherein the diamonds $(\$)$ represent the data points obtained during the heating cycles and the circles $(\bullet)$ denote the measurements upon cooling. Also, as a reproducibility check, the Y-direction sample was rerun (Table 5 and Figure 15), but 


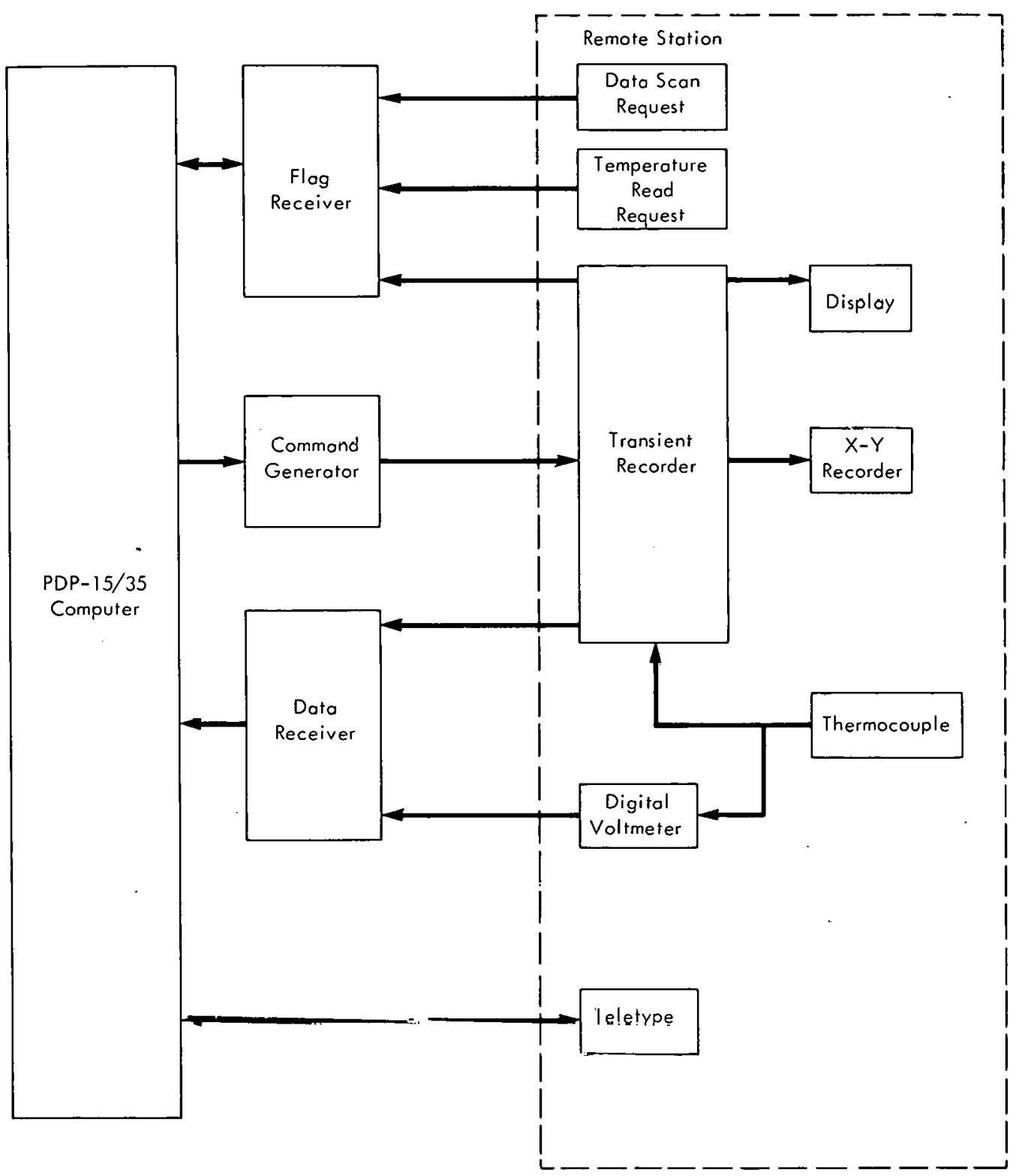

Figure 11. COMPUTER ANALYSIS SYSTEM FOR THERMAL-DIFFUSIVITYDATA.

showed little variation. Both the heating and cooling data were combined and reduced by least-squares analysis to compute the polynomial functions of the temperature for $\Delta l / l_{0}$ as follows:

Base Material $-\Delta \ell / \ell_{0}\left(\times 10^{-6}\right)=-440.7+16.95 T+3.058 \times 10^{-3} T^{2}$,

$X$ Direction $-\Delta \ell / \ell_{0}\left(\times 10^{-6}\right)=-419.6+16.61 \mathrm{~T}+2.85 \times 10^{-3} \mathrm{~T}^{2}$,

$Y$ Direction $-\Delta \ell / \ell_{0}\left(\times 10^{-6}\right)=-462.6+17.72 T+3.787 \times 10^{-3} T^{2}$, and

$Z$ Direction $-\Delta \ell / \ell_{0}\left(\times 10^{-6}\right)=-506.2+16.47 \mathrm{~T}+2.968 \times 10^{-3} \mathrm{~T}^{2}$, 
Table 2

LINEAR THERMAL EXPANSION OF TYPE 304 STAINLESS STEEL [VD 84-3; Base Material]

Table 1

TYPICAL CHEMICAL EOMPOSITION OF TYPES 304 AND 308 STAINLESS STEELS USED IN THE FAST FLUX TEST FACILITY

\begin{tabular}{lcc}
\hline & \multicolumn{2}{c}{ Composition. (wt \%) } \\
\cline { 2 - 3 } \cline { 3 - 3 } Element & $\begin{array}{c}\text { Type 304 SS } \\
\text { (base material) }\end{array}$ & $\begin{array}{c}\text { Typz 308 SS } \\
\text { (vveld material) }\end{array}$ \\
\hline $\mathrm{C}$ & 0.061 & 0.065 \\
$\mathrm{Cr}$ & 18.88 & 19.73 \\
$\mathrm{Fe}(1 !$ & 69.349 & 67.169 \\
$\mathrm{Mn}$ & 1.48 & 1.95 \\
$\mathrm{Ni}$ & 9.56 & 9.88 \\
$\mathrm{P}$ & 0.016 & 0.043 \\
$\mathrm{~S}$ & 0.014 & 0.015 \\
$\mathrm{Si}$ & 0.64 & 0.52 \\
$\mathrm{Othe}-12)$ & - & 0.625 \\
\hline
\end{tabular}

(1) By differerice.

(2) Includes $\mathrm{Mo}, \mathrm{Nb}, \mathrm{Ti}, \mathrm{Cu}, \mathrm{B}, \mathrm{V}$, and $\mathrm{N}$.

\begin{tabular}{|c|c|c|c|c|}
\hline \multirow{2}{*}{$\begin{array}{c}\text { Temperature } \\
\left({ }^{\circ} \mathrm{C}\right)\end{array}$} & \multicolumn{3}{|c|}{$\Delta \mathrm{l} / \mathrm{I}_{\mathrm{o}}\left(\times 10^{-6}\right)$} & \multirow{2}{*}{$\begin{array}{c}\epsilon_{\text {instant }} \\
\left(\times 10^{-6} /{ }^{\circ} \mathrm{C}\right) \\
\end{array}$} \\
\hline & Measured & Computed(1) & Difference & \\
\hline $0.2500 E+02$ & $0.0000 E+00$ & $-0.1495 E+02$ & $0.1495 E+02$ & $0.1711 E+02$ \\
\hline $0.4100 E+02$ & $0.2360 E+03$ & $0.2595 E+03$ & $-0.2354 E+02$ & $0.1720 E+02$ \\
\hline $0.5400 E+02$ & $0.4100 E+03$ & $0.4837 E+03$ & $-0.7372 E+02$ & $0.1728 E+02$ \\
\hline $0.7000 E+02$ & $0.6440 E+03$ & $0.7611 E+03$ & $-0.1171 \hat{E}+03$ & $0.1738 E+02$ \\
\hline $0.1080 E+03$ & $0.1299 E+04$ & $0.1426 E+04$ & $-0.1270 E+03$ & $0.1761 E+02$ \\
\hline $0.16: 0 E+03$ & $0.2219 E+04$ & $0.2368 E+04$ & $-0.1492 E+03$ & $0.1794 E+02$ \\
\hline $0.2340 E+03$ & $0.3611 E+04$ & $0.3694 E+04$ & $-0.8297 E+02$ & $0.1839 E+02$ \\
\hline $0.3080 E+03$ & $0.4996 E+04$ & $0.5071 E+04$ & $-0.7521 E+02$ & $0.1884 E+02$ \\
\hline $0.3830 E+03$ & $0.64 .72 E+04$ & $0.6501 E+04$ & $-0.2923 E+02$ & $0.1930 E+02$ \\
\hline $0.4560 E+03$ & $0.7889 E+04$ & $0.7926 E+04$ & $-0.3715 E+02$ & $0.1974 E+02$ \\
\hline $0.5280 E+03$ & $0.9253 E+04$ & $0.9363 E+04$ & $-0.1105 E+03$ & $0.2018 E+02$ \\
\hline $0.5990 E+03$ & $0.1073 E+05$ & $0.1081 E+05$ & $-0.8388 E+02$ & $0.2060 E+02$ \\
\hline $0.6700 E+03$ & $0.1222 E+05$ & $0.1229 E+05$ & $-0.7312 E+02$ & $0.2105 \mathrm{E}+02$ \\
\hline $0.7400 E+03$ & $0.1377 E+05$ & $0.1378 E+05$ & $-0.1370 E+02$ & $0.2148 E+02$ \\
\hline $0.7560 E+03$ & $0.1418 E+05$ & $0.1412 E+05$ & $0.5985 E+02$ & $0.2158 E+02$ \\
\hline $0.7450 E+03$ & $0.1393 E+05$ & $0.1389 E+05$ & $0.4283 E+02$ & $0.2151 E+02$ \\
\hline $0.7320 E+03$ & $0.1362 E+05$ & $0.1361 E+05$ & $0.1694 E+02$ & $0.2143 E+02$ \\
\hline $0.6930 E+03$ & $0.1280 E+05$ & $0.1278 E+05$ & $0.2008 E+02$ & $0.2119 E+02$ \\
\hline $0.6250 E+03$ & $0.1136 E+05$ & $0.1135 E+05$ & $0.1400 E+02$ & $0.2078 E+02$ \\
\hline $0.5540 E+03$ & $0.9909 E+04$ & $0.9890 E+04$ & $0.1870 E+02$ & $0.2034 E+02$ \\
\hline $0.4850 E+03$ & $0.8526 E+04$ & $0.8501 E+04$ & $0.2474 E+02$ & $0.1992 E+02$ \\
\hline $0.4150 E+03$ & $0.7172 E+04$ & $0.7122 E+04$ & $0.5016 E+02$ & $0.1949 E+02$ \\
\hline $0.3430 E+03$ & $0.5809 E+04$ & $0.5734 E+04$ & $0.7473 E+02$ & $0.1905 E+02$ \\
\hline $0.2760 E+03$ & $0.4563 E+04$ & $0.4472 E+04$ & $0.9146 E+02$ & $0.1864 E+02$ \\
\hline $0.2090 E+03$ & $0.3378 E+04$ & $0.3236 E+04$ & $0.1417 E+03$ & $0.1823 E+02$ \\
\hline $0.1480 E+03$ & $0.2311 E+04$ & $0.2135 E+04$ & $0.1755 E+03$ & $0.1786 E+02$ \\
\hline $0.1120 E+03$ & $0.1635 E+04$ & $0.1497 E+04$ & $0.1385 E+03$ & $0.1764 E+02$ \\
\hline $0.1030 E+03$ & $0.1450 E+04$ & $0.1338 E+04$ & $0.1120 E+03$ & $0.1758 E+02$ \\
\hline
\end{tabular}

(1) $\angle \mathrm{L} / \mathrm{I}_{\mathrm{O}}\left(\times 10^{-6}\right)=-440.7+16.95 \mathrm{~T}+3.058 \times 10^{-3} \mathrm{~T}^{2} ; \sigma=90$. 
Table 3

LINEAR THERMAL EXPANSION OF TYPE 308 STAINLESS STEEL IVD 84-1: Weld Pass (x) Direr:tion!

\begin{tabular}{|c|c|c|c|c|}
\hline \multirow{2}{*}{ 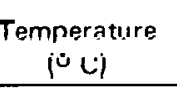 } & \multicolumn{3}{|c|}{$\Delta / / I_{0}(x 106)$} & \multirow{2}{*}{$\begin{array}{c}\epsilon_{\text {instant }} \\
\left(\times 10^{-0} / 0(\mathrm{C})\right. \\
\end{array}$} \\
\hline & Mèạsưưrèd & Computed(1) & U $_{1}$ terence & \\
\hline $0.2500 E+02$ & $0.0000 E+00$ & $-0.2477 E+01$ & $0.2477 E+01$ & $0.1675 E+02$ \\
\hline $0.4300 E+02$ & $0.3250 E+03$ & $0.3000 E+03$ & $0.2497 E+02$ & $0.1686 E+02$ \\
\hline $0.5400 E+02$ & $0.4870 E+03$ & $0.4858 E+03$ & $0.1194 E+01$ & $0.1692 \mathrm{E}+02$ \\
\hline $0.6900 E+02$ & $0.7220 E+03$ & $0.7402 E+03$ & $-0.1825 E+02$ & $0.1701 E+02$ \\
\hline $0.1070 E+03$ & $0.1357 E+04$ & $0.1391 E+04$ & $-0.3357 \varepsilon+02$ & $0.1722 E+02$ \\
\hline $0.1610 E+03$ & $0.2108 \mathrm{E}+04$ & $0.2154 E+04$ & $-0.4587 E+02$ & $0.1 \% 4 \% E+02$ \\
\hline $0.1950 E+03$ & $0.2874 E+04$ & $0.2928 E+04$ & $-0.5420 E+02$ & $0.1772 E+02$ \\
\hline $0.2580 E+03$ & $0.4041 E+04$ & $0.4056 E+04$ & $-0.1513 E+02$ & $0.1808 E+02$ \\
\hline $0.3200 E+03$ & $0.5217 E+04$ & $0.5188 E+04$ & $0.2876 E+02$ & $0.1844 E+02$ \\
\hline $0.3930 E+03$ & $0.6575 E+04$ & $0.6549 E+04$ & $0.2569 E+02$ & $0.1885 E+02$ \\
\hline $0.4640 E+03$ & $0.7916 E+04$ & $0.7902 E+04$ & $0.1377 E+02$ & $0.1926 E+02$ \\
\hline $0.5340 E+03$ & $0.9248 E+04$ & $0.9264 E+04$ & $-0.1624 E+02$ & $0.1966 \mathrm{E}+02$ \\
\hline $0.6040 E+03$ & $0.1063 E+05$ & $0.1065 E+05$ & $-0.2018 E+02$ & $0.2006 \mathrm{E}+02$ \\
\hline $0.6720 \mathrm{E}+03$ & $0.1193 E+05$ & $0.1203 E+05$ & $-0.9617 E+02$ & $0.2 n 44 E+n ?$ \\
\hline $0.7400 E+03$ & $0.1344 E+05$ & $0.1343 E+05$ & $0,8484 E+01$ & $0.2083 E+02$ \\
\hline $0.7300 E+03$ & $0.1334 E+05$ & $0.1323 E+05$ & $0.1105 E+03$ & $0.2077 E+02$ \\
\hline $0.7170 E+03$ & $0.1295 E+05$ & $0.1296 E+05$ & $-0.3904 E+01$ & $0.2070 E+02$ \\
\hline $0.6910 E+03$ & $0.1239 E+05$ & $0.1242 E+05$ & $-0.2763 E+02$ & $0.2055 E+02$ \\
\hline $0.6240 E+03$ & $0.1106 \mathrm{E}+05$ & $0.1106 E+05$ & $0.4558 E+01$ & $0.2017 E+02$ \\
\hline $0.5550 E+03$ & $0.9671 E+04$ & $0.9678 E+04$ & $-0.7289 E+01$ & $0.1978 E+02$ \\
\hline $0.4870 E+03$ & $0.8325 E+04$ & $0.8347 E+04$ & $-0.2167 E+02$ & $0.1939 E+02$ \\
\hline $0.4190 \mathrm{E}+03$ & $0.7028 E+04$ & $0.7041 E+04$ & $-0.1341 E+02$ & $0.1900 E+02$ \\
\hline $0.3500 E+03$ & $0.5773 E+04$ & $0.5744 E+04$ & $0.2909 E+02$ & $0.1861 E+02$ \\
\hline $0.2820 E+03$ & $0.4533 E+04$ & $0.4492 E+04$ & $0.4123 E+02$ & $0.1822 E+02$ \\
\hline $0.2170 E+03$ & $0.3355 E+04$ & $0.3320 E+04$ & $0.3549 E+02$ & $0.1785 E+02$ \\
\hline $0.1540 E+03$ & $0.2255 E+04$ & $0.2206 \mathrm{E}+04$ & $0.4868 E+02$ & $0.1749 E+02$ \\
\hline $0.1120 E+03$ & $0.1496 E+04$ & $0.1477 E+04$ & $0.1924 E+02$ & $0.1725 \mathrm{E}+02$ \\
\hline $0.9700 E+02$ & $0.1198 E+04$ & $0.1219 E+04$ & $-0.2064 E+02$ & $0.1717 E+02$ \\
\hline
\end{tabular}

(1) $\Delta / / I_{0}\left(\times 10^{-6}\right)=-419.6+16.61 T+2.851 \times 10^{-3} T^{2} ; \sigma=40$.
Table 4

LINEAR THERMAL EXPANSION OF TYPE 308 STAINLESS STEEL [VD 81.2; Wold Width (y) Dircotion]

\begin{tabular}{|c|c|c|c|c|}
\hline $\begin{array}{c}\text { Temperature } \\
190.1\end{array}$ & Moacurod & $\begin{array}{l}\Delta / / I_{0}\left(\times 10^{-6}\right) \\
\text { Computed }\end{array}$ & Difference & 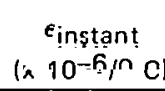 \\
\hline $0.2500 E+02$ & $0.0000 E+00$ & $-0.1732 E+02$ & $0.1732 E+02$ & $0.1791 E+02$ \\
\hline $0.3600 E+02$ & $0.1620 E+03$ & $0.1801 E+03$ & $-0.1812 E+02$ & $0.1799 E+02$ \\
\hline $0.4900 E+02$ & $0.4000 E+03$ & $0.4146 E+03$ & $-0.1464 E+02$ & $0.1809 E+02$ \\
\hline $0.6500 E+02$ & $0.7040 E+03$ & $0.7050 E+03$ & $-0.1040 E+01$ & $0.1821 E+02$ \\
\hline $0.8200 E+02$ & $0.1051 E+04$ & $0.1016 \mathrm{E}+04$ & $0.3529 E+0 ?$ & $0.1834 F+0 ?$ \\
\hline $0.1040 E+03$ & $0.1443 E+04$ & $0.1421 E+04$ & $0.2199 E+02$ & $0.1851 E+02$ \\
\hline $0.1250 E+03$ & $0.1832 E+04$ & $0.1811 E+04$ & $0.2070 E+02$ & $0.1866 E+02$ \\
\hline $0.1470 E+03$ & $0.2219 E+04$ & $0.2224 E+04$ & $-0.4755 E+01$ & $0.1883 E+02$ \\
\hline $0.2190 E+03$ & $0.3584 E+04$ & $0.3599 E+04$ & $-0.1525 E+02$ & $0.1938 E+02$ \\
\hline $0: 2930 E+03$ & $0.1988 E+04$ & $0.5054 E+04$ & $-0.6586 \mathrm{E} 102$ & $0.1994 E+02$ \\
\hline $0.3650 E+03$ & $0.6491 E+04$ & $0.6509 E+04$ & $-0.1797 E+02$ & $0.2048 \mathrm{E}+02$ \\
\hline $0.4380 E+03$ & $0.7971 E+04$ & $c .8024 E+04$ & $-0.5337 E+02$ & $0.2104 E+02$ \\
\hline $0.5080 E+03$ & $0.9408 E+04$ & $0.9515 E+04$ & $-0.1074 E+03$ & $0.2157 E+02$ \\
\hline $0.6770 E+03$ & $0.1090[105$ & $0.1102 E+0 \sqrt{3}$ & $=0.1183 E+03$ & $0.2209 \mathrm{E}+02$ \\
\hline $0.6450 E+03$ & $0.1240 E+05$ & $0.1264 E 105$ & $0.1430[103$ & $0.2200[102$ \\
\hline $0.7130 E+03$ & $0.1401 E+05$ & $0.1410 E+05$ & $-0.8648 E+02$ & $0.2312 E+02$ \\
\hline $0.7430 E+03$ & $0.1472 E+05$ & $0.1479 E+05$ & $-0.6743 E+02$ & $0.2335 E+02$ \\
\hline $0.7260 F+03$ & . $1449 E+05$ & $0.1440 E+05$ & $0.8135 E+02$ & $0.2322 E+02$ \\
\hline $0.6740 E+0.3$ & $n 1.3 .36 \mathrm{~F}+\mathrm{n} 5$ & ก 137nf +05 & $0.1621 E+03$ & $0.2382 E+02$ \\
\hline $0.6080 E+03$ & $0.1186 E+05$ & $0.1171 E+05$ & $0.1532 E+03$ & $0.2232 E+02$ \\
\hline $0.5400 E+03$ & $0.1029 E+05$ & $0.1021 E+05$ & $0.8262 F+02$ & $0.2181 E+02$ \\
\hline $0.4720 E+03$ & $0.8781 E+04$ & $0.8744 E+04$ & $0.3705 E+02$ & $0.2129 E+02$ \\
\hline $0.4030 E+03$ & $0.7341 E+04$ & $0.7293 E+04$ & $0.4823 E+02$ & $0.2077 E+02$ \\
\hline $0.3320 E+03$ & $0.5872 \mathrm{E}+04$ & $0.5837 E+04$ & $0.3483 E+02$ & $0.2023 \mathrm{E}+02$ \\
\hline $0.2650 E+03$ & $0.4540 E+04$ & $0.4499 E+04$ & $0.4141 F+n ?$ & $n 1.97 .3 F+n ?$ \\
\hline $0.2020 E+03$ & $0.3300 E+04$ & $0.3271 E+04$ & $0.2906 \mathrm{E}+02$ & $0.1925 E+02$ \\
\hline $0.1320 E+03$ & $0.1967 E+04$ & $0.1942 E+04$ & $0.2486 F+n 2$ & $0,1872 F+0 ?$ \\
\hline $0.1010 E+03$ & $0.1279 E+04$ & $0.1366 E+04$ & $-0.8652 E+02$ & $0.1848 E+02$ \\
\hline
\end{tabular}

(1) $\mathrm{N} / \mathrm{O}_{\mathrm{O}}\left(\times 10^{-6}\right)=-462.6+17.72 \mathrm{~T}+3.787 \times 10^{-3} \mathrm{~T}^{2}: \sigma=77$ 
Table 5

LINEAR THERMAL EXPANSION OF TYPE 308 STAINLESS STEEL

[VD 84.2 Rerun; Weld Width (v) Direction]

\begin{tabular}{|c|c|c|c|c|}
\hline \multirow{2}{*}{$\begin{array}{c}\text { Temperature } \\
\left(0^{\circ} \mathrm{C}\right)\end{array}$} & \multicolumn{3}{|c|}{$\Delta / /_{0}\left(\times 10^{-6}\right)$} & \multirow{2}{*}{$\begin{array}{c}\epsilon_{\text {instant }} \\
\left(\times 10^{-6} /{ }^{\circ} \mathrm{C}\right) \\
\end{array}$} \\
\hline & Measured & Computed (1) & Difference & \\
\hline $0.2500 E+02$ & $0.0000 E+00$ & $0.9429 E+01$ & $-0.9429 E+01$ & $0.1752 E+02$ \\
\hline $0.3600 E+02$ & $0.2080 E+03$ & $0.2027 E+03$ & $0.5310 E+01$ & $0.1762 E+02$ \\
\hline $0.5000 \mathrm{E}+02$ & $0.4550 E+03$ & $0.4503 E+03$ & $0.4699 E+01$ & $0.1775 E+02$ \\
\hline $0.7300 E+02$ & $0.8430 E+03$ & $0.8611 E+03$ & $-0.1808 E+02$ & $0.1797 E+02$ \\
\hline $0.9400 E+02$ & $0.1198 E+04$ & $0.1240 E+04$ & $-0.4248 E+02$ & $0.1817 E+02$ \\
\hline $0.1470 E+03$ & $0.2105 E+04$ & $0.2216 E+04$ & $-0.1114 E+03$ & $0.1866 E+02$ \\
\hline $0.2190 E+03$ & $0.3343 E+04$ & $0.3584 E+04$ & $-0.2414 E+03$ & $0.1934 E+02$ \\
\hline $0.2920 E+03$ & $0.4886 E+04$ & $0.5021 \mathrm{E}+04$ & $-0.1351 E+03$ & $0.2002 E+02$ \\
\hline $0.3660 E+03$ & $0.6393 E+04$ & $0.6529 E+04$ & $-0.1356 E+03$ & $0.2072 E+02$ \\
\hline $0.4370 E+03$ & $0.7847 E+04$ & $0.8023 E+04$ & $-0.1762 E+03$ & $0.2138 \mathrm{E}+02$ \\
\hline $0.5080 E+03$ & $0.9341 E+04$ & $0.9565 E+04$ & $-0.2241 E+03$ & $0.2205 E+02$ \\
\hline $0.5770 E+03$ & $0.1087 E+05$ & $0.1111 E+05$ & $-0.2429 \mathrm{E}+03$ & $0.2270 E+02$ \\
\hline $0.6460 E+03$ & $0.1248 E+05$ & $0.1270 E+05$ & $-0.2164 E+03$ & $0.2335 E+02$ \\
\hline $0.7140 E+03$ & $0.1417 E+05$ & $0.1431 E+05$ & $-0.1336 E+03$ & $0.2398 E+02$ \\
\hline $0.7420 E+03$ & $0.1502 E+05$ & $0.1498 E+05$ & $0.3713 E+02$ & $n 2425 F+n ?$ \\
\hline $0.7300 E+03$ & $0.1478 E+05$ & $0.1469 E+05$ & $0.8541 E+02$ & $0.2413 E+02$ \\
\hline $0.6790 E+03$ & $0.1365 E+05$ & $0.1347 E+05$ & $0.1770 E+0.3$ & $0.2366 E+02$ \\
\hline $0.6790 E+03$ & $0.1209 E+05$ & $0.1191 E+05$ & $0.1819 E+03$ & $0.2303 E+02$ \\
\hline $0.5440 E+03$ & $0.1052 E+05$ & $0.1037 E+05$ & $0.1560 E+03$ & $0.2239 E+02$ \\
\hline $0.4750 E+03$ & $0.8998 E+04$ & $0.8843 E+04$ & $0.1554 E+03$ & $0.2174 E+02$ \\
\hline $0.4060 E+03$ & $0.7557 E+04$ & $0.7365 E+04$ & $0.1922 E+03$ & $0.2109 \varepsilon+02$ \\
\hline $0.3380 E+03$ & $0.6147 E+04$ & $0.5952 E+04$ & $0.1949 E+03$ & $0.2046 E+02$ \\
\hline $0.2710 E+03$ & $0.4807 E+04$ & $\cap .4$ กก.3F+ก4 & $n \geq \cap \triangle 3 F+n 3$ & $0.1983 E+02$ \\
\hline $0.2060 E+03$ & $0.3492 E+04$ & $0.3334 E+04$ & $0.1582 E+03$ & $0.1922 E+02$ \\
\hline $0.1360 E \cdot .03$ & $0.2129 E+04$ & $0.2012 E+04$ & $0.1173 E+03$ & $0.1856 E+02$ \\
\hline $0.1050 E+03$ & $0.1458 E+04$ & $0.1441 \mathrm{E}+04$ & $0.1714 \mathrm{E}+02$ & $0.1827 E+02$ \\
\hline
\end{tabular}

(1) $\Delta 1 / \mathrm{I}_{\mathrm{o}}\left(\times 10^{-6}\right)=-425.6+17.28 \mathrm{~T}+4.692 \times 10^{-3} \mathrm{~T}^{2} ; \sigma=160$
Table 6

LINEAR THERMAL EXPANSION OF TYPE 308 STAINLESS STEEL [VD 84-4; Weld Depth (z) Direction]

\begin{tabular}{|c|c|c|c|c|}
\hline \multirow{2}{*}{$\begin{array}{c}\text { Temperature } \\
\left({ }^{\circ} \mathrm{C}\right)\end{array}$} & \multicolumn{3}{|c|}{$\Delta l / I_{0}\left(\times 10^{-6}\right)$} & \multirow{2}{*}{$\begin{array}{c}\epsilon_{\text {instant }} \\
\left(\times 10^{-6 / 0} \mathrm{C}\right) \\
\end{array}$} \\
\hline & Measured & Computed (1) & Difference & \\
\hline $0.2500 E+02$ & $0.0000 E+00$ & $-0.9258 E+02$ & $0.9258 E+02$ & $0.1662 E+02$ \\
\hline $0.4400 E+02$ & $0.2910 E+03$ & $0.2243 E+03$ & $0.6673 E+02$ & $0.1673 E+02$ \\
\hline $0.7600 E+02$ & $0.7550 E+03$ & $0.7627 E+03$ & $-0.7748 E+01$ & $0.1692 E+02$ \\
\hline $0.1160 E+03$ & $0.1434 E+04$ & $0.1444 E+04$ & $-0.1039 E+02$ & $0.1716 E+02$ \\
\hline $0.1580 E+03$ & $0.2168 E+04$ & $0.2170 E+04$ & $-0.2343 E+01$ & $0.1741 E+02$ \\
\hline $0.2000 E+03$ & $0.2940 E+04$ & $0.2907 E+04$ & $0.3324 E+02$ & $0.1766 E+02$ \\
\hline $0.2540 E+03$ & $0.3906 \mathrm{E}+04$ & $0.3869 E+04$ & $0.3702 E+02$ & $0.1798 E+02$ \\
\hline $0.3260 E+03$ & $0.5277 E+04$ & $0.5179 E+04$ & $0.9815 E+02$ & $0.1841 E+02$ \\
\hline $0.3990 E+03$ & $0.6653 E+04$ & $0.6538 E+04$ & $0.1147 E+03$ & $0.1884 E+02$ \\
\hline $0.4700 E+03$ & $0.8002 E+04$ & $0.7891 E+04$ & $0.1111 E+03$ & $0.1926 E+02$ \\
\hline $0.5410 E+03$ & $0.9317 E+04$ & $0.9273 E+04$ & $0.4356 \mathrm{E}+02$ & $0.1968 E+02$ \\
\hline $0.6090 E+03$ & $0.1067 E+05$ & $0.1063 E+05$ & $0.4642 E+02$ & $0.2009 E+02$ \\
\hline $0.6780 E+03$ & $0.1197 E+05$ & $0.1203 E+05$ & $-0.5467 E+02$ & $0.2050 E+02$ \\
\hline $0.7450 E+03$ & $0.1342 .5+0.5$ & $01.341 F+05$ & $0.7773 E+01$ & $0.2088 E+02$ \\
\hline $0.7280 E+03$ & $0.1309 E+05$ & $0.1306 E+05$ & $0.3611 E+02$ & $0.2079 E+02$ \\
\hline $0.6370 E+03$ & $0.1114 E_{2}+05$ & $0.1119 E+05$ & $-0.4633 E+02$ & $0.2025 E+02$ \\
\hline $0.5680 E+03$ & $0.9738 E+04$ & $0.9807 E+04$ & $-0.6903 E+02$ & $0.1984 E+02$ \\
\hline $0.5000 E+03$ & $0.8390 E+04$ & $0.8471 E+04$ & $-0.8144 E+02$ & $0.1944 E+02$ \\
\hline $0.4310 E+03$ & $0.7092 E+04$ & $0.7144 E+04$ & $-0.5225 E+02$ & $0.1903 E+02$ \\
\hline $0.3620 E+03$ & $0.5810 E+04$ & $0.5845 E+04$ & $-0.3533 E+02$ & $0.1862 E+02$ \\
\hline $0.2940 E+03$ & $0.4553 E+04$ & $0.4593 E+04$ & $-0.3989 E+02$ & $0.1822 E+02$ \\
\hline ก ว2RกF + +n3 & $0.3361 E+01$ & $0.3101 E+01$ & $0.1263 E-102$ & $0.1782[102$ \\
\hline $0.1650 E+03$ & $0.2244 E+04$ & $0.2292 E+04$ & $-0.4835 E+02$ & $0.1745 E+02$ \\
\hline $0.1200 \varepsilon+03$ & $0.1433 E+04$ & $0.1513 E+04$ & $-0.8008 E+02$ & $0.1718 E+02$ \\
\hline $0.1040 E+03$ & $0.1122 E+04$ & $0.1239 E+04$ & $-0.1169 E+03$ & $0.1709 E+02$ \\
\hline
\end{tabular}

(1) $\Delta 1 / I_{0}\left(\times 10^{-6}\right)=-506.2+16.47 \mathrm{~T}+2.968 \times 10^{-3} \mathrm{~T}^{2} \cdot \sigma=68$ 
22

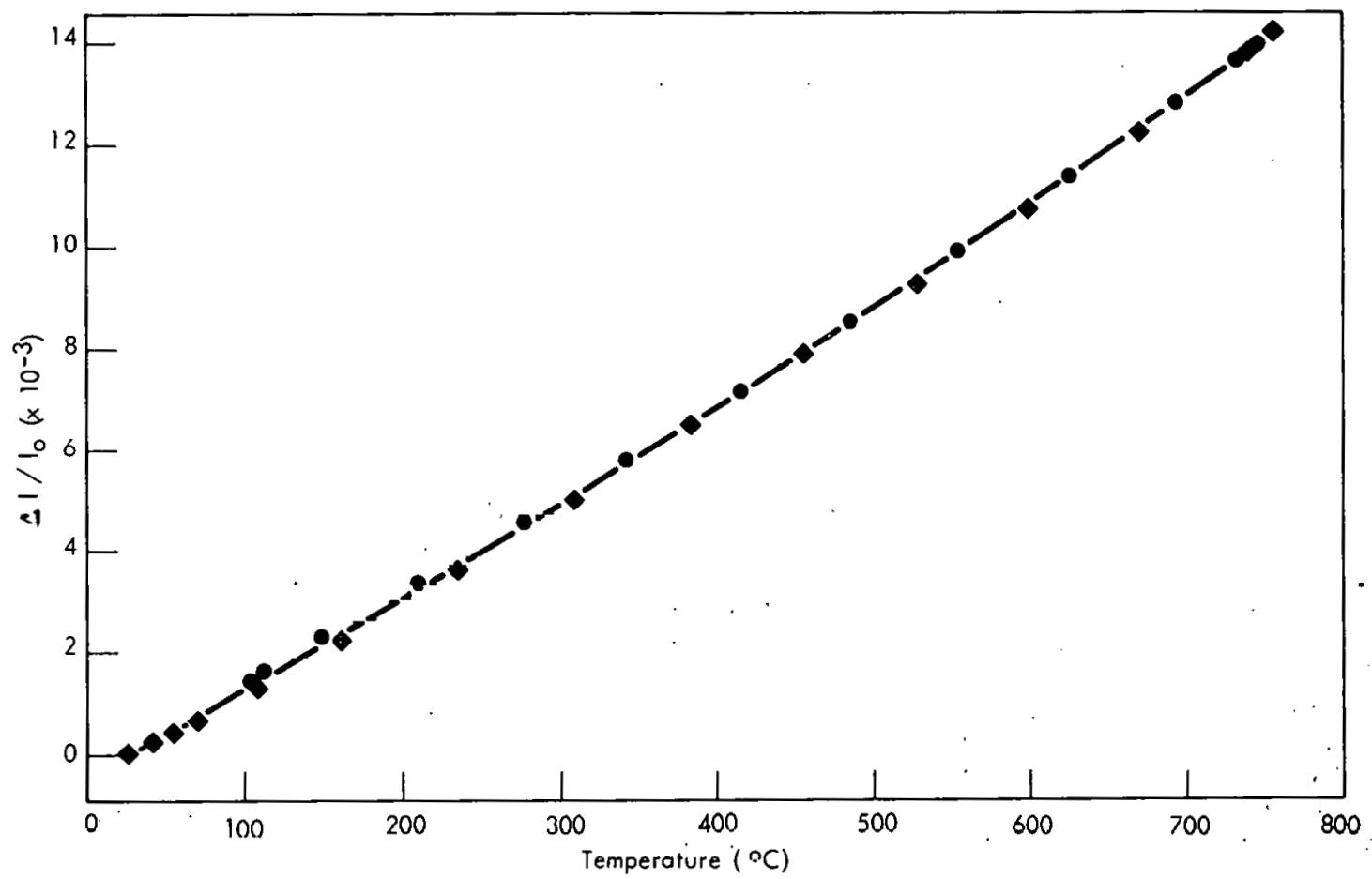

Figure 12. THERMAL EXPANSION OF TYPE 304 STAINLESS STEEL BASE MATERIAL. (VD 84-3)

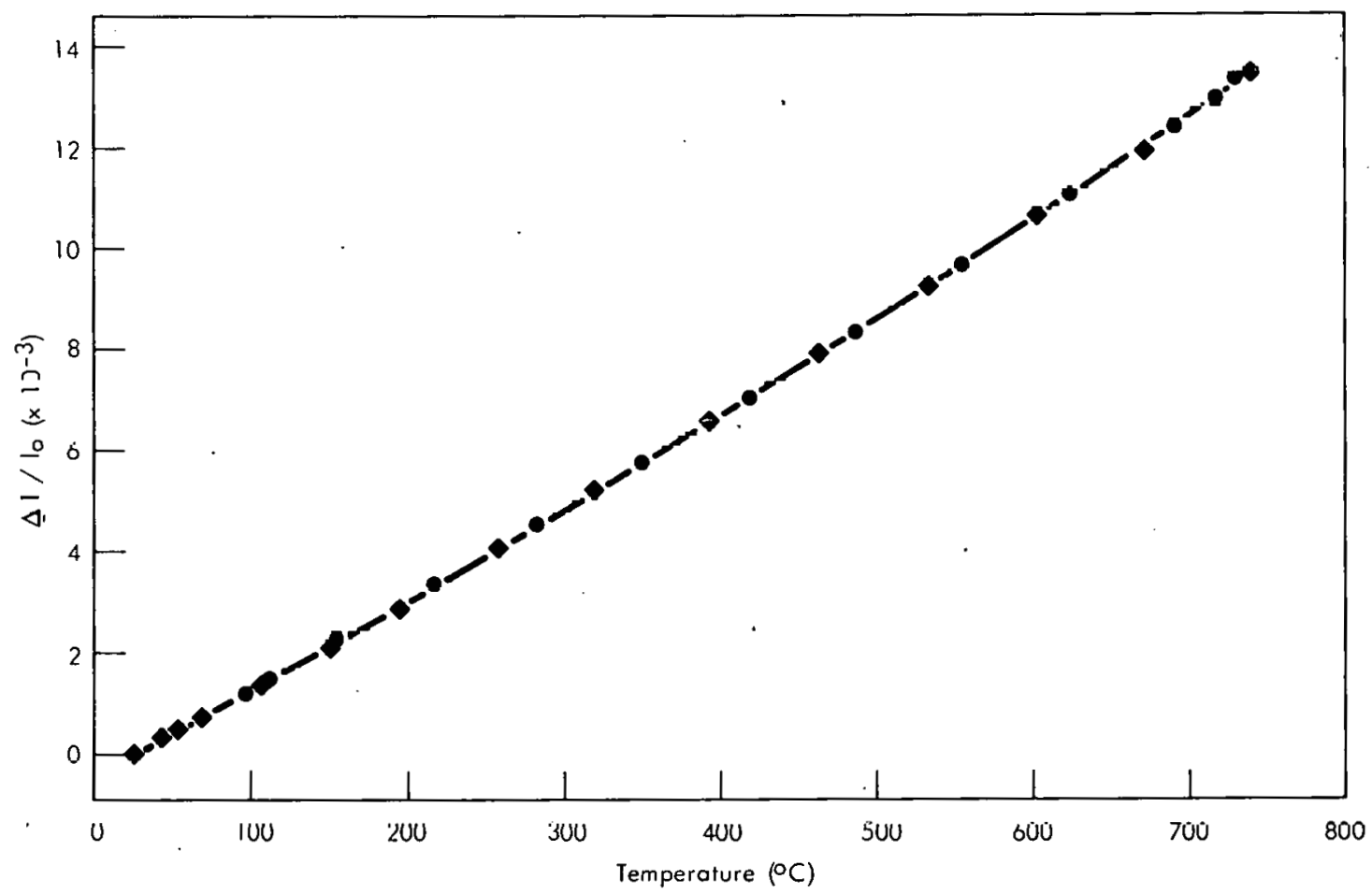

Figure 13. THERMAL EXPANSION OF TYPE 308 STAINLESS STEEL IN THE WELD PASS (X) DIRECTION. (VD 84-1) 


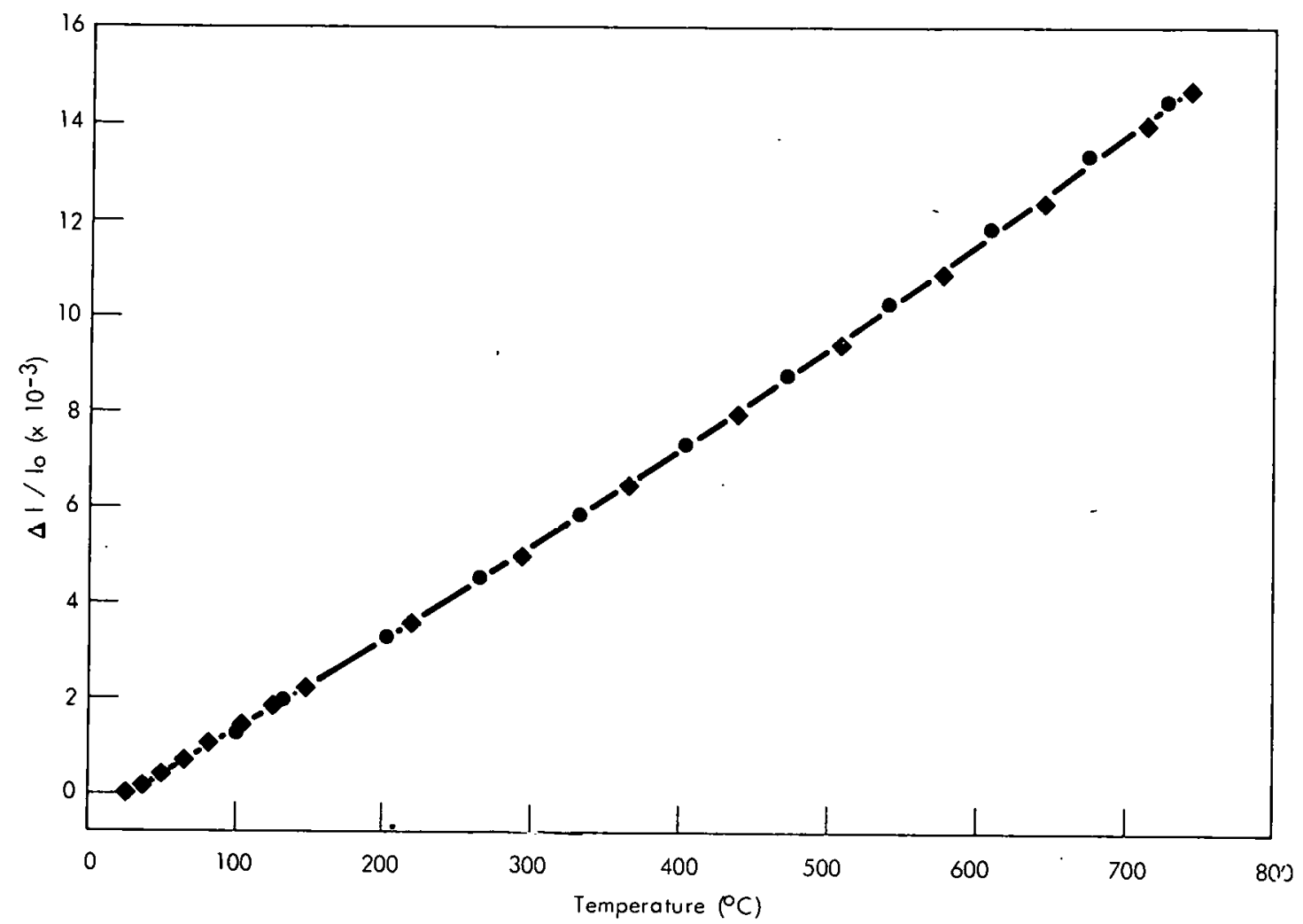

Figure 14. THERMAL EXPANSION OF TYPE 308 STAINLESS STEEL IN THE WELD WIDTH (Y) DIRECTION. (VD 84-2)

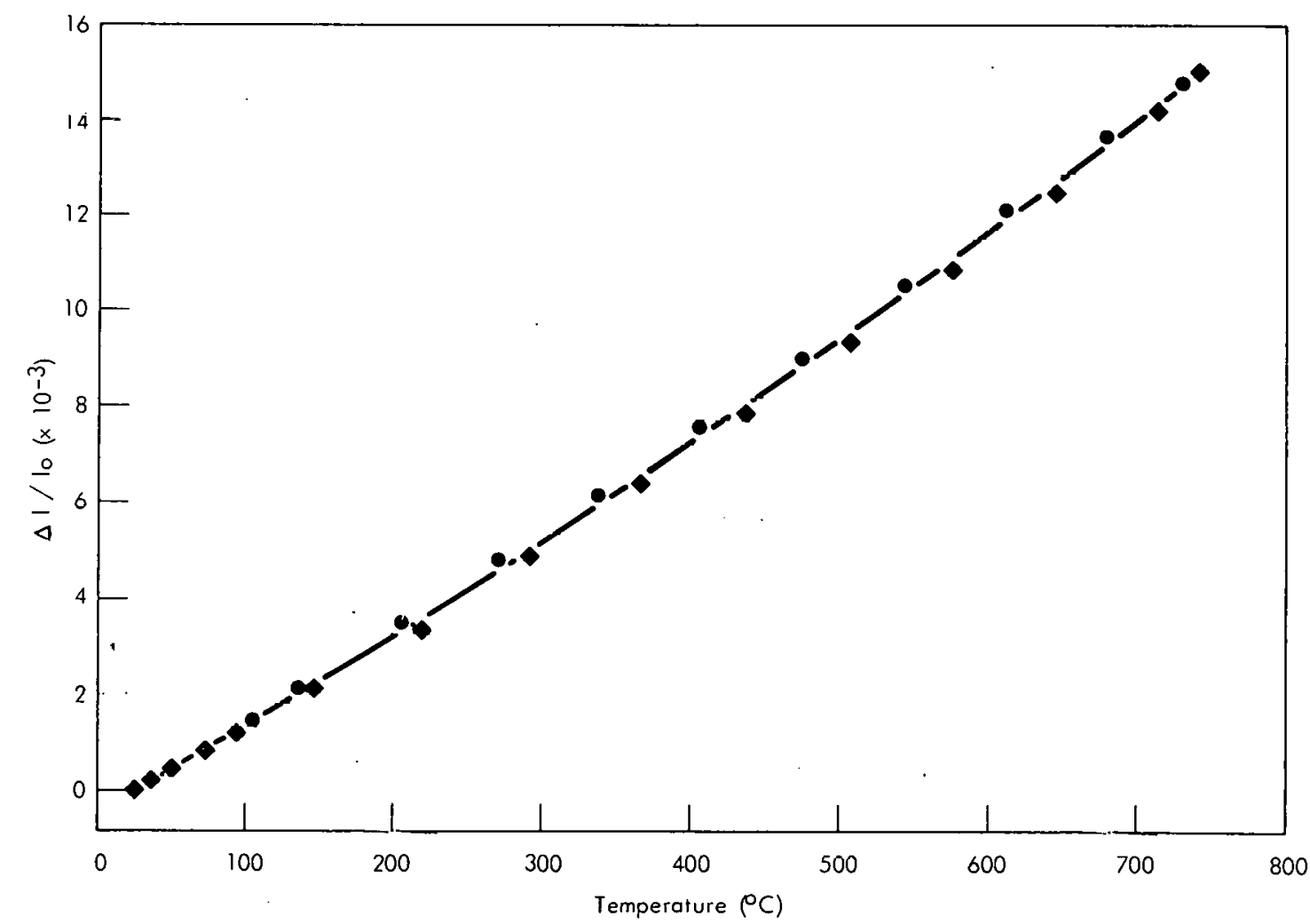

Figure 15. THERMAL EXPANSION RERUN OF TYPE 308 STAINLESS STEEL IN THE WELD WIDTH (Y) DIRECTION. (VD 84-2r) 


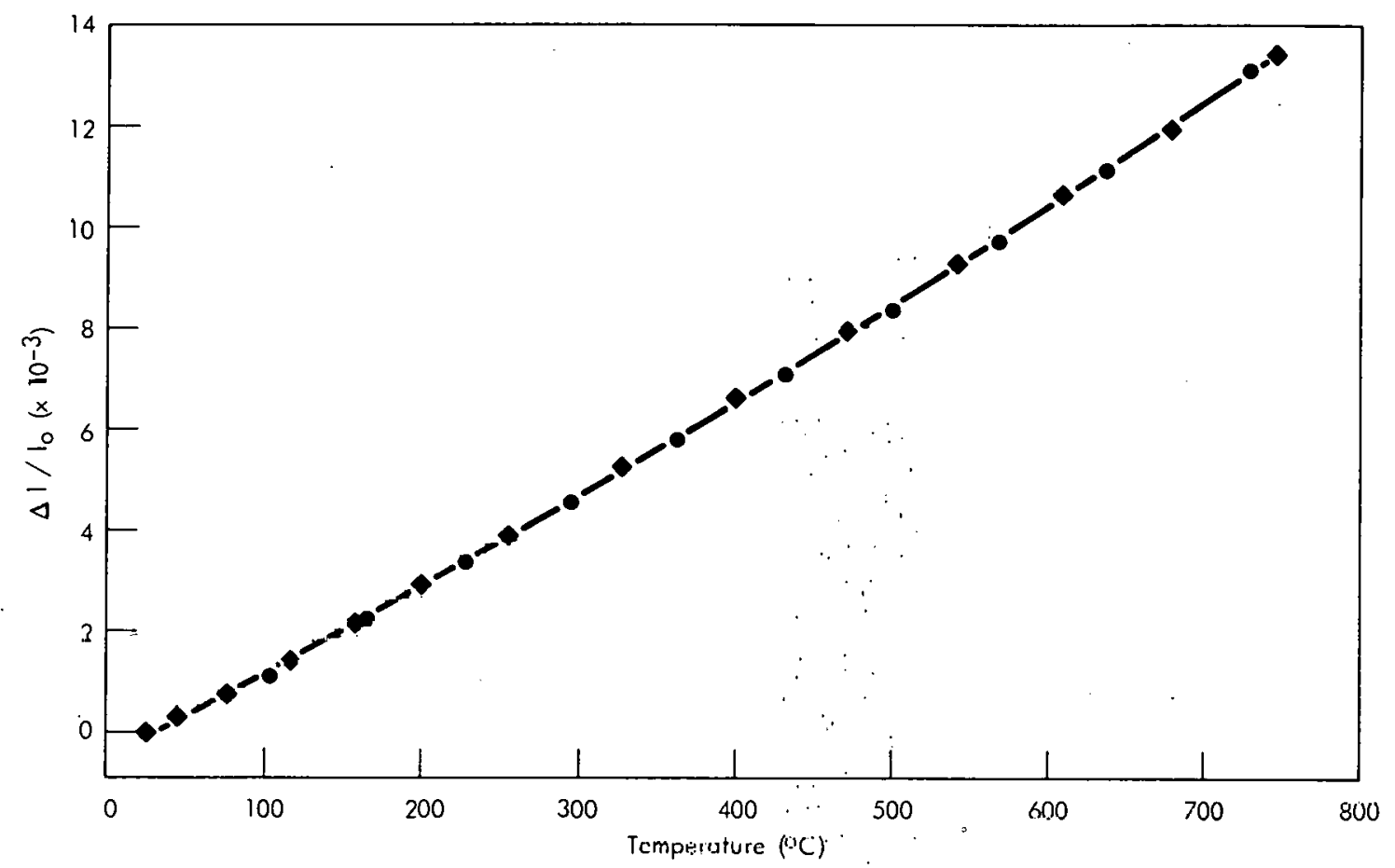

Figure 16. THERMAL EXPANSION OF TYPE 308 STAINLESS STEEL IN THE WELD DEPTH (Z) DIRECTION. (VD 844)

where:

$\triangle \ell \quad$ Represents the change in length,

$\ell_{0} \quad$ the length at $25^{\circ} \mathrm{C}$, and

$\mathrm{T}$ the temperature in ${ }^{\circ} \mathrm{C}$.

The linear coefficients of expansion $(\bar{\epsilon})$, as defined by Fquation 2, ai e yiven in Tąble 7.

Táble 7

LINEAR COEFFICIENTS OF THERMAL EXPPANSION OF TYPE 308 STAINLESS

STEEL BASE MATERIAL AND THE $x, y, z$ WELD DIRECTIONS

AT 100-DEGREE TEMPERATURE INTERVALS

\begin{tabular}{|c|c|c|c|c|c|}
\hline \multirow{3}{*}{$\begin{array}{c}\text { Temperature } \\
\text { Range } \\
\left(0^{\circ} \mathrm{Cl}\right. \\
\end{array}$} & \multirow{3}{*}{$\begin{array}{c}x \\
\text { VD841 } \\
\end{array}$} & \multicolumn{4}{|c|}{1 inear Coefficlent of Expansion [E $\left.\left(x 10^{-6 / 0} \mathrm{C}\right)\right]$} \\
\hline & & \multicolumn{2}{|c|}{$y$} & \multirow{2}{*}{$\begin{array}{c}\text { BM(1) } \\
\text { VD84-3 }\end{array}$} & \multirow{2}{*}{$\begin{array}{c}z \\
\text { VD84-4 } \\
\end{array}$} \\
\hline & & VD84-2 & VD84-2R & & \\
\hline $25 \cdot 100$ & 16.93 & 17.96 & 17.99 & 17.13 & 15.61 \\
\hline $25-200$ & 17.24 & 18.47 & 18.39 & $17.5 b$ & 16.61 \\
\hline $25-300$ & 17.53 & 18.89 & 18.84 & 17.89 . & 17.10 \\
\hline $25-400$ & 17.81 & 19.28 & 19.30 & 18.21 & 17.48 \\
\hline $25-500$ & 18.10 & 19.67 & 19.76 & 18.52 & 17.83 \\
\hline $25-600$ & 18.39 & 20.06 & 20.23 & 18.84 & 18.16 \\
\hline $25-700$ & 18.67 & 20.44 & 20.70 & 19.14 & 18.48 \\
\hline
\end{tabular}

(1) Base material. 
Specific-heat results for the base-metal and weld-metal sections, as given in Table 8 , were indistinguishable and were therefore aggregated for regression analysis, as compiled in Tables 9 through 12 and illustrated as a linear dependence of temperature in Figure 17. Base and weldmetal results agreed to within $\pm 1 \%$, which is the stated accuracy of the differential scanning calorimeter. (10)

Thermal-diffusivity measurements on the base material were obtained using both the intrinsic thermocouple (IT) and the noncontact (NC) techniques in order to assess their relative merits for this application. Comparative results with reference data are compiled in Table 13 and are displayed in Figure 18. Base-metal values based on IT measurements do agree with the Thermophysical Properties Research Center's (TPRC) provisional mean reference data for AISI Type 304 austenitic stainless steel to within $9 \%$ over the temperature interval from 25 to $1000^{\circ} \mathrm{C} .(11)$ The base metal was totally austenitic in structure; the weld metal was 5 to $7 \%$ ferritic. Diffusivities based on NC measurements, however, diverge from the TPRC data with increasing temperatures, exhibiting a progressively increasing positive bias. Radiative-heat-loss effects would give rise to the same tendency, and radial-conduction losses may also contribute to this trend of divergence. Figure 19 illustrates the characteristic heat-pulse transients as recorded by the IT and NC techniques. The IT temperature maxima were flat over ten half-time intervals, whereas the NC maxima were progressively skewed with increasing temperatures. Thus, numerical and qualitative indications of excessive heat losses and nonideal behavior were evidenced for the NC technique. Such losses would install a positive bias for diffusivity, as computed by Equation 7. The utility and desirability of implementing heat-loss corrections for such data by computer analysis of the nonideal transients is a recognized need that has not yet been realized. Thus, the IT technique was adopted for this test application.

Measured IT values of $\alpha$ using Equation 7, typically variant to $\pm 0.7 \%$ relative to the mean of four observations at a given temperature and average $C p$ values $( \pm 1.0 \%)$ variant, are compiled in Tables 9 through 12 and are illustrated in Figures 20 through 24. Thermal-diffusivity and specific-heat values were separately grouped and statistically reduced to mathematical expressions (Tables $9-12$ ) to facilitate the condition of isothermicity for Equation 12, to expedite interpolative and extrapolative operations necessary for determining the computed $K$ values, and for construction of the temperature functions noted in Figure 25 through 29. Tolerance intervals ( \pm tolerance limit) are defined 
Table 9

SPECIFIC-HEAT, THERMAL-DIFFUSIVITY, AND THERMAL-CONDUCTIVITY RESULTS FOR TYPE 304 STAINLESS STEEL

\begin{tabular}{|c|c|c|c|c|c|c|c|}
\hline \multirow{2}{*}{$\begin{array}{c}\text { Average } \\
\text { Temperature } \\
10 \mathrm{Cl} \\
\end{array}$} & \multicolumn{2}{|c|}{$\begin{array}{c}\text { Thermal Diffusivity, } \\
a \\
\left(\times 10^{-2} \mathrm{~cm}^{2}-\sec ^{-1}\right)\end{array}$} & \multirow[t]{2}{*}{$\begin{array}{c}\text { Standard } \\
\text { Deviation } \\
\text { of Fit, } \\
\sigma^{(4)}\end{array}$} & \multirow{2}{*}{$\begin{array}{c}\text { Correlation } \\
\text { Coefficient, } \\
\text { r(5) } \\
\end{array}$} & \multicolumn{2}{|c|}{$\begin{array}{c}\text { Specific Heat, } \\
C_{p} \\
\left(\text { cal-q.o } \mathrm{C}^{-1)}\right.\end{array}$} & \multirow{2}{*}{$\begin{array}{c}\text { Computed } \\
\text { Thermal } \\
\text { Conductivity, } \\
\mathrm{k}^{(7)} \\
\text { (watt- } \mathrm{m}^{-1.0} \mathrm{C}^{-1}\end{array}$} \\
\hline & & Computed (3) & & & Measured & Computed $(6)$ & \\
\hline 25 & & 3.38 & 0.0019 & 0.944 & & $0.115^{(8)}$ & 12.8 \\
\hline 26 & 3.40 & 3.38 & & & & & \\
\hline 100 & & 3.53 & & & 0.120 & 0.119 & 13.8 \\
\hline 114 & 3.64 & 3.56 & & & & & \\
\hline 154 & $\begin{array}{l}3.58 \\
3.58\end{array}$ & $\begin{array}{l}3.63 \\
371\end{array}$ & & & & . & \\
\hline $\begin{array}{l}191 \\
200\end{array}$ & 3.92 & $\begin{array}{l}3.71 \\
3.72\end{array}$ & & & 0.125 & 0.124 & 15.2 \\
\hline 229 & 3.76 & 3.78 & & & & & \\
\hline 282 & 4.01 & 3.85 & & & & & \\
\hline 300 & & 3.92 & & & 0.131 & 0.129 & 16.7 \\
\hline 322 & 3.88 & 3.97 & & & & & \\
\hline 350 & 4.18 & 4.02 & & & & & \\
\hline 395 & 4.00 & 4.11 & & & & & \\
\hline 400 & & 4.12 & & & 0.134 & 0.135 & 18.3 \\
\hline 430 & 4.24 & 18 & & & & & \\
\hline $\begin{array}{l}479 \\
500\end{array}$ & 4.18 & $\begin{array}{l}4.28 \\
4.32\end{array}$ & & & 0.139 & 0.140 & 19.9 \\
\hline 505 & 4.40 & 4.33 & & & & & \\
\hline & 4.29 & 4.42 & & & & & \\
\hline & 4.40 & 4.48 & & & & & \\
\hline 600 & & 4.52 & & & 0.145 & 0.145 & 21.6 \\
\hline 631 & 4.33 & & & & & & \\
\hline 663 & 4.54 & $\begin{array}{l}4.64 \\
-77 .\end{array}$ & & & & & \\
\hline 697 & 4.36 & 4.71 & & & & & \\
\hline 700 & & 4.72 & & & 0.150 & 0.150 & 23.4 \\
\hline 734 & 4.75 & 88 & & & & & \\
\hline $\begin{array}{l}769 \\
800\end{array}$ & 4.47 & $\begin{array}{l}4.05 \\
4.92\end{array}$ & & & & $0.156^{(8)}$ & 25.2 \\
\hline & 5.20 & 4.92 & & & & & \\
\hline 843 & 4.88 & & & & & & \\
\hline & 5.37 & 5.0 & & & & & \\
\hline 900 & & 5.1 & & & & $0.104^{(8)}$ & 27.9 \\
\hline & 5.35 & & & & & & \\
\hline $\begin{array}{r}958 \\
1000\end{array}$ & 5.44 & $\begin{array}{l}5.23 \\
5.31\end{array}$ & & & & $0.1 \in \in(8)$ & 29.1 \\
\hline
\end{tabular}

(1) Average apparent density, $\rho=7.90 \mathrm{g-cm}-3$

(2) Number of observations, $n_{0}=4$.

(3) Values computed by regression analyses, $a_{c o m p}=3.33 \times 10^{-2}+1.98 \times 10^{-5} \mathrm{~T}$.

(4) $\sigma=\mid \sum\left(a_{\text {meas }}-a_{\text {comp }}|2 / n i-p-1|^{1 / 2}\right.$, where ni $=$ the number of data points and the order of the polynomial

(5) $r=\mid 1-\Sigma\left(a_{\text {meas }}-a_{\text {comp }}\right)^{2 /\left.\Sigma\left(a_{\text {meas }}-\bar{a}\right)^{2}\right|^{1 / 2}}$

(6) Values computed by regression analyses, $\mathrm{C}_{\mathrm{c}} \mathrm{comp}=0.114+5.24 \times 10^{-5} \mathrm{~T}$

(7) Values computed by regression analyses, $k=12.5+1.32 \times 10^{-2} \mathrm{~T}+3.43 \times 10^{-6} \mathrm{~T}^{2}$.

8) Extrapolated value.
Table 10

SPECIFIC-HEAT, THERMAL-DIFFUSIVITY, AND THERMAL-CONDUCTIVITY RESULTS FOR TYPE 308 STAINLESS STEEL
(n) Casured in the Weld Pass (x) Direction of Weldment CE-76)

\begin{tabular}{|c|c|c|c|c|c|c|c|}
\hline \multirow{2}{*}{$\begin{array}{c}\text { Average } \\
\text { Temperature } \\
10^{\circ} \mathrm{Cl} \\
\end{array}$} & \multicolumn{2}{|c|}{$\begin{array}{l}\text { Thermal Diffusivity, } \\
a \\
\left(\times 10^{-2} \mathrm{~cm}^{2} \text {-sec-1 }\right)\end{array}$} & \multirow{2}{*}{$\begin{array}{l}\text { Standard } \\
\text { Deviation } \\
\text { of Fit, } \\
\sigma^{(4)}\end{array}$} & \multirow{2}{*}{$\begin{array}{l}\text { Correlation } \\
\text { Coefficient, } \\
\text { r(5) }\end{array}$} & \multicolumn{2}{|c|}{$\begin{array}{l}\text { Specific Heat, } \\
\quad \text { Cp } \\
\left.\text { (cal-q1.0 } \mathrm{C}^{-1}\right)\end{array}$} & \multirow[t]{2}{*}{$\begin{array}{c}\text { Computed } \\
\text { Thermal } \\
\text { Conductivity, } \\
k^{(7)} \\
\text { (watt-m } \mathrm{m}^{-1.0} \mathrm{C}^{-1} \\
\end{array}$} \\
\hline & & Computed (3) & & & & & \\
\hline 25 & 3.01 & 3.01 & 0.0008 & 0.986 & & $0.115^{(8)}$ & 11.4 \\
\hline 25 & & 3.01 & & & & & \\
\hline 25 & 3.20 & 3.01 & & & & & \\
\hline 100 & 3.00 & 3.12 & & & & & \\
\hline 100 & & 3.12 & & & 0.120 & 0.119 & 12.2 \\
\hline $\begin{array}{l}114 \\
171\end{array}$ & $\begin{array}{l}3.07 \\
3.14\end{array}$ & & & & & & \\
\hline & & 3.23 & & & & & \\
\hline 200 & & $\begin{array}{l}3.26 \\
3.28\end{array}$ & & & 0.126 & 0.124 & 13.4 \\
\hline 242 & 3.34 & 3.34 & & & & & \\
\hline 274 & 3.38 & 3.40 & & & & & \\
\hline 300 & & 3.43 & & & 0.130 & 0.129 & 14.6 \\
\hline 318 & 3.47 & 3.46 & & & & & \\
\hline 350 & 3.51 & 3.51 & & & & & \\
\hline $\begin{array}{l}392 \\
400\end{array}$ & 3.58 & $\begin{array}{l}3.58 \\
3.59\end{array}$ & & & 0.135 & 0.135 & 15.9 \\
\hline 434 & 3.67 & 3.64 & & & & & \\
\hline 480 & 3.78 & 3.72 & & & & & \\
\hline 500 & & 3.75 & & & 0.140 & 0.140 & 17.3 \\
\hline 510 & 3.73 & 3.78 & & & & & \\
\hline 551 & 3.88 & 3.83 & & & & & \\
\hline 589 & 3.87 & 3.89 & & & & & \\
\hline 600 & & 3.90 & & & 0.145 & 0.145 & 18.7 \\
\hline 614 & 3.93 & 3.92 & & & & & \\
\hline 663 & 4.09 & 4.00 & & & & & \\
\hline $\begin{array}{l}696 \\
700\end{array}$ & 4.13 & $\begin{array}{l}4.05 \\
4.06\end{array}$ & & & 0.150 & 0.150 & 20.1 \\
\hline 737 & 4.10 & 4.12 & & & & & \\
\hline 767 & 4.18 & 4.16 & & & & & \\
\hline 000 & & 4.21 & & & & $0.156 !(8)$ & 21.6 \\
\hline 807 & 4.25 & 4.22 & & & & & \\
\hline 854 & 4.28 & 4.30 & & & & & \\
\hline 885 & 4.44 & 4.35 & & & & & \\
\hline 900 & & 4,37 & & & & $0,161(8)$ & 23.2 \\
\hline 932 & 4.34 & 4.42 & & & & & \\
\hline $\begin{array}{r}964 \\
1000\end{array}$ & 4.29 & $\begin{array}{l}4.47 \\
4.53\end{array}$ & & & & $0.166(8)$ & 24.8 \\
\hline \multicolumn{8}{|c|}{ (1) Average apparent density, $\rho=7.88 \mathrm{~g}$} \\
\hline \multirow{2}{*}{\multicolumn{8}{|c|}{ (2) Number of observations, $n_{0}=4$. }} \\
\hline & & & & & & & \\
\hline \multicolumn{8}{|c|}{$\begin{array}{l}\text { (4) } a=\left|\sum\left(a_{\text {meas }}-a_{c o m p}\right)^{2 / n i} \cdot-p \cdot 1\right|^{1 / 2} \text {, where ni = the number of data points and the order of the polynomial } \\
\text { function, } p=1 \text {. }\end{array}$} \\
\hline \multirow{2}{*}{\multicolumn{8}{|c|}{$\begin{array}{l}\text { (5) } r=\left.\left|1-\Sigma\left(a_{\text {meas }}-a_{\text {comp }}\right)^{2} / \Sigma\left(a_{\text {meas }}-\bar{a}\right)\right|\right|^{1 / 2} \\
\text { (6) Values computed by regression analyses, } C P_{\text {comp }}=0.114+5.24 \times 10^{-5} \mathrm{~T} \text {. }\end{array}$}} \\
\hline & & & & & & & \\
\hline I) Values.co & ed by : & ion analy & & $0 \times 10^{-}$ & & & \\
\hline & & & & & & & \\
\hline
\end{tabular}


STECIFC.HEAT, THERMAL-DIFFUSIVITY, AND THERMAL-CONDUCTIVITY

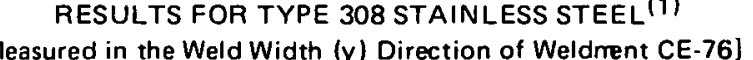

\begin{tabular}{|c|c|c|c|c|c|c|c|}
\hline $\begin{array}{l}\text { Average } \\
\text { Temperature } \\
\left({ }^{\circ} \mathrm{C}\right)\end{array}$ & $\begin{array}{l}\text { Thermal } \\
\frac{\left(\times 10^{-2}\right.}{\text { Measured }}\end{array}$ & $\begin{array}{l}\text { Diffusivity, } \\
\begin{array}{c}a \\
\text { cm.-sec }-1)\end{array} \\
\text { Computed }\end{array}$ & 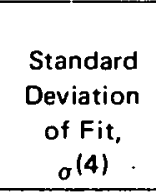 & $\begin{array}{l}\text { Correlation } \\
\text { coefficient, } \\
(15)\end{array}$ & $\begin{array}{l}\text { Spec } \\
\frac{\text { Ical-c }}{\text { Mesurued }}\end{array}$ & 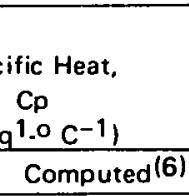 & $\begin{array}{c}\text { Computed } \\
\text { Themal } \\
\text { Conductivity, } \\
k \text { (7) } \\
\left.\text { (watr- } \mathrm{m}^{-1.0} \mathrm{C}^{-1}\right)\end{array}$ \\
\hline 24 & 3.38 & 3.32 & 0.0015 & 0.951 & & $0.115^{(8)}$ & 12.6 \\
\hline $\begin{array}{l}25 \\
99\end{array}$ & 3.51 & $\begin{array}{l}3.32 \\
3.43\end{array}$ & & & & & \\
\hline 100 & & 3.44 & & & 0.120 & 0.119 & 13.5 \\
\hline $\begin{array}{l}125 \\
167 \\
197\end{array}$ & $\begin{array}{r}3.42 \\
3.88 \\
3.6\end{array}$ & $\begin{array}{l}3.48 \\
3.55 \\
359\end{array}$ & & & & & \\
\hline $\begin{array}{l}193 \\
200\end{array}$ & & $\begin{array}{l}3.59 \\
3.60\end{array}$ & & & 0.126 & 0.124 & 14.8 \\
\hline $\begin{array}{l}245 \\
772 \\
772\end{array}$ & $\begin{array}{l}3.68 \\
3771\end{array}$ & $\begin{array}{l}3.68 \\
3.72\end{array}$ & & & & & \\
\hline 300 & 376 & $\begin{array}{l}3.77 \\
388\end{array}$ & & & 0.130 & 0.129 & 16.1 \\
\hline $\begin{array}{l}320 \\
358\end{array}$ & $\begin{array}{l}3.184 \\
3.84\end{array}$ & 3.86 & & & & & \\
\hline $\begin{array}{l}400 \\
401 \\
401\end{array}$ & 3.90 & $\begin{array}{l}3.93 \\
3.93\end{array}$ & & & 0.135 & 0.135 & 177.4 \\
\hline $\begin{array}{l}434 \\
478 \\
478\end{array}$ & $\begin{array}{l}3.80 \\
4.06\end{array}$ & $\begin{array}{l}3.99 \\
4.06\end{array}$ & & & & & \\
\hline $\begin{array}{l}500 \\
517\end{array}$ & 3.85 & $\begin{array}{l}4.099 \\
4.12\end{array}$ & & & 0.140 & 0.140 & 18.9 \\
\hline $\begin{array}{l}557 \\
591\end{array}$ & $\begin{array}{l}4.12 \\
4.08\end{array}$ & $\begin{array}{l}4.19 \\
4.24\end{array}$ & & & & & \\
\hline 600 & 4.42 & 4.26 & & & 0.145 & 0.145 & 20.4 \\
\hline & $\begin{array}{l}4.32 \\
4.42\end{array}$ & $\begin{array}{l}4.36 \\
4.44\end{array}$ & & & & & \\
\hline & A 28 & 4.42 & & & 0.150 & 0.150 & 21.9 \\
\hline $\begin{array}{l}730 \\
767\end{array}$ & $\begin{array}{l}4.30 \\
4.54\end{array}$ & $\begin{array}{l}4.47 \\
4.53\end{array}$ & & & & & \\
\hline $\begin{array}{l}800 \\
8004\end{array}$ & 4,47 & $\begin{array}{l}4.58 \\
4.59\end{array}$ & & & & $0.156(8)$ & 23.5 \\
\hline & 4.85 & 4.65 & & & & & \\
\hline $\begin{array}{l}900 \\
900\end{array}$ & 4.02 & $\begin{array}{l}4.75 \\
4.75\end{array}$ & & & & $0.161^{188}$ & 25.2 \\
\hline $\begin{array}{l}920 \\
954\end{array}$ & $\begin{array}{l}5.20 \\
4.78\end{array}$ & $\begin{array}{l}4.78 \\
4.83\end{array}$ & & & & & \\
\hline & & 4.91 & & & & $0.166(8)$ & 26.9 \\
\hline
\end{tabular}

(1) Average apparent densitv, $\rho=7.88 \mathrm{~g}-\mathrm{cm}-3$.
(2) Vumber of observations, $n_{0}=4$.

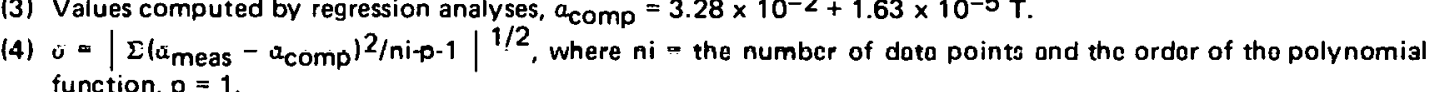
(5) $r=\left|1-\Sigma\left(a_{\text {meas }}-a_{\text {comp }}\right) 2 / \Sigma\left(a_{\text {meas }}-\bar{a}\right)^{2}\right|^{1 / 2}$

Values computed by regression analusses, $C_{0} C_{C o m}=0.114+5.24 \times 10^{-5}$

(7) Values computed by regression analyses, $\mathrm{k}=12.3+1.18 \times 10^{-2} \mathrm{~T}+2.82 \times 10^{-6} \mathrm{~T}$
Table 12

PECIFIC-HEAT, THERMAL-DIFFUSIVITY, AND THERMAL-CONDUCFIVIVITY TYPE 308 STAINLESS STEEL(1)

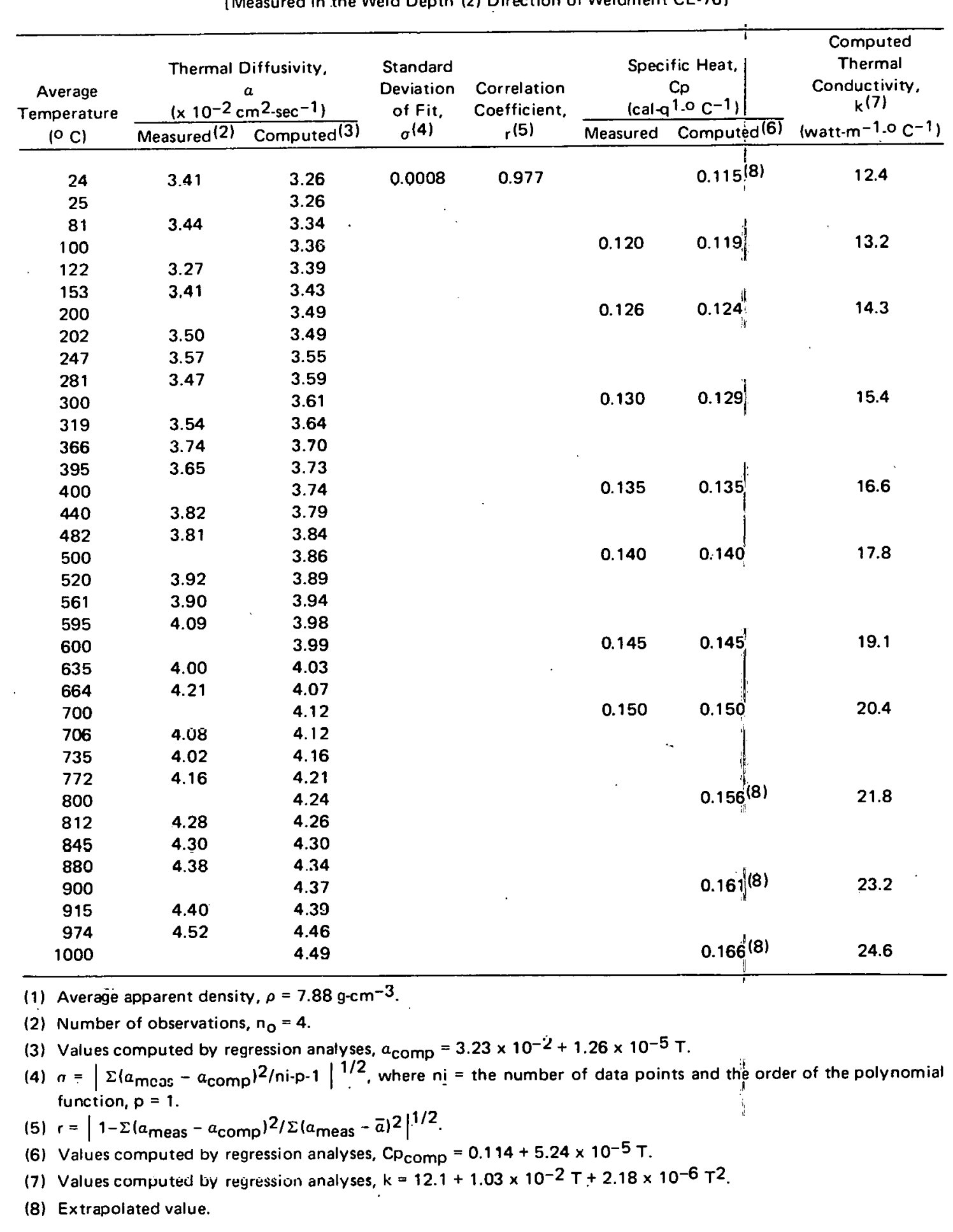




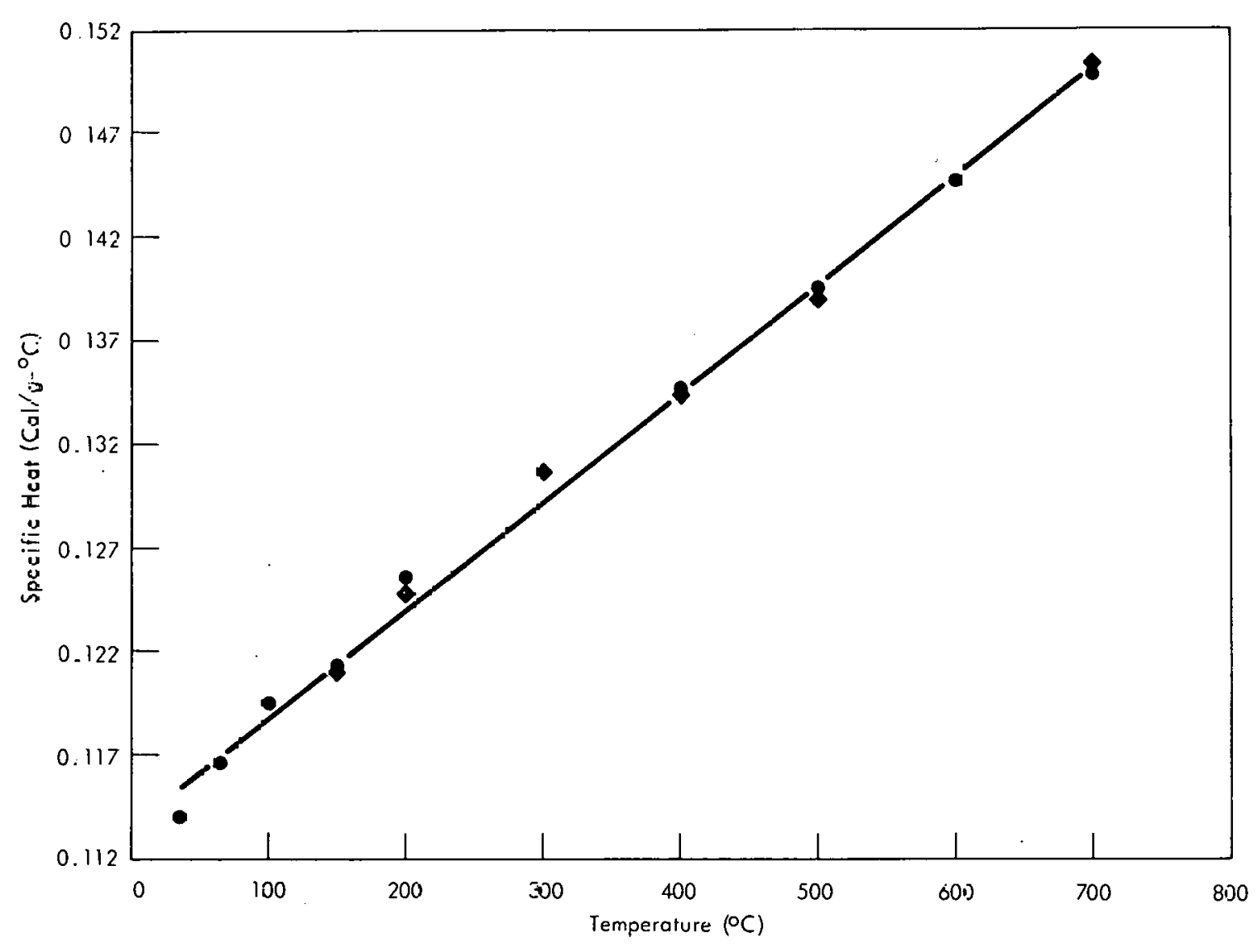

Figure 17. SPECIFIC HEAT OF TYPE 304 AMD 308 STAINLESS STEELS FROM WELDED AND BASE MATERIAL AREAS. IDSC 3223

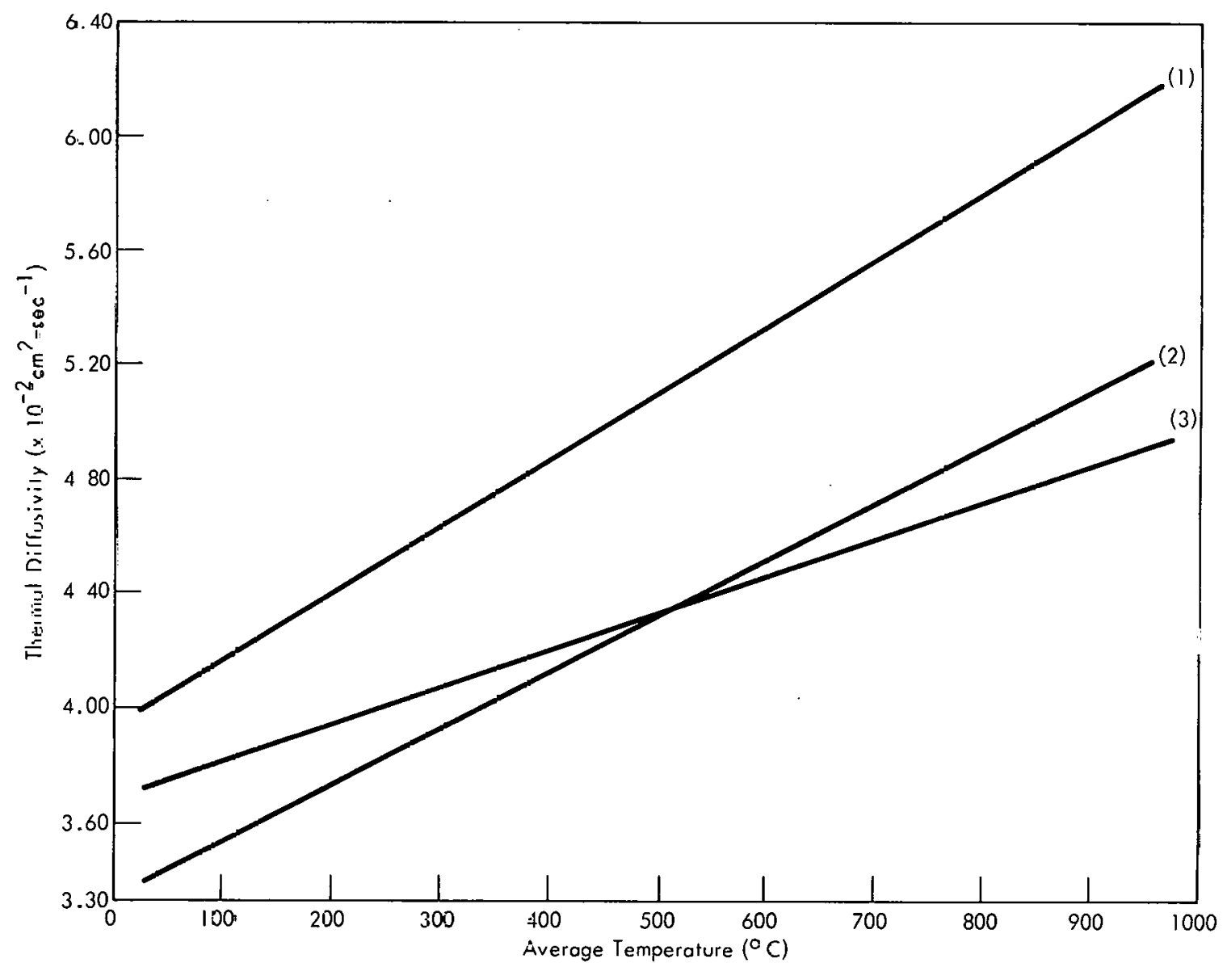

Figure 18. CGMPARISON OF THERMAL-DIFFUSIVITY TRENDS FOR TYPE 304 STAINLESS STEEL. (Data Based the: (1) Noncontact and (2) intrinsic Thermocouple Techniques Versus the (3) TPRC Provisional Datal

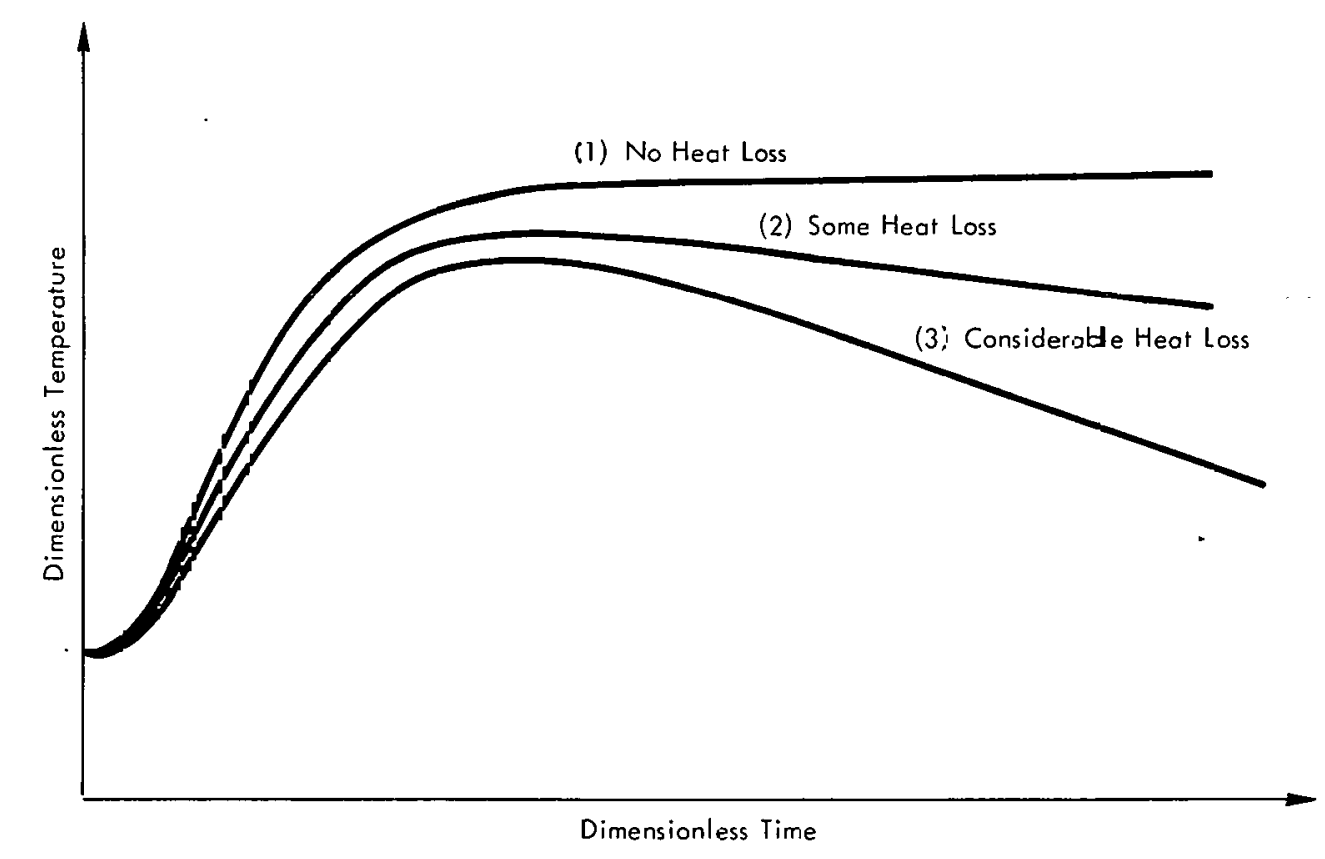

Figure 19. TYPICAL HEAT.PULSE TRANSIENT WAVEFORMS FOR TYPE 304 STAINLESS STEEL. (Curves Illustrate: (1) the Intrinsic Thermacouple and Noncontact Techniques at (2) Low $-500^{\circ} \mathrm{C}$ and (3: Hig -501) - $1000^{\circ} \mathrm{C}$ Termperatu'es:

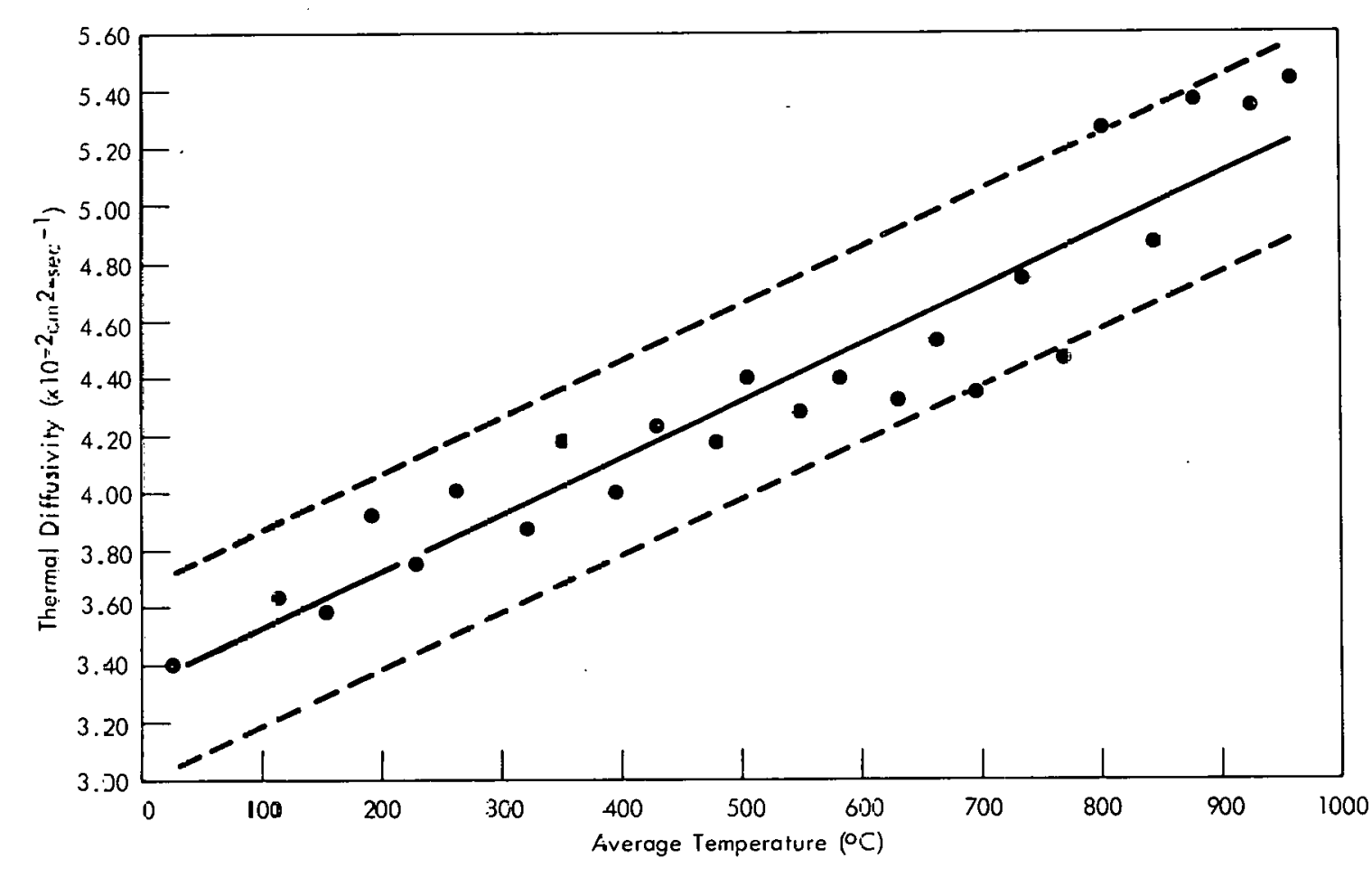

Figure 20. THERMALL DIFFUSIVITY OF BASE MATERIAL FROM TYPE 304 STAINLESS STEEL WELDMENT. 


$$
\sum
$$




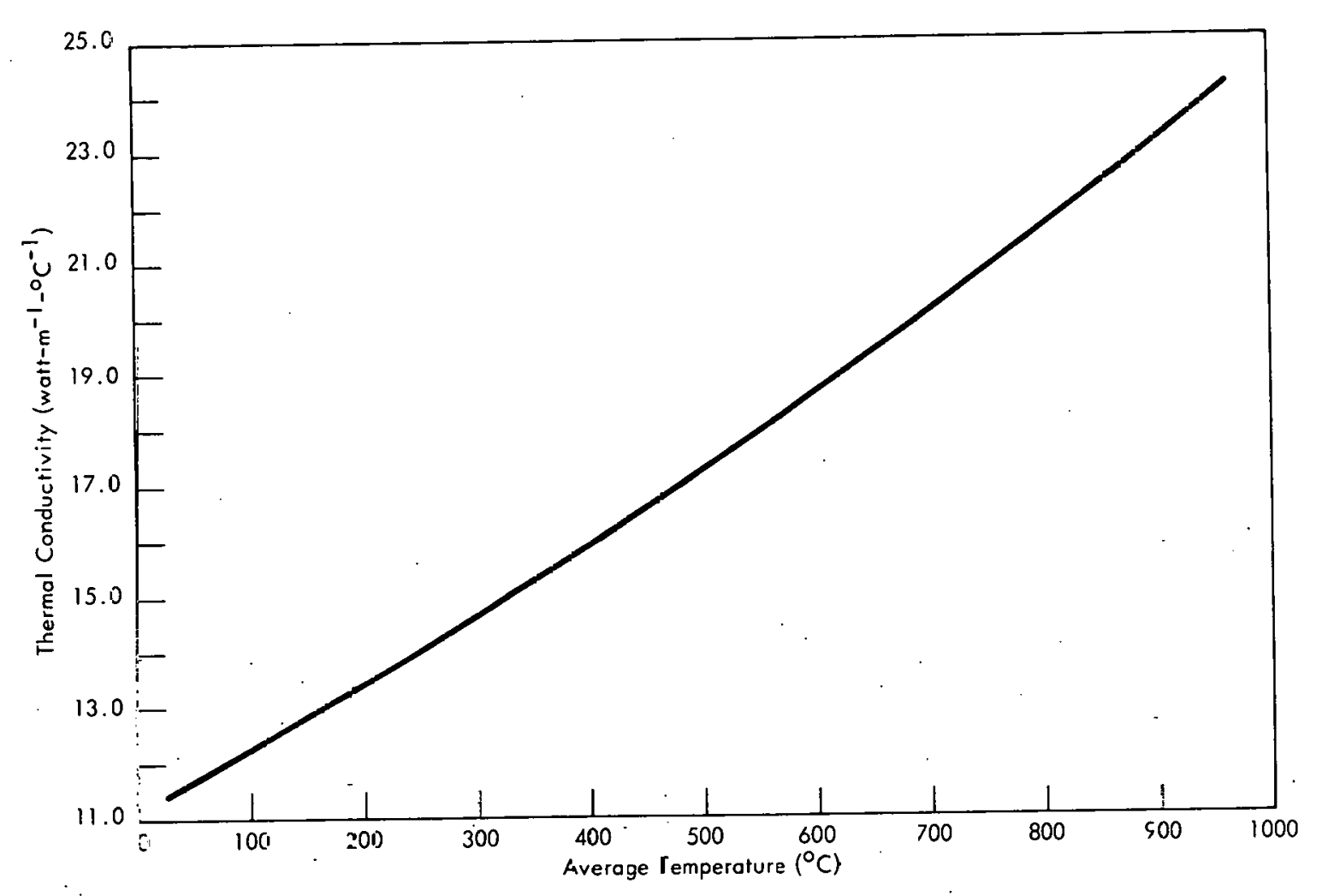
Figure 26. TH
(X) Direction]

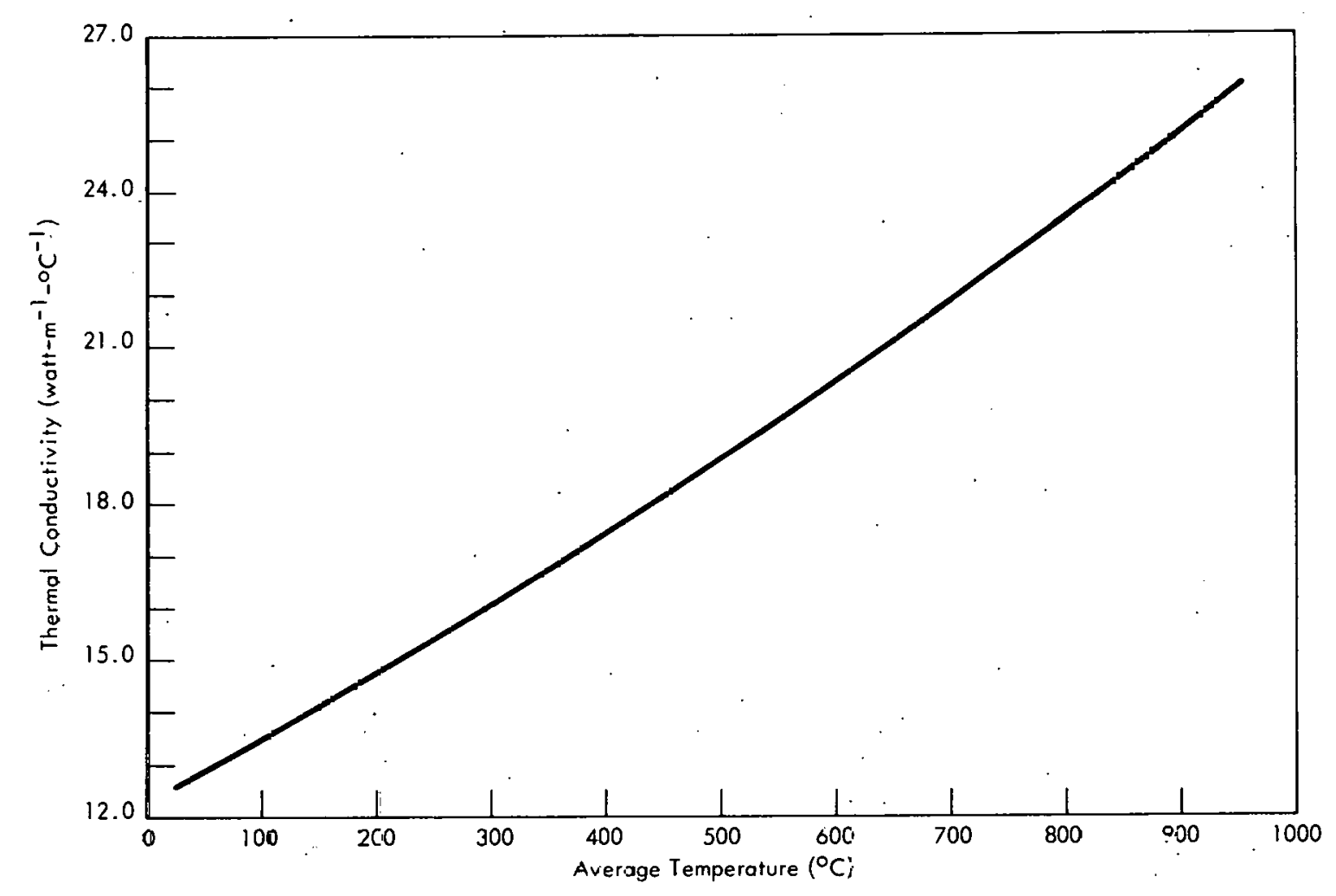

Figure 27. THERMAL CONDUCTIVITY OF TYP 308 STAINLESS STEEL WELDMENT. IMeasured in the Weld Width (Y) Direction]



Figure 28. THERMAL CONCUCTIVITY OF TYPE 308 STAINLESS STEEL WELDMENT. [Measured in the Weld Depth (Z) Direction]



Figure 29. COMPARISON OF THE THERMAL-CONDUCTIVITY TRENDS. [For Base Material (1) and in the $X$ (2), $Y$ (3), and $Z$ (4) Weld Direction] 
Table 13

COMPARISON OF THERMAL-DIFFUSIVITY DATA OBTAINED FOR TYPE 304 STAINLESS STEEL

\begin{tabular}{|c|c|c|c|c|c|}
\hline \multirow{3}{*}{$\begin{array}{c}\text { Average } \\
\text { Temperature, } \mathrm{T} \\
\left({ }^{\circ} \mathrm{C}\right)\end{array}$} & \multirow{2}{*}{\multicolumn{3}{|c|}{$\begin{array}{l}\text { Thermal Diffusivity } \\
\alpha\left(\times 10^{-2} \mathrm{~cm}^{2}-\mathrm{sec}^{-1}\right)\end{array}$}} & \multicolumn{2}{|c|}{ Percent Difference, \% D } \\
\hline & & & & \multirow{2}{*}{$\begin{array}{c}\text { NC vs } \\
\text { TPRC }(4)\end{array}$} & \multirow{2}{*}{$\begin{array}{c}\text { IT vs } \\
\text { TPRC (5) }\end{array}$} \\
\hline & TPRC(1) & $I T(2)$ & $\mathrm{NC}(3)$ & & \\
\hline 25 & 3.71 & 3.38 & 3.98 & +7.3 & -8.9 \\
\hline 100 & 3.81 & 3.53 & 4.16 & +9.2 & -7.3 \\
\hline 200 & 3.94 & 3.72 & 4.40 & +11.7 & -5.6 \\
\hline 300 & 4.07 & 3.92 & 4.63 & +13.8 & -3.7 \\
\hline 400 & 4.20 & 4.12 & 4.86 & +15.7 & -1.9 \\
\hline 500 & 4.33 & 4.32 & 5.10 & +17.8 & -0.2 \\
\hline 600 & 4.46 & 4.52 & 5.31 & +19.7 & +1.3 \\
\hline 700 & 4.58 & 4.72 & 5.57 & +21.6 & +3.1 \\
\hline 800 & 4.71 & 4.92 & 5.81 & +23.4 & +4.4 \\
\hline 900 & 4.85 & 5.11 & 6.04 & +24.5 & +5.4 \\
\hline 1000 & 4.98 & 5.31 & 6.27 & +25.9 & +6.6 \\
\hline
\end{tabular}

(1) Thermophysical Properties Research Center mean provisional values: $18-20 \mathrm{wt} \% \mathrm{Cr}$. $8-12$ wt $\% \mathrm{Ni}, 0.08$ wt \% C, 2 wt \% Mn, 0.045 wt \% P, 0.03 wt \% S, 1 wt \% Si, and $64.845-70.845$ wt \% Fe (by difference). Nominal composition from Crucible Data Book, Crucible Steel Company of America. The austenitic specimen was cut from Number 2 finish cold-rooled steel, subjected to a minimum of working and tested without further surface preparation. No heat treatment occurred prior to testing. Thermal pulses were supplied by a xenon flash tube. Values were computed by regression analysis:

$$
\alpha=3.68 \times 10^{-2}+1.30 \times 10^{-5} \mathrm{~T} \text { (see Toularkion, et al }{ }^{(11)} \text { ). }
$$

(2) Intrinsic thermocouple technique using chromel-alumel thermojunction:

$$
\alpha=3.33 \times 10^{-2}+1.98 \times 10^{-5} \mathrm{~T} .
$$

(3) Noncuntact lechilicue using the inSb detcctor:

$$
\alpha=3.92 \times 10^{-2}+2.35 \times 10^{-5} \mathrm{~T} .
$$

(4) $\% D=\frac{\alpha_{N C}{ }^{-\alpha}{ }_{\text {TPRC }}}{\alpha_{\text {TPRC }}} \times 10^{2}$.

(5) $\% D=\frac{\alpha_{1 T}-\alpha_{T P R C}}{\alpha_{T P R C}} \times 10^{2}$.

for the directly determined thermal-diffusivity-temperature dependencies of Figures 20 through 24 by dashed lines. This interval represents the limits around the computed mean regression line within which the mean value for an infinite number of normally distributed measurements can be expected to be found with a $90 \%$ probability.

\section{Interpretation}

Adoption of linear $\alpha(T)$ trend lines (shown in Figures 20 through 24) was somewhat arbitrary in light of the data scatter, which is indicative of both the material nonhomogeneity between duplicate specimens (differentiated symbolically) and/or experimental error.

The linear $\alpha(T)$ model correlates with experimental findings about as well as any polynomial of order three or lower, according to covariance analyses. The $\rho \operatorname{Cp}(T) \alpha(T)$ product, 
representing the coupling of two linear functions, becomes a polynomial of the second order, which is consistent with the findings of this laboratory for a vacuum-arc-remelted Type 304- $L$ stainless steel, as determined by the steady-state axial rod technique.

Figure 29 illustrates the trends of thermal conductivity with increasing temperatures for the base and weld materials. The base metal trendline conductivities were from 6 to $15 \%$ higher than the mean weld metal values for the $X, Y$, and $Z$ measurement directions. The range of $X, Y$, and $Z$ values at a given temperature was approximately $9 \%$. At $500^{\circ} \mathrm{C}, k$ for the base metal was approximately $11 \%$ greater than the mean $k$ value for the weld metal. At and above this temperature [after accounting for the average weld $90 \%$ tolerance limit (TL) bandwidth of approximately $\pm 6 \%$, the larger magnitude of base metal $k$ values $( \pm 10 \%$, $90 \%$ TL) begins to have some significance.

\section{CONCLUSIONS AND RECOMMENDATIONS}

In summary, thermal conductivities of the weld material, while somewhat variant (depending upon the direction of measurement) are essentially equivalent over the temperature interval from 25 to $1000^{\circ} \mathrm{C}$. Trends in the base material $\mathrm{k}$ values are predominantly higher than for weld material, and these differences become statistically valid above approximately $500^{\circ} \mathrm{C}$.

Additional studies are planned with other candidate weld materials. Development of the noncontact InSb detector to provide credible results would allow extension of the thermal diffusivity test to temperatures in the melting range of stainless steel ( 1400 to $1450^{\circ} \mathrm{C}$ ). These data would provide a more accurate evaluation of the thermal performance of such materials in the event of any incident which might cause the reactor to overheat. When practical, direct steady-state thermal-conductivity measurements by the axial-rod technique should be obtained for the candidate steel materials as a confirmatory check analysis. 


\section{REFERENCES}

(1) King, R. T., et al; ."Relation Between Mechanical Properties and Microstructures in CRE Type 308 Stainless Steel Weldments", Welding Journal (Miami); 53, (7), pp 307-308; July 1974.

(2) Parker, W. J., et al; "Flash Method of Determining Thermal Diffusivity, Heat Capacity, and Thermal Conductivity", J App/ Phys, 32, p 1679 (1961).

(3) Deem, H. W., et al; "Flash Thermal Diffusivity Measurements Using A Laser", Rev Sci Inst, 33, p 1107 (1962).

(4) Parker, W., et al; Advanced Energy Conversion, 2, p 87 (1962).

(5) Cowan, R. D.; "Pulse Method of Measuring Thermal Diffusivity at High Temperatures", J Appl Phys, 34, (4), p 926 (1963).

(6) Cape, J. A., et al; "Temperature and Finite Pulse Time Effects in the Flash Method for Measuring Thermal Diffusivity", J Appl Phys, 34, (7), p 1909 (1963).

(7) Bates, J. L.; “High-Temperature Thermal Conductivity of Round Robin Uranium Dioxide", BNWL-1431; Battelle Memorial Institute, Pacific Northwest Laboratories, Richland, Washington; July 1970.

(8) Taylor, R. E., et al; "Finite Pulse Time Effects in Flash Diffusivity Technique", Appl Phys Letters, 5, (10), p. 212 (1964).

(9) Davenport, C. M., et al; Real Time Analysis of Thermal Diffusivity Data from a Pulsed Laser Facility, Y-1841; Union Carbide Corporation-Nuclear Division, Oak Ridge Y-12 Plant, Oak Ridge, Tennessee; September 11, 1972.

(10) Thermal Analysis News/etter, 10; Perkin-Elmer Corporation, Norwalk, Connecticut.

(11) Touloukian, Y. S., et al; Thermophysical Properties of Matter; Volume 10: Thermal Diffusivity; IFI/Plenum, New York (1973). 


\section{ACKNOWLEDGEMENTS}

The authors wish to thank C. M. Davenport, D. W. Carver, P. G. Schneider, B. W. Speller, and A. E. Stephens of the Y-12 Laboratory Development Department, who developed the techniques for real-time analysis of the thermal-diffusivity data from the pulsed laser facility. M. E. Ward, of the Plant Laboratory, and W. G. Delones and H. H. Law, of the Y-12 Fabrication Division, devised design and machining criteria for the various test fixtures. R. D. Gibson, of the Judson Research and Manufacturing Company, Conshohocken, PA, designed the noncontact detection system which, with minor modifications, was integrated into the existing transient analysis electronics. 


\section{APPENDIX A}

\section{LASER THERMAL ANALYSIS PROGRAM GUIDE}

The laser thermal analysis program provides for two modes of operation: data acquisition and data reduction. These modes are interlinked so that acquired data may be readily introduced to the analysis program.

Descriptions of the data acquisition and data reduction formats follow; and, in Appendix B, typical report-form summaries are reproduced.

The data acquisition program (Appendixes $A$ and $B$ ) requests and assimilates pertinent measurement parameters and then cycles through the TEMPERATURE POINT statement as data are acquired. At the conclusion of the test, either termination or introduction to the data-reduction program is available.

The data reduction program (Appendixes $A$ and $B$ ) operates on stored data points obtained in the data acquisition sequence. After requesting and assimilating the sample density and the predetermined least-squares equation for specific heat, the routine of curve-fitting commences. Least-squares equations, representing the thermal diffusivity and thermal conductivity-temperature dependencies, are next obtained with standard statistical parameters, defining the precision of the regression analyses.

After selection of the most appropriate equations for $a(T)$ and $k(T)$, off-line mechanical plotting of these functions with or without data points and tolerance limits is available. Tables and figures displaying $a(T)$ and $k(T)$ dependencies, included in the body of this report, were obtained using these routines.

\section{Data Acquisition}

Upon program initiation, the program identifies itself by typing

THERMAL MAIN

CURVE FIT?

If the operator types " $Y$ ", see data analysis section. If " $N$ " is inputted, then

ANALYTICAL REO \#?

Input floating point number (decimal point required).

TRANSDUCER OPTION

Input the employed temperature measurement technique.

SAMPLE THICKNESS (CM)?

Enter sample thickness in $\mathrm{cm}$, floating point format. 


\section{PULSE WIDTH (MSEC)?}

Enter floating point laser burst time for half-time correction.

\section{CURVE FIT INITIATION POINT?}

Input integer (no decimal point) number representing the channel address where the curve fit will start. This channel must be after the fall of the laser burst and not nearer than 300 channels to the scale change channel. This value must be between 100 and 400 .

\section{START OVER?}

If an error has been made, type "Y"; and the question-answer sequence will restart. Assume "N".

\section{TEMPERATURE POINT \#?}

Enter integer number between $1-50$. This number is used to identify the data point.

SHOT TEMP T $1 / 2$ DIFFUS

ANOTHER?

Type "Y" to allow data collection. The operator may now push TEMP SEND and DATA SEND buttons. The computer responds by outputting the results under the appropriate headings and asking for another. This process continues until " $N$ " is typed or 10 shots have hee.n sent.

\section{AVERAGE WHICH SHOTS?}

Type the shot numbers $(0-9)$ in ascending order and separated by commas. The temperature point averages and standard deviation are printed.

\section{KEEP?}

If "Y" is typed, this data overlays the previous data at this temperature point.

\section{ANOTHER POINT?}

Type " $Y$ ", and the computer will return to the temperature point number question after the TEMP SEND button is pushed. This button is examined immediately and every two minutes thereafter. Assume " $N$ " in the following.

\section{CURVE FIT?}

"N" terminates the laser program. "Y" enters the data analysis mode. 


\section{Data Reduction}

INPUT POINTS:



The point number is between 01 and 50, right justified integer. The data are entered in floating point format anywhere beneath the asterisks. This data will replace any previous data for the same point number. A 00 point number will terminate the data input.

\section{CHANGE THERMAL COND CONSTANTS?}

" $N$ " input causes control to transfer to program ALLFIT. Assume " $Y$ " in the following.

DENSITY (GM/CC)?

Input floating point sample density.

\section{CURVE TYPE?}

Enter integer curve type (1 - 9).

\section{(X) SP HT COEF?}

$X$ is outputted as the number of coefficients. Enter coefficients, one per line, in ascending order in either floating-point or scientific notation format.

\section{PROGRAM ALLFIT}

\section{LIST CURVE OPTIONS?}

Type "Y" for a list of options.

OPTION?

Input integer option (0 - 9).

POINT LIMITS?

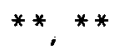

Enter point limits (01 - 50), right justified.

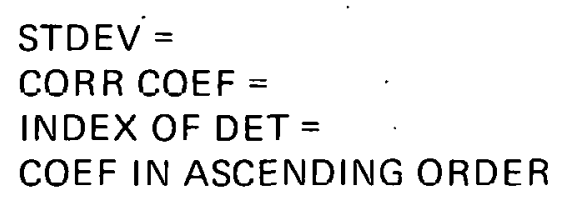

These values are listed.

COMPARISON TABLE? 
Type "N" and control goes to "FIT ANOTHER CURVE". Assume " $Y$ " in the following.

EVERY NTH POINT WILL BE PRINTED, INPUT N.

Input integer value. The values are written under the proper heading. $X=25,100$, 200. . 1,000 is included in the table even if $N=0$. The headings are:

$X \quad Y \quad$ YS.AIT. \%MIFF SLDPE

FIT ANOTHER CURVE?

If "N" is inputted, control goes to "PLOT". Assume " $Y$ " in the following.

FIT THERMAL COND?

If " $N$ " is inputted, control goes to "INPUT POINTS". If " $Y$ " is inputted, the conductivity is calculated from the last diffusivity fit. Control goes to "PROGRAM ALLFIT".

PLOT?

If "N" is inputted, the laser program terminates. Assume " $\mathrm{Y}$ " in the following.

FILE NAME?

Input a 5 character alphanumeric name which will identify the data set.

HEADER?

Enter up to 40 alphanumeric characters to identify the graph. .

PLOT COND?

If the answer is "Y", the conductivity data will be plotted. If the answer is "N", diffusivity data will be plotted.

$$
\text { PLOT OPTIONS? (1 = DATA, } 2 \text { = FIT, } 3 \text { = CLS, } 4 \text { = SAME PLOT) }
$$

Enter integer values separated by commas. Option 4 refers to the next plot, which can be plotted on the same set of coordinates.

FIT ANOTHER CURVE?

Enter "Y" or " $N$ ", the sequence repeats as before.

\section{Equations of Interest}

Diffusivity (a) (at temperature, T):

$$
a=\frac{d^{2}}{t_{c} \pi^{2}}, \text { and }
$$




$$
\mathrm{t}_{\mathrm{c}}=\frac{\mathrm{t}_{1 / 2}-0.55 \tau}{1.37}
$$

where:

d represents the sample thickness,

$t_{c}$ the characteristic time,

$t_{1 / 2}$ the half time, and

$\tau \quad$ the laser pulse width.

Conductivity (K), (at temperature, T):

$$
K=\rho a_{c} C p,
$$

where:

$$
\begin{aligned}
& \rho \quad \text { represents the density, } \\
& a_{\mathrm{C}} \quad \text { the calculated diffusivity, and } \\
& \mathrm{Cp} \text { the calculated specific heat. }
\end{aligned}
$$

Standard deviation $(\sigma)$ :

$$
\sigma=\sqrt{\frac{\sum\left(Y-Y^{\prime}\right)^{2}}{(n-0-1)}}
$$

where:

$Y$ represents the experimental value,

$Y^{\prime}$ the calculated value,

$\mathrm{n}$ the number of points, and

o the order of equation of fit.

Index of determination $\left(r^{2}\right)$ :

$$
r^{2}=1-\frac{\Sigma\left(Y-Y^{\prime}\right)^{2}}{\Sigma(Y-\bar{Y})^{2}}
$$

where: 
$\bar{Y} \quad$ represents the average $Y$ value.

Correlation coefficient $(r)$ :

$$
r= \pm \sqrt{r^{2}}
$$

90\% Tolerance İnterval (TI):

$$
T I= \pm \sigma \cdot t(0.95, d f)^{\cdot} \cdot(1+1 / n)^{1 / 2},
$$

where:

$(0.95, d f)$

represents a $t$ factor from stunent $t$ distribution with df degrccs ul frepritum.

\section{Computer Operator Guide}

$\begin{array}{llll}\text { TAPE } & \text { UNIT 2 } & \text { LUN } & 8 \\ \text { TTY } & \text { UNIT } 1 & \text { LUN } & 6\end{array}$

\section{Partition USER2}

Entries to Laser Program:

1. LASR - restores core images from tape and requests LASR 1

2. LÁŚR1 - assume core image unchanged.

3. LSCHD - Between shots LSCHD monitors "TEMP SEND" button every two minutes. MCR partition. To signal this operation, LASER STANDBY + RFr. MATA lights are on. USE $\bar{R} \overline{2}$ partition is free durıng this time. The system may be restarted if LSCHD is requested.

A tape image is always saved at laser sign off.

\section{Plot Program}

PLOT PROGRAM

PDP-15/20, KM9-V5A

PROGRAM LASR

.DAT SLOTS:
A_DKC1_-4/DTC1_3/CP_2/TT_4
E_LASR

Enter file names in order. Plotter pen should be $<4$ inches from right stop.

LASR XCT and LASR XCU are on a DECTAPE marked LASER PLOT BIN and should be transferred to disk 1 , if not already there. Source copies and batch files are on LASER PLOT SRC. 
APPENDIX B

TYPICAL REPORT FORM SUMMARY FOR LASER THERMAL ANALYSIS

\section{Data Acquisition}

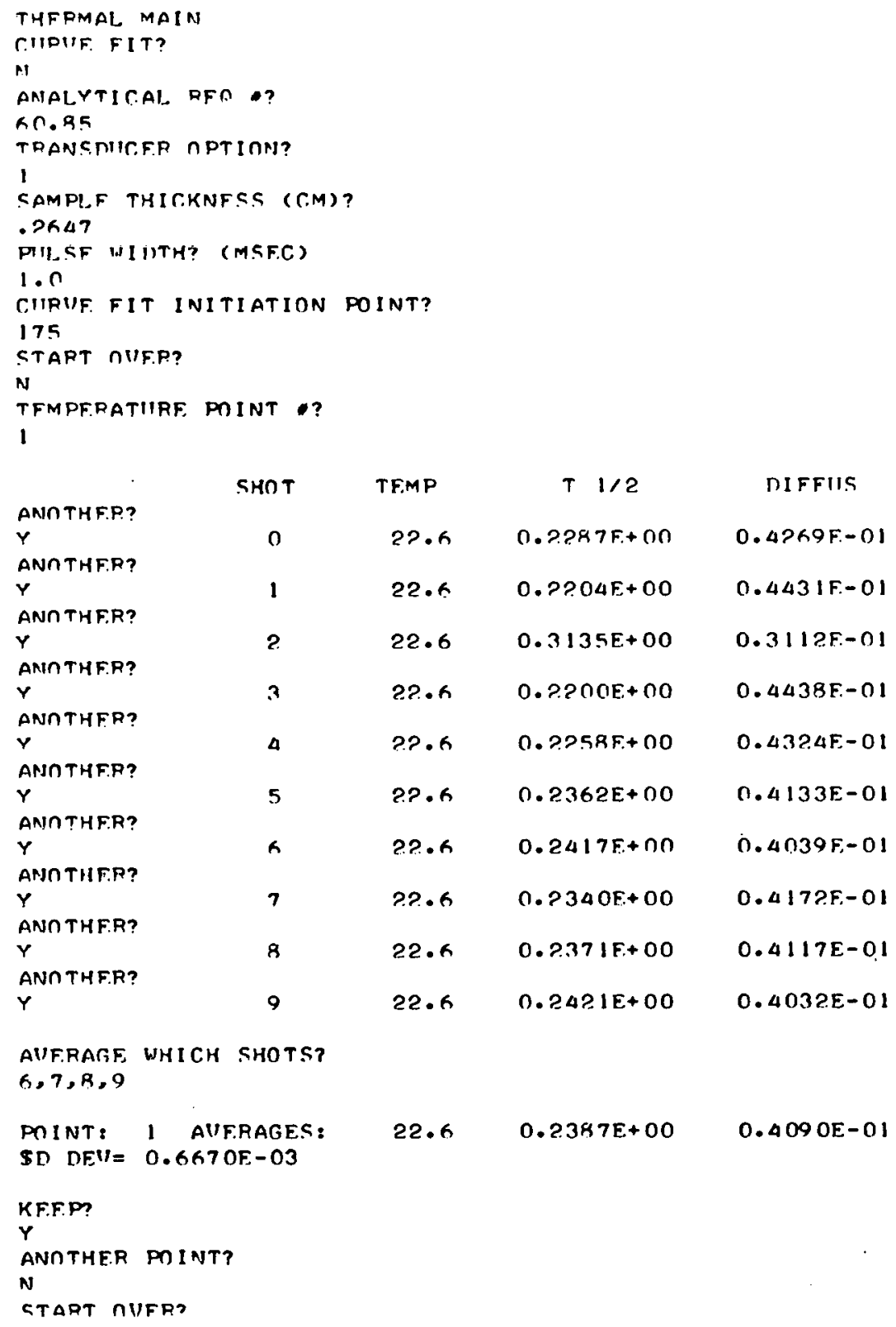




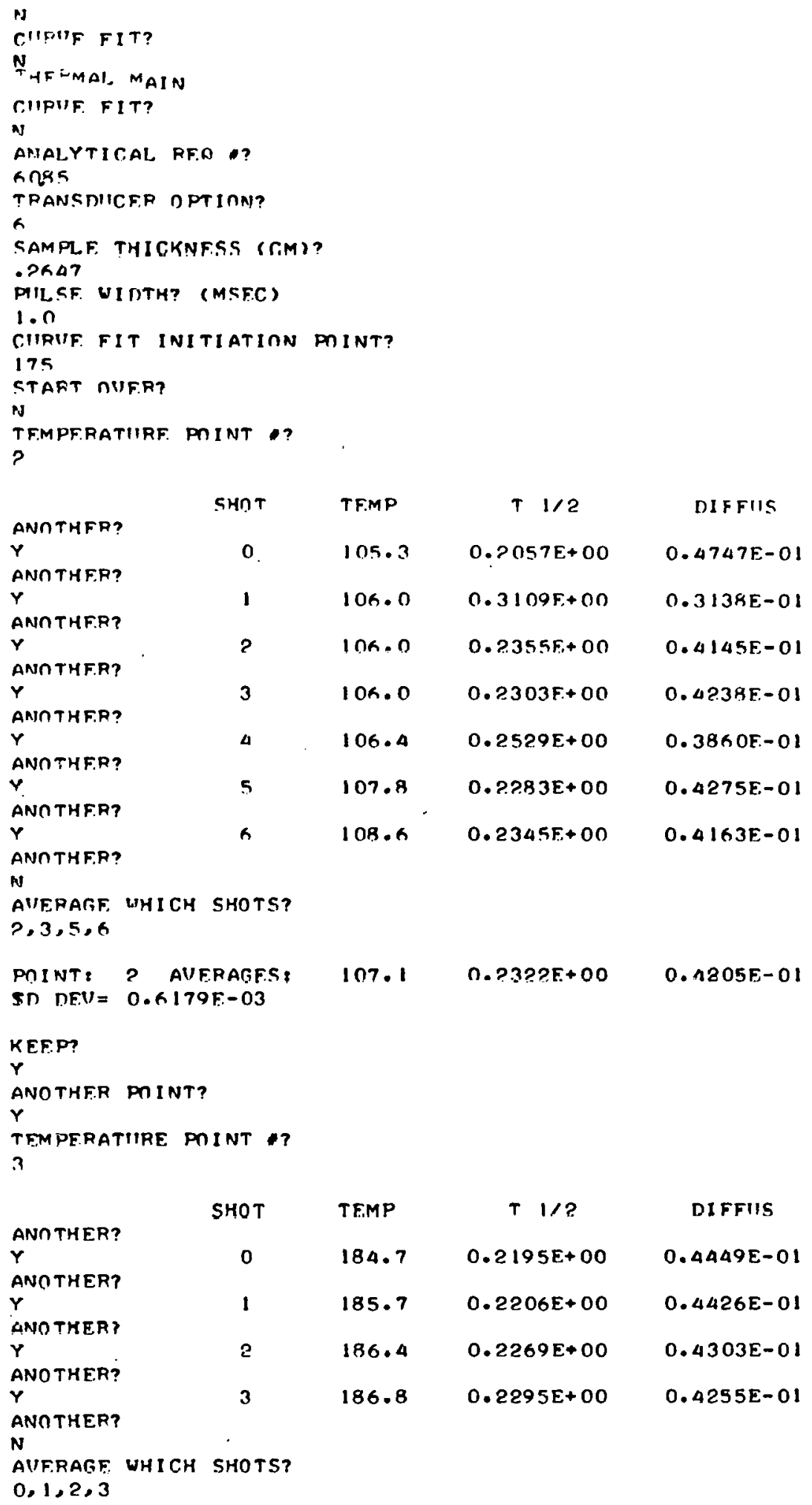

\begin{tabular}{|c|c|c|c|c|}
\hline ANOTHFR? & SHOT & TF.MP & $T 1 / 2$ & DIFFIIS \\
\hline$Y$ & 0 . & 105.3 & $0.2057 E+00$ & $0.4747 \mathrm{E}-01$ \\
\hline $\begin{array}{l}\text { ANOTHFE? } \\
\text { Y } \\
\text { ANOTHFR? }\end{array}$ & $\mathbf{1}$ & 106.0 & $0.31095+00$ & $0.3138 E-01$ \\
\hline $\begin{array}{l}Y \\
\text { ANOTHF.R? }\end{array}$ & $?$ & $10 x .0$ & $0.23555+00$ & $0.4145 E-01$ \\
\hline $\begin{array}{l}Y \\
\text { ANINTHF.R? }\end{array}$ & 3 & $10 x .0$ & $0.2303 F+00$ & $0.42 .39 E-01$ \\
\hline $\begin{array}{l}\text { Y } \\
\text { ANOTHFR? }\end{array}$ & 4 & 106.4 & $0.2529 \mathrm{E}+00$ & $0.3860 F-01$ \\
\hline $\begin{array}{l}Y \\
\text { ANOTHF.R? } \\
Y\end{array}$ & 5 & $\begin{array}{l}107.8 \\
108.6\end{array}$ & $0 . ? . ? .83 E+00$ & $\begin{array}{l}0.4275 E-01 \\
0.4163 E-01\end{array}$ \\
\hline
\end{tabular}

ANOTHF.R?

AVERAFF WHICH SHOTS?

$?, 3,5,6$ 


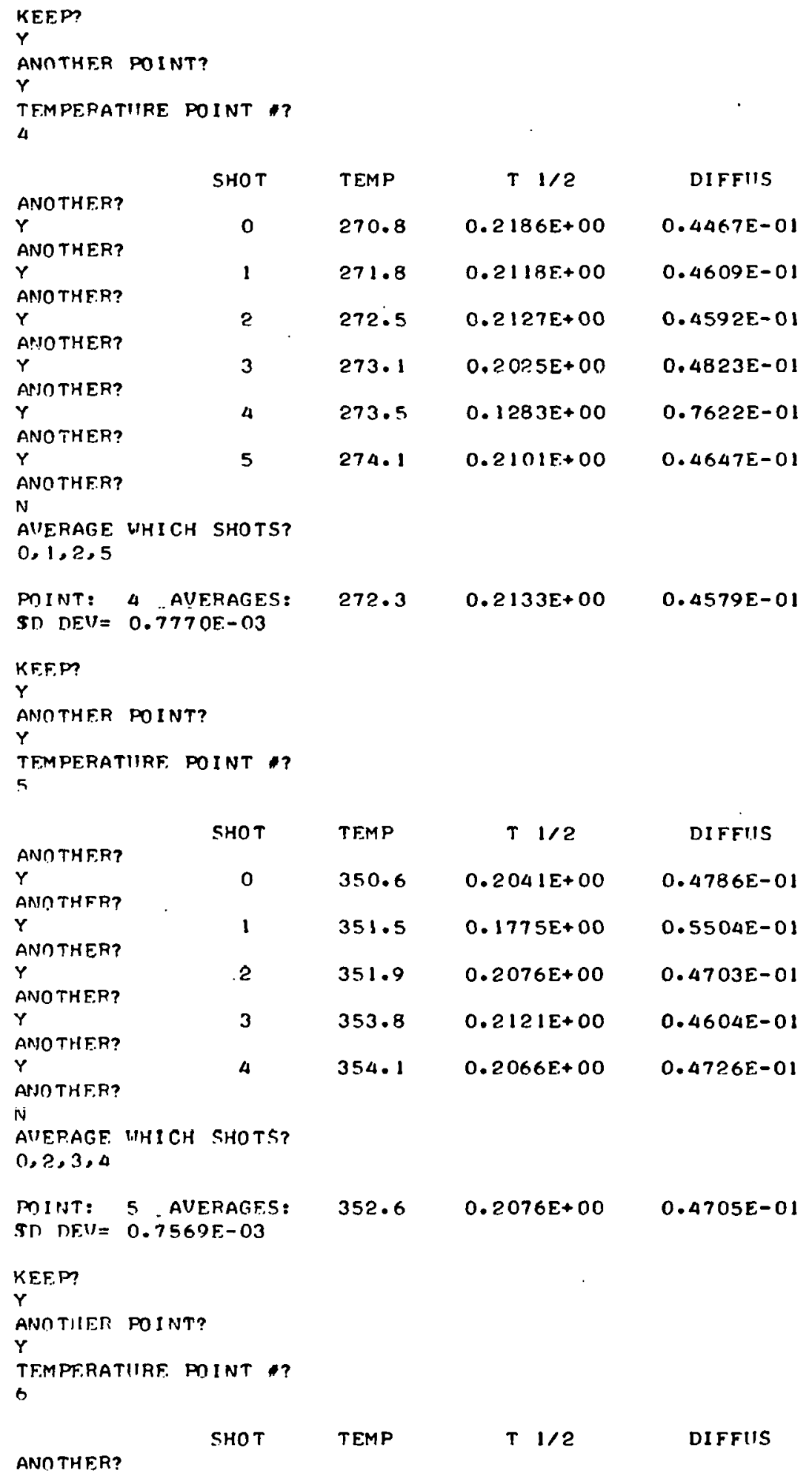

\begin{tabular}{|c|c|c|c|c|}
\hline ANOTHFR? & SHOT & TEMP & $T 1 / 2$ & DIFFIIS \\
\hline $\begin{array}{l}Y \\
\text { ANO THFR? }\end{array}$ & 0 & 350.6 & $0.2041 E+00$ & $0.4786 \mathrm{E}-01$ \\
\hline $\begin{array}{l}Y \\
\text { ANOTHER? }\end{array}$ & 1 & $351 \cdot 5$ & $0.1775 E+00$ & $0.5504 E-01$ \\
\hline $\begin{array}{l}\text { Y } \\
\text { ANO THE.R? }\end{array}$ & 2 & 351.9 & $0.2076 E+00$ & $0.4703 E-01$ \\
\hline $\begin{array}{l}Y \\
\text { ANOTHE.R? } \\
Y\end{array}$ & 3 & 353.8 & $0.2121 E+00$ & $0.4604 E-01$ \\
\hline
\end{tabular}




$\begin{array}{lcccc}Y & 0 & 440.0 & 0.1965 E+00 & 0.4970 E-01 \\ \begin{array}{l}\text { ANOTHER? } \\ Y\end{array} & 1 & 440.9 & 0.2021 E+00 & 0.4833 E-01 \\ \begin{array}{l}\text { ANOTHER? } \\ Y\end{array} & 2 & 442.5 & 0.1906 E+00 & 0.5125 E-01 \\ \begin{array}{l}\text { ANOTHER? } \\ Y\end{array} & 3 & 443.7 & 0.1488 E+00 & 0.6571 \mathrm{E}-01 \\ \begin{array}{l}\text { ANOTHER? } \\ Y\end{array} & 4 & 444.0 & 0.2035 E+00 & 0.4799 \mathrm{E}-01 \\ \begin{array}{l}\text { ANOTHER? } \\ Y\end{array} & 4 & 44.6 & 0.1980 \mathrm{D}+00 & 0.4934 \mathrm{E}-01\end{array}$

ANOTHER?

$\mathrm{N}$

AVERATE WHICH SHOTS?

$0,1,4,5$

POINT: 6 AVERAGES:

442.4

$0.2000 E+00$

$0.4884 E-01$

STD DEV = $0.8081 E-03$

KF.F.P?

$Y$

ANOTHER POINT?

Y

TFMPERATURE POINT ?

7

$\begin{array}{lcccc}\text { ANOTHER? } & \text { SHOT } & \text { TFMP } & T 1 / 2 & \text { DIFFIIS } \\ \begin{array}{l}\text { YNOTHER? } \\ \text { Y }\end{array} & 0 & 516.0 & 0.1941 E+00 & 0.5032 E-01 \\ \begin{array}{l}\text { ANOTHER? } \\ \text { Y }\end{array} & 1 & 516.9 & 0.1919 \mathrm{E}+00 & 0.5091 \mathrm{E}-01 \\ \begin{array}{l}\text { ANOTHER? } \\ \text { Y }\end{array} & 2 & 517.2 & 0.1885 \mathrm{E}+00 & 0.5180 \mathrm{E}-01 \\ & 3 & 518.0 & 0.1996 \mathrm{E}+00 & 0.4892 \mathrm{E}-01\end{array}$

ANOTHER?

N

AUERAGE WHICH SHOTS?

$U, 1,2,3$

PIINT: 7 AVERAGES:

STD $D E V=0.1211 \mathrm{E}-02$

517.0

$0.1935 E+00$

$0.5049 E-01$

KE.EP?

$Y$

ANOTHER POINT?

$Y$

TFMPFRATIIRF: PIINT I?

8

\begin{tabular}{|c|c|c|c|c|}
\hline & SHOT & TE.MP & T $1 / 2$ & DIFFIIS \\
\hline $\begin{array}{l}\text { ANOTHER? } \\
Y\end{array}$ & 0 & $-22 \cdot 0$ & $0.1817 \mathrm{E}+00$ & $0.5375 E=01$ \\
\hline $\begin{array}{l}\text { ANO THER? } \\
Y \\
\text { ANO THER? }\end{array}$ & 1 & 607.4 & $0.1817 \bar{E}+00$ & $0.5375 E-01$ \\
\hline $\begin{array}{l}Y \\
\text { ANOTHER? }\end{array}$ & 2 & 607.9 & $0.1788 E+00$ & $0.5464 \mathrm{E}-01$ \\
\hline $\begin{array}{l}Y \\
\text { ANOTHER? } \\
Y\end{array}$ & 3 & 608.5 & $0.1811 E+00$ & $0.5395 E-01$ \\
\hline ח & & 000.1 & & $0+3<46-19$ \\
\hline
\end{tabular}

N

AUERAGE WHICH SHOTS?

$1,2,3,4$ 


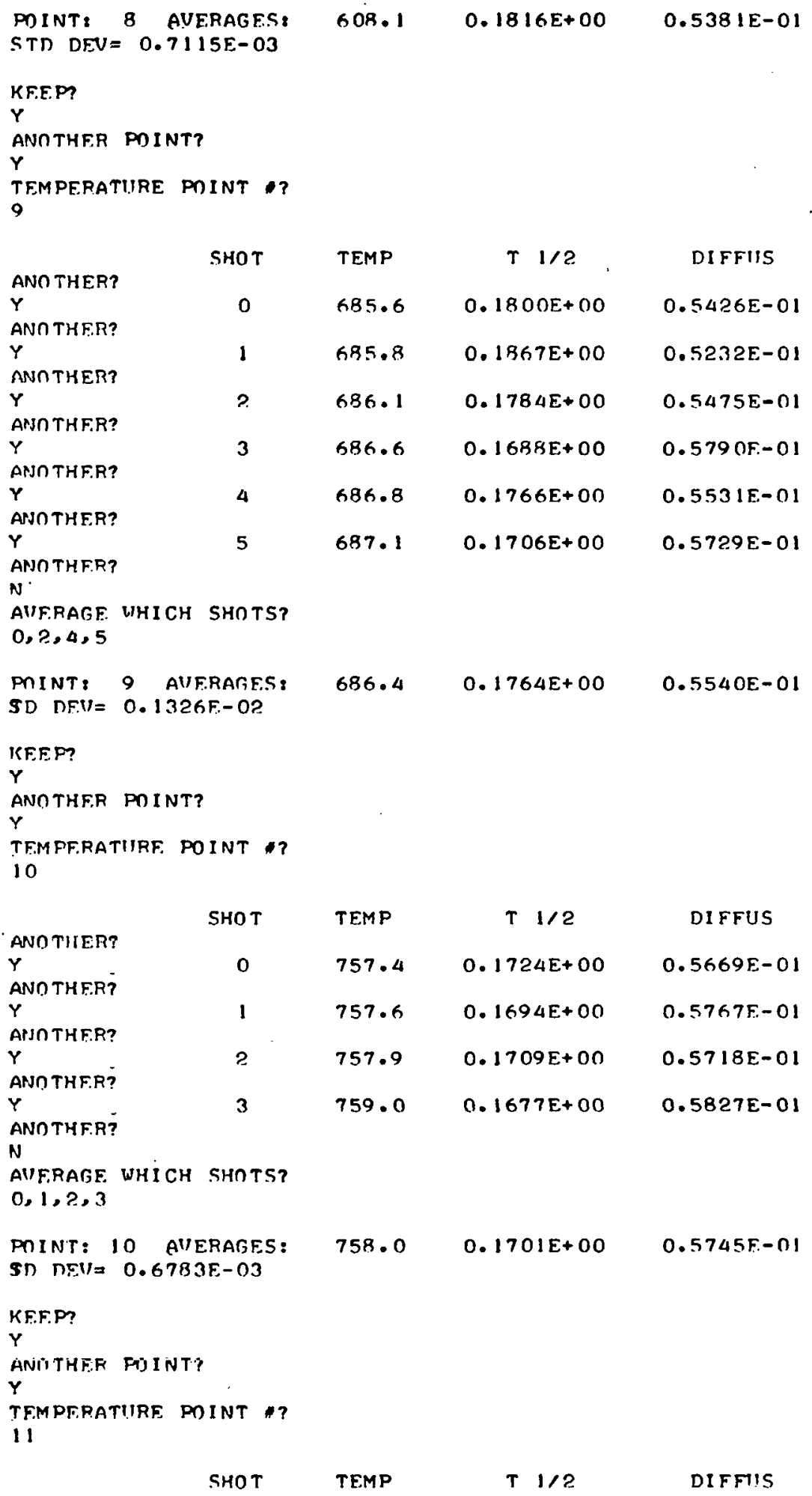




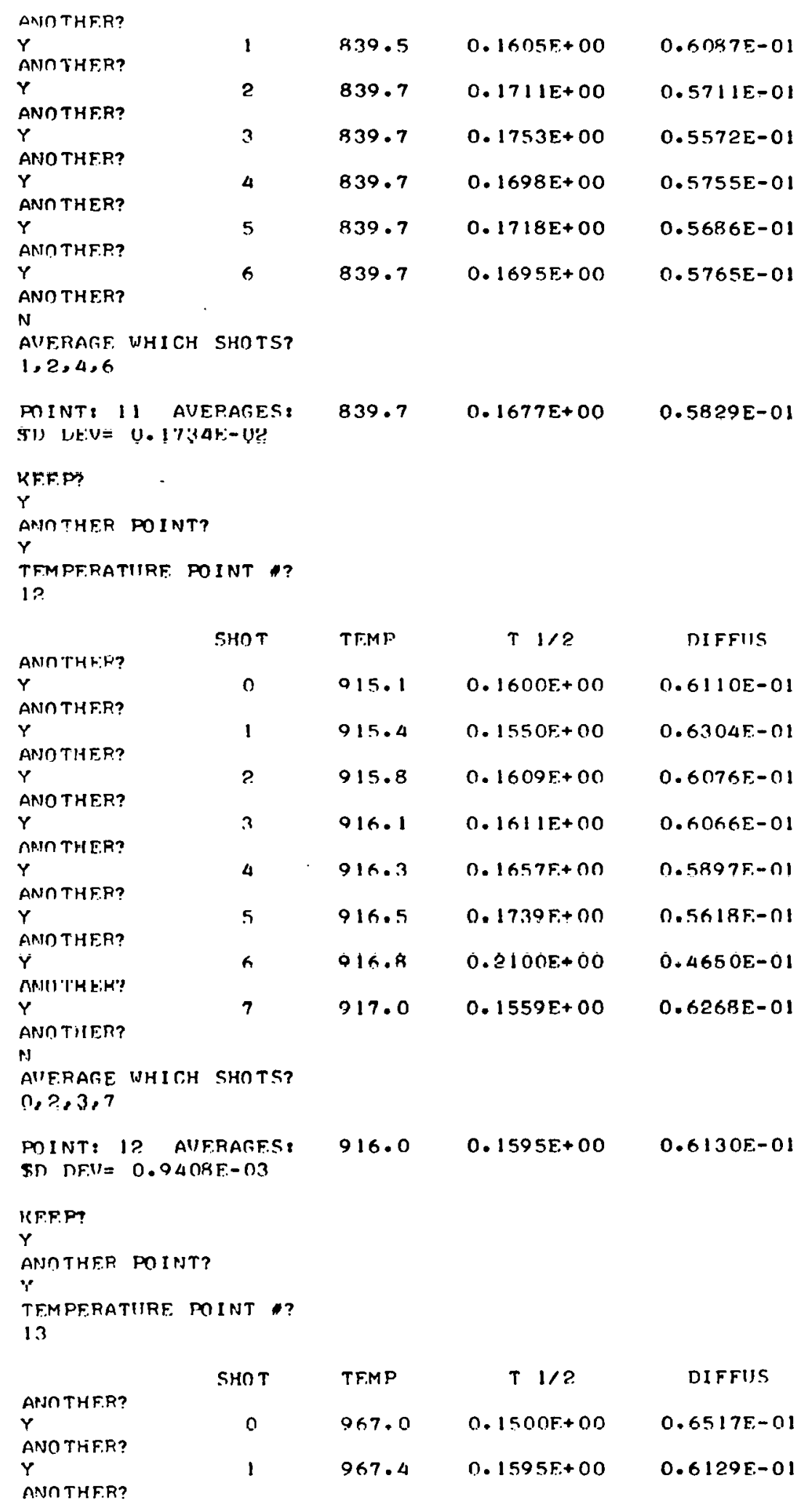




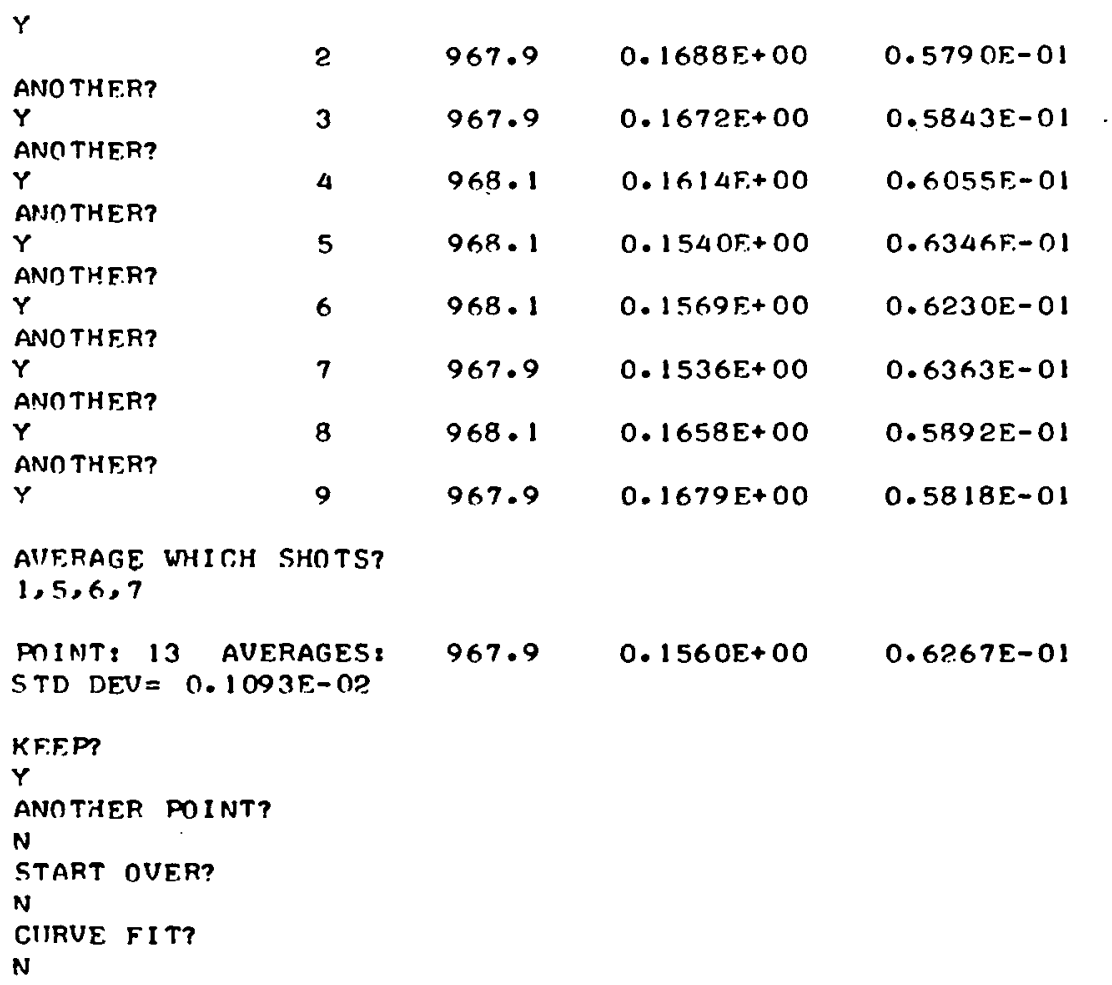




\section{Data Reduction}

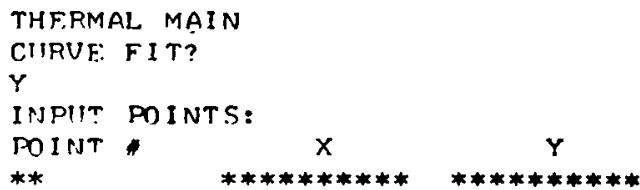

CHANGE THERMAL COND CONSTANTS?

$Y$

DFNS: TY (GM/CC)?

7.90

SPF.C HT CIIRUE TYPF?

1

$?$ SP IIT COFF?

$.11,3555$

5. $241 \cap 1 F-5$

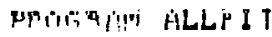

LITT CIINUE OTTIOAS?

$Y$

1-6 DFGRF.F. 1-6 POLYNOMIALS

$7 Y=A / T$

$8 Y=A+H / T$

$9 Y=A+B * T+C / T$

10 $Y=A+R * T+C /(T * T)$

QPT I DN?

PIINT LIMITS?

**,**

$01,2.5$

STD DFI $\quad 0.570403 E-03$

CORR COFF $\quad 0.996774 \mathrm{~F}+00$

INDF.X OF DF.T $\quad 0.993559 \mathrm{E}+00$

C.OFF IN ASCENDING ORDFR

$0.39 ? .457 \mathrm{~T} . \mathrm{n} 1$

$0.235128 E-04$

COMPARI SON TARLF?

FVFPY NTH PIINT WILL RE. PRINTED. INPIT N:

$x$
$0.2 ? 64 \mathrm{~F}+02$
(1. $111715 .+03$
$0.1859 F+03$
0. $2.72 .35+03$
$0.3526 \mathrm{~F}+03$
$0.4424 E+03$
$0.517 D E+03$
$0.6081 E+03$
$0.6864 \varepsilon+133$
$0.7580 r+03$

Y

\begin{abstract}
$0.4090 \%-01$
$0.47 .05 E-0.1$

$0.4358 \mathrm{E}-01$

$0.4579 E-01$

$0.4705 E-01$

$0.4884 \mathrm{E}-0.1$

$0.5049 E-0.1$

$0.538 \mid E-01$

U. $5540 \mathrm{E}-0.1$

$0.5745 \mathrm{~F}-01$
\end{abstract}

YCALC

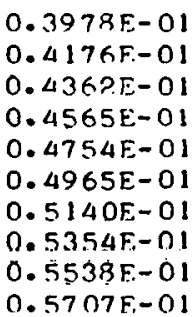

PCT DIFF

SLOPE:

$$
\begin{array}{rl}
0.2747 E+01 & 0.2351 E-04 \\
0.6880 F+00 & 0.2351 E-04 \\
-0.8049 E-01 & 0.2351 E-04 \\
0.3028 E+00 & 0.2351 E-04 \\
-0.1042 E+01 & 0.2351 E-04 \\
-0.1656 E+01 & 0.2351 E-04 \\
-0.1811 E+01 & 0.2351 E-04 \\
0.4941 E+00 & 0.2351 E-0.4 \\
0.3121 E-01 & 0.2351 E-04 \\
0.6718 E+00 & 0.2351 E-04
\end{array}
$$

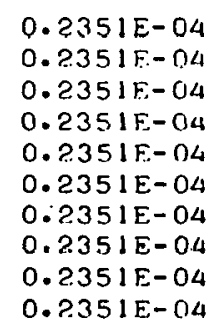$$
0.6718 E+00
$$ 

$0.83975+03$
$0.9160 F+03$
$0.9679 F+03$
$0.8295 E+02$
$0.1537 E+03$
$0.2370 F+03$
$0.3110 E+0.3$
$0.397 \mathrm{OF}+03$
$0.4846 E+03$
$0.5775 E+03$
$0.6465 F+03$
$0.7214 F+03$
$0.7982 \mathrm{E}+03$
$0.882 .9 \mathrm{E}+03$
$0.9411 E+03$
$0.2500 F+02$
$0.1000 F+03$
$0.2 .000 E+03$
$0.3000 \mathrm{~F}+03$
$0.41) 00 F+03$
$0.5000 F+03$
$0.6000 F+03$
$0.7 D O N E+03$
$0.8000 \mathrm{E}+03$
$0.9000 E+03$
n. $1000 E+04$

\begin{abstract}
$0.5399 \%-01$
$0.6078 F-01$

$0.6200 E-01$

$0.41205-01$

$0.4286 \mathrm{~F}-01$

$0.4656 \mathrm{~F}-01$

$0.4858 \mathrm{E}-01$

$0.5064 E-01$

$0.5282 \mathrm{E}-01$

$0.5445 \mathrm{E}-01$

$0.5621 \mathrm{E}-01$

$0.5801 E-01$

$0.6000 \mathrm{~F}-01$

$0.6137 E-01$

$0.3983 E-01$

$0.4160 E-01$

$0.4395 \mathrm{E}-01$

$0.4630 E-01$

$0.4865 \mathrm{E}-0.1$

$0.5100 E-0.1$

$0.5570 \mathrm{E}-01$

$0.5806 \mathrm{E}-01$

$0.6041 \mathrm{E}-01$

$0.6276 E-01$
\end{abstract}
$0.4482 E-01$
$0.5335 E-01$

$-0.1192 .+\mathrm{U} 1$

$0.8401 E+00$

$0.1063 E+01$

$-0.5017 E+00$

$0.1951 E+01$

$0.62 .41 E-01$

$-0.3753 E+00$

$-0.2311 E+00$

$-0.2332 E+01$

$-0.4811 E+00$

$-0.4021 E+00$

$0.1641 E+00$

$-0.5877 E+00$

$0.5348 E+00$

$0.1129 \mathrm{E}+01$
U.:3:301 $5-6: 4$

$0.2 .351 E-04$

$0.2351 \mathrm{E}-04$

$0.2351 E-04$

$0.2351 E-04$

$0.2351 E-04$

$0.2351 E-04$

$0.2351 \mathrm{E}-04$

$0.2351 \mathrm{E}-04$

$0.2351 F:-04$

$0.2351 \mathrm{E}-04$

$0.2 .351 E-04$

$0.2351 \mathrm{E}-04$

$0.2351 E-04$

$0.2351 \mathrm{~F}-04$

$0.2351 \mathrm{E}-04$

$0.2351 E-04$

$0.2351 E-04$

$0.2351 E-04$

$0.2351 \mathrm{E}-04$

$0.2351 E-04$

$0.2351 E-04$

$0.2351:-04$

$0.2351 E-04$

$0.2351 \mathrm{E}-04$

$0.2351 \mathrm{E}-04$

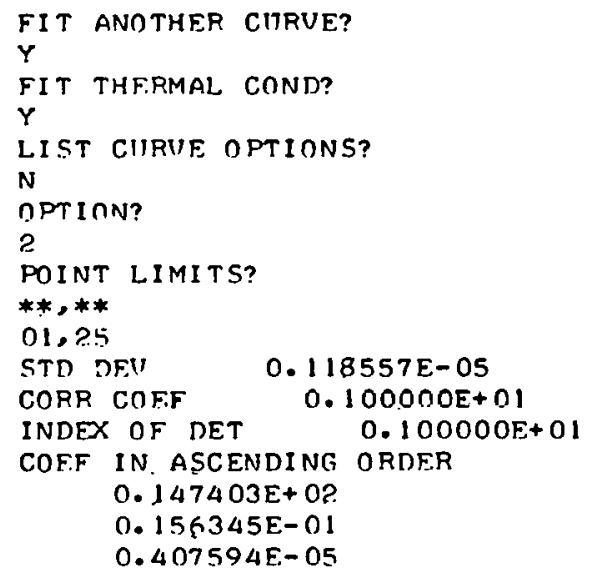

$x$

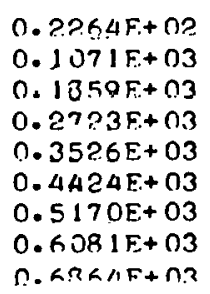

$Y$
$0.1510 E+02$
$0.1646 E+02$
0. $1779 F+n ?$
$0.1930 E+02$
$0.2076 \mathrm{E}+02$
$0.22115 F+02$
$0.2391 E+02$
$0.2576 E+0$ ?
n. $77.39 F+0.2$

YCALC
$0.1510 E+02$ $0.1646 E+0$ ? $0.1779 \mathrm{~F}+0$ ? $0.1930 E+02$ $0.2076 E+0$ ? $0.22 .55+02$ $0.2391 \mathrm{E}+02$ $0.2576 E+02$ $0.2739 \mathrm{~F}+\mathrm{n?}$

$P C, T$ DIFF

$0.1579 \mathrm{~F}-04$ 0.869 OF. -05 $0.5361 \mathrm{~F}-05$ $0.0000 \mathrm{E}+00$ -0.2297 F. 05 $-0.4247 \mathrm{E}-05$ $-0.5982 E-05$ $-0.5554 F-05$ -0.248 ?. -05
SLOPE.

U. 1582t:- 01 $0.1651 E-01$ $0.1715 E-01$ $0.1785 \mathrm{E}-01$ $0.1851 E-01$ $0.1924 E-01$ $0.1985 \mathrm{E}-01$ $0.2059 \mathrm{~F}-01$ ก.? I?.35-C1 


\begin{tabular}{|c|c|c|c|c|}
\hline $0.75961 F+03$ & $0.280 .3 r+0 \%$ & $0.2 \times 031 \%+0$ & (I. ROONOF+OO & $0 . \because 1 B|F-n|$ \\
\hline ก. $83.3 \overline{9} 7 E+03$ & $0.3074 E+0 ?$ & $0.307 \angle E+O ?$ & $-0.1551 \mathrm{~F}-0.05$ & $0.2 ? 48 \mathrm{E}-01$ \\
\hline $0.9160 F+n .3$ & C. 3PA9E+ OP? & $0.3248 F+0 ?$ & $0.29 .36 \mathrm{~F}-0.5$ & $0 .>1111 \mathrm{~F}-01$ \\
\hline $0.96795+0.3$ & $r_{0} \therefore \therefore \alpha \therefore F+1 \cdots$ & $\because \because \cdots F+\cdots$ & $0.5 G G \mid E-05$ & $0 . ? 35 \% F-01$ \\
\hline $0.8295 F+02$ & $0.1607 \mathrm{~F}+0 ?$ & $0.1607 F+02$ & $0.1187 E-04$ & $0.16315-01$ \\
\hline $0.15 .37 F+0.3$ & $0.172 .4 F+02$ & $0.1724 F+n ?$ & $0.553 ? . F-05$ & $0.1689 E-01$ \\
\hline $0.2370 \pi+0.3$ & $0.1867 F+0 ?$ & $0.1867 F+02$ & $0.0000 E+00$ & $0.1757 \mathrm{~F}-01$ \\
\hline $0.3110 F+0.3$ & $0 . ? 00 n F+02$ & $0.2000 F+n 2$ & $-0.4769 E-05$ & $0.1817 \mathrm{E}-01$ \\
\hline $0.397(1 F+03$ & $0.2159 E+02$ & $0.2159 E+02$ & $-0.2209 E-05$ & $0.1887 E-01$ \\
\hline $0.4846 \mathrm{~F}+03$ & $0.2327 E+02$ & $0.2327 \mathrm{E}+02$ & $-0.4098 E-05$ & $0.1958 E-01$ \\
\hline $0.5775 \mathrm{~F}+03$ & $0.2513 E+02$ & $0.2513 E+02$ & $-0.3795 F-05$ & $0.2034 E-01$ \\
\hline $0.646 .5 F+03$ & $0.2655 E+02$ & $0.2655 F+02$ & $-0.3592 \mathrm{~F}-05$ & $0.2090 E-01$ \\
\hline $0.7 \geqslant 14 \mathrm{~F}+03$ & $0.2814 E+02$ & $0.2814 F+02$ & $-0.3389 E-05$ & $0.2152 F-01$ \\
\hline $0.7982 \mathrm{E}+03$ & $0.2982 E+02$ & $0.2982 E+02$ & $0.1599 E-05$ & $0.2 ?|4 E-0|$ \\
\hline $0.88 ? 9 \mathrm{~F}+03$ & $0.3172 E+0 ?$ & $0.3172 .5+02$ & $0.3006 E .-05$ & $0.2 .283 \mathrm{E}-\mathrm{C} 1$ \\
\hline $0.9411 F+03$ & $0.3306 E+0 ?$ & $0.3306 F+02$ & $0.2884 E-05$ & $0.2 .331 E-01$ \\
\hline n.? $5 \cap 0 \cap++0 ?$ & & $0.1513 \mathrm{~F}+02$ & & $0.15 R \angle F-n \mid$ \\
\hline $0.1000 E+03$ & & $0.16 .34 F+02$ & & $0.1645 E-01$ \\
\hline $0.2 \cap 0 \cap F+\cap .3$ & & $0.18 \cap 35+03$ & & $0.17265-01$ \\
\hline $0.300 \cap 5.103$ & & 0.19 की & & $01.180 .14 \pi-01$ \\
\hline$n, 1 \cap \cap 0,+n ?$ & & $0.216 .5 \mathrm{E}, 02$ & & $0.18900 .-201$ \\
\hline $0.5000 E+03$ & & $E+0 ?$ & & $0.197 \mid E-01$ \\
\hline $0.60005+03$ & & $0.2559 E+02$ & & $0.2053 E-01$ \\
\hline $0.7000 E+03$ & & $0.2768 E+02$ & & $0.2134 E-01$ \\
\hline $0.8000 F+03$ & & $0.2986 E+02$ & & $0.2216 E-0.1$ \\
\hline $0.9000 F+03$ & & $0.3211 \mathrm{E}+02$ & & $0.2297 \mathrm{E}-01$ \\
\hline n. $1000 F+04$ & & $0.3445 E+02$ & & $0.2379 E-$ \\
\hline
\end{tabular}

FIT ANOTHER CINRUE?

$\mathrm{N}$

rent?

$Y$

FILE. NAMF?

กO37A

HF.AחF.R?

FAO037A. ARN 60.85-.90. DE.G. 1

MUTT CONTI?

i.I

SYMBOL CHANGF MINT?

14

PIOT OPTIONS? ( $1=$ DATA, $2=F I T, 3=C l \cdot S, \quad 4=S A M E$ PLOT)

$1, ?, .3$

FIT ANOTHER CIIRUE?

P.

ก.กT?

$Y$

FILF NAMF.?

OOBSK

HF.ADF.P.?

FHO03816. AnN 60.05.30. DEQ. 2

PLOT COND?

it

SYMPOL CHANGE POINT?

14

PLOT OPTIONS? ( $1=$ DATA, $2=F I T, 3=C L \cdot S, \quad 4=S A M E$ PLOT) 2

FIT ANOTHER CIIRVF? 


\section{Distribution}

Energy Research and Development

Administration - Oak Ridge

Hickman, H. D.

Leed, R. E.

Zachry, D. S., Jr

Technical Information Center (2)

\section{Holifield National Laboratory}

Brinkman, C. R.

Corum, J. M.

Cunningham, J. E.

King, R. T. (12)

Martin, W. R.

McCurdy, H. C.

Patriarca, P.

Williams, R. K.

Oak Ridge Gaseous Diffusion Plant

Barton, J. C.

Ward, M. E.

Wilcox, W. J., Jr

Winkel, R. A.

\section{Uak Rıdge Y-12 Plant}

Briscoe, O. W.

Burditt, R. B.

Burkhart, L. E.

Cadden, J. L.

Carver, D. W.

Darby, D. M. (4)

Davenport, C. M.

Dodson, W. H.

Ebert, T. H.

Fraser, R. J.

Greene, L. M.

Holcombe, C. E., Jr

Jones, F.W.

Kahl, K. G.

Keith, A.

Kite, H. T. (12)
Lore, J. D. (20)

Lundin, M. I.

Marrow, G. B.

Mason, D. L.

McLendon, J. D.

Mills, J. M., Jr

Neeley, A. C.

Phillips, L. R.

Pollock, C. B.

Reynolds, C. D.

Richards, H. L. (16)

Rowan, J. H.

Schreyer, J. M.

Smith, D. D.

Smith, R. D.

Speller, B. W.

Stephens, A. E.

Tewes, W. E.

Townsend, A. B.

Weathersby, W. E.

Yaggi, W. J./Googin, J. M.

Y-12 Central Files (15)

$Y-12$ Central Files (master copy)

$Y-12$ Central Files (route copy)

Y-12 Central Files (Y-12RC)

Zerby, C. D.

Paducah Gaseous Diffusion Plant Levin, R. W.

In addition, this report is distributed in accordance with the category UC-79h, LMFBR-Structural Materials and Design Engineering, as given in the USERDA Standard Distribution Lists for Unclassified Scientific and Technical Reports TID-4500. 